\title{
5HT 2 Rezeptor vermittelte Kontrolle des neonatalen medullären respiratorischen Netzwerks \\ des Säugers
}

\author{
Dissertation \\ zur Erlangung des Doktorgrades \\ der Mathematisch-Naturwissenschaftlichen Fakultäten \\ der Georg-August-Universität zu Göttingen
}

vorgelegt von

Silke Kerstin Karin Günther

aus Schweinfurt

Göttingen 2002 
D7

Referent:

Prof. Dr. F.W. Schürmann

Korreferent:

Prof. Dr. N. Elsner

Tag der mündlichen Prüfung: 25.04.2002 
Die im Rahmen dieser Arbeit vorgestellten Untersuchungen wurden an der

Abteilung für Anatomie mit Schwerpunkt Neurobiologie des Zentrum Anatomie der

Georg-August-Universität Göttingen durchgeführt. 


\section{Verwendete Abkürzungen}

ACSF

$\alpha$-Methyl 5HT

AP 5

DAG

DRG

GIRK

$5 \mathrm{HT}$

$\mathbf{I P}_{\mathbf{3}}$

NA

NTS

8 OH DPAT

PBC

PDGF

$\mathbf{P I P}_{2}$

VRG

XII Motoneurone

ZNS
Artifizielle Cerebro-spinale Flüssigkeit

$\alpha$-Methyl-5-Hydroxy-Tryptamin

(士)-2-Amino-5-phosphopentanon Säure

1,2-Diacylglycerin

Dorsale respiratorische Gruppe

G-proteine-dependend inwardly rectifying $\mathrm{K}^{+}$ conductances

5-Hydroxy-Tryptamin - Serotonin

Inositot $(1,4,5)-\mathrm{P}_{3}$

Nucleus ambiguus

Nucleus tractus solitarius

(士)-8-Hydroxy-Dipropylaminotetralin Hydrobromid

Prä-Bötzinger Komplex

Patelet-derived growth factor

1-Phosphatidyl-1 D-myo-Inositol-(4,5)

Ventrale respiratorische Gruppe

Hypoglossus Motoneurone

Zentrales Nervensystem 


\section{Inhaltsverzeichnis}

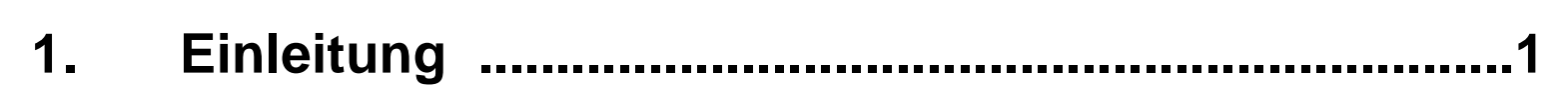

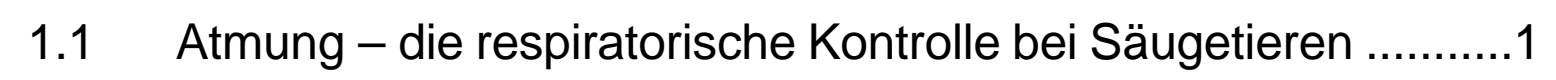

1.2 Das medulläre respiratorische Netzwerk .............................3

\begin{tabular}{|ll}
\hline 1.3 & Die Entwicklung des respiratorischen Systems $\quad \ldots \ldots \ldots \ldots \ldots \ldots \ldots \ldots . . \ldots 7$ \\
\hline
\end{tabular}

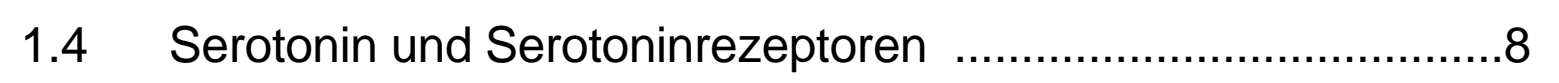

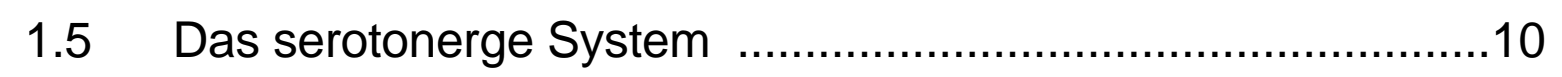

1.6 Serotonerge Modulation der respiratorischen Aktivität ..........12

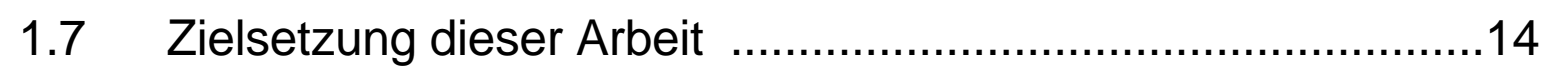

2. Material und Methoden ........................................16

$2.1 \quad$ Versuchstiere und Präparation .........................................16

2.1.1 Präparation des spontan rhythmisch aktiven Schnittpräparats ..............16

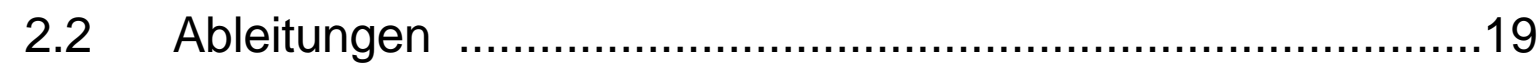

\begin{tabular}{|c|c|}
\hline 2.2 .1 & Ableitung des Nervus hypoglossus \\
\hline 2.2 .2 & Patch clamp Experimente \\
\hline 2.2 .3 & Aufzeichnung der Daten \\
\hline
\end{tabular}

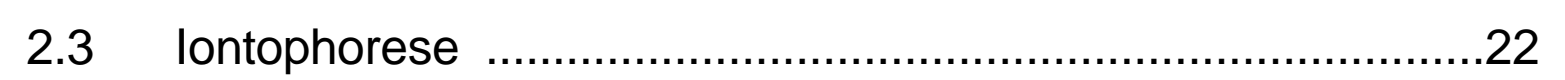

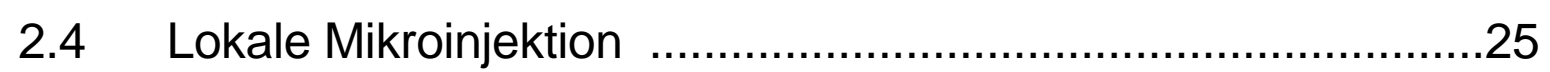

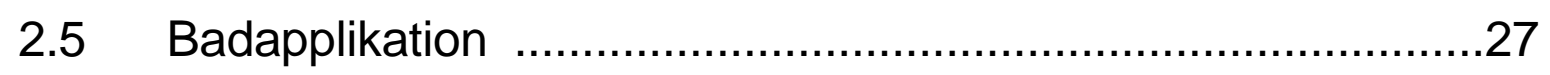

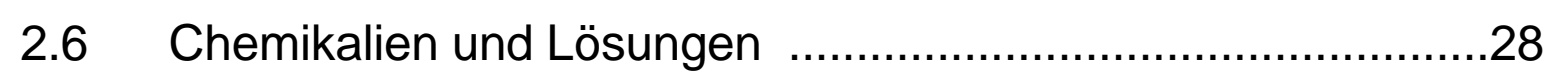




\section{3. $\quad$ Ergebnisse}

\begin{tabular}{|llll|}
\hline 3.1 & Intrazelluläre Ableitungen respiratorischer Interneurone .......32 \\
\hline
\end{tabular}

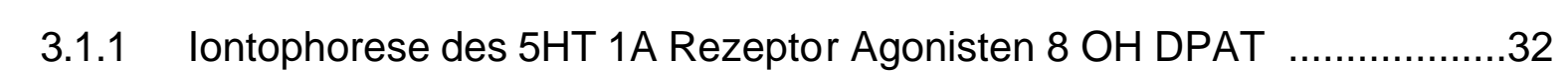

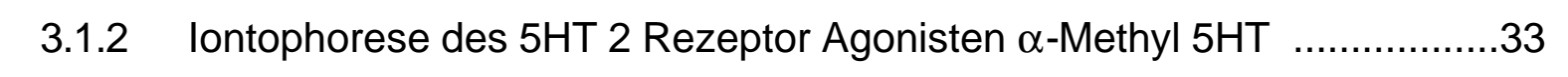

3.2 Mikroinjektionen in den Prä-Bötzinger Komplex und In den Nucleus hypglossus .........................................36

\begin{tabular}{|ll|}
\hline 3.2.1 & Mikroinjektionen in den Prä-Bötzinger Komplex $\ldots \ldots \ldots \ldots \ldots \ldots \ldots \ldots \ldots \ldots \ldots . .38$ \\
\hline \hline 3.2.2 & Mikroinjektionen in den Nucleus hypoglossus $\ldots \ldots \ldots \ldots \ldots \ldots \ldots \ldots \ldots \ldots \ldots \ldots \ldots . .42$ \\
\hline
\end{tabular}

3.3 $\quad$ Badapplikationen ............................................... 48

\begin{tabular}{|c|c|c|}
\hline 3.3.1 & Badapplikation des 5HT 2B Rezeptor Agonisten BW $723 \mathrm{C} 86$ & .48 \\
\hline 3.3 .2 & Badapplikation des 5HT 2 Rezeptor Agonisten $\alpha$-Methyl 5HT & .50 \\
\hline 3.3.3 & Badapplikation des 5HT 2B Rezeptor Antagonisten LY272015 & .50 \\
\hline 3.3.4 & Badapplikation des 5HT 2A Rezeptor Antagonisten Ketanserin & .52 \\
\hline
\end{tabular}

\section{Diskussion}

\begin{tabular}{|c|c|}
\hline 4.1 & Das rhythmisch aktive Schnittpräparat des Hirnstamms ........54 \\
\hline 4.2 & Intrazelluläre Ableitungen \\
\hline 4.3 & Iontophorese \\
\hline 4.4 & 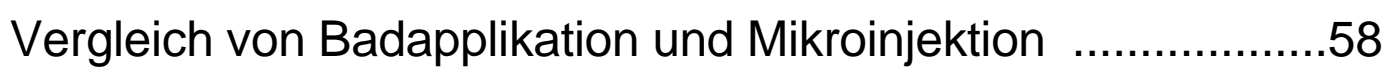 \\
\hline 4.5 & Verwendete 5HT Rezeptor Agonisten und Antagonisten . \\
\hline 4.6 & $\begin{array}{l}\text { Modulatorische Wirkungen von 5HT Rezeptoren an } \\
\text { respiratorischen Interneuronen }\end{array}$ \\
\hline 4.7 & $\begin{array}{l}\text { Lokale Wirkungsweise der verschiedenen 5HT } 2 \text { Rezeptor } \\
\text { Subtypen }\end{array}$ \\
\hline 4.8 & $\begin{array}{l}\text { 5HT 2A und 5HT 2B Rezeptor vermittelte 5HT Effekte auf das } \\
\text { Atemzentrum im Prä-Bötzinger Komplex }\end{array}$ \\
\hline 4.9 & 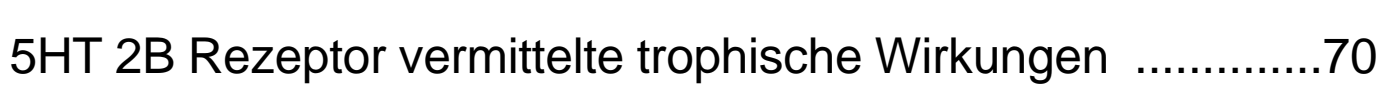 \\
\hline
\end{tabular}


5. Zusammenfassung $\quad$...............................................72

6. Literaturverzeichnis ...............................................77 


\section{Einleitung}

\subsection{Atmung - die respiratorische Kontrolle bei Säugetieren}

Für die Lebensfähigkeit eines Organismus ist eine ständige Sauerstoffzufuhr für den oxidativen Zellstoffwechsel zwingend notwendig. Genauso essentiell ist aber auch, dass der Abtransport schädlicher Stoffwechselprodukte, wie $\mathrm{CO}_{2}$. Letztlich sind alle Funktionen des Körpers auf eine ausreichende $\mathrm{O}_{2}$ - Sättigung des Blutes und einen funktionierenden Gasaustausch angewiesen. Dieser Gasaustausch ist über das Blutkreislaufsystem, dem innerem Transporter der Atemgase zwischen den Atemorganen - der Lunge - und den Orten des zellulären Stoffwechsels gekoppelt (Wehner und Gehring, 1990). Aus diesem Grund ist eine strenge Koordination zwischen respiratorischem und kardiovaskulärem System notwendig. (Richter, 1990; Feldmann et al., 1988) Beide Systeme müssen in der Lage sein, schnell auf Veränderungen im physiologischen Zustand des Organismus zu reagieren.

Eine Regulation der Atmung erfolgt bei Wirbeltieren über eine Regulation der Ventilation (Penzlin, 1991). Bei der sogenannten Saugventilation, wie sie bei Vögeln und Säugetieren vorkommt, wird durch die Vergrößerung des Brustkorbes während des Einatmens ein Unterdruck erzeugt. Dies geschieht zum einen durch die Rippen- oder Brustatmung (kostale Atmung), bei der die Rippen über die Interkostalmuskulatur bewegt werden, welches eine Vergrößerung des Brustkorbes zur Folge hat; zum Anderen wird bei der Zwerchfellatmung (abdominale Atmung) durch das Absenken des in den Thoraxraum 
hereinragenden Zwerchfells der untere Thoraxraum vergrößert (Thews, 1997). Diese beiden Atmungstypen ventilieren die Säugetierlunge. Welcher Atmungstyp hauptsächlich zum Einsatz kommt, ist abhängig von dem physiologischen Zustand des Organismus (Herder Lexikon der Biologie, erster Band, S. 284; 1994). Die Kontrolle der Atemmuskulatur ist sehr präzise, so dass eine äußerst feine Regulierung des Luftstroms möglich wird. Diese genaue Regulierung ist für komplexe menschliche Tätigkeiten, wie zum Beispiel Singen, Pfeifen und Sprechen, aber auch bereits für "einfaches" Atmen notwendig (Eckert et al., 1993, Jacobs et al., 1993). Die Atemmuskulatur wird von medullären und spinalen respiratorischen Motoneuronen aktiviert, die von den in der Medulla oblongata lokalisierten respiratorischen Interneuronen des Atemzentrums rhythmische Impulse erhalten.

Die Atmung bei Säugetieren findet über eine aktive Inspiration und eine eher passiv verlaufende Expiration statt (Herder, 1994; Richter, 1997); beide Phasen sind für einen funktionierenden Gasaustausch unerlässlich. Darüber hinaus existiert noch eine dritte Phase der aktiven Expiration, bei der durch die Erregung und Kontraktion der expiratorischen Interkostalmuskeln der unteren Thorakalsegmente und der expiratorischen Abdominat und Lumbalmuskulatur der abdominale Druck erhöht und gleichzeitig die Zwerchfellkuppel angehoben wird (Richter, 1997).

Tritt eine Veränderung bestimmter Faktoren des inneren Milieus oder des Atemmediums auf, so findet eine Anpassung der Leistung der Atmungsorgane statt, oftmals verbunden mit einer zusätzlichen Anpassung des Kreislaufs. Die wichtigsten veränderbaren Parameter dabei sind der $\mathrm{O}_{2}$ - bzw. $\mathrm{CO}_{2}$ - Partialdruck im Organismus bzw. im Atemmedium, sowie pH - Wert Verschiebungen im Blut. 
Des weiteren besteht die Möglichkeit unspezifischer Atmungsantriebe, wie Wärme- und Kältereize; Schmerz, Hormone sowie Veränderungen der Körpertemperatur. Chemosensoren im Glomus caroticum und Glomus aorticum überwachen Änderungen der Partialdrucke von $\mathrm{O}_{2}$ und $\mathrm{CO}_{2}$ im arteriellen Blut (Eckert et al., 1993). Bei Säugetieren kontrollieren und steuern außerdem zentrale, in der Medulla oblongata gelegene Chemorezeptoren die Lungenventilation, die auf eine $\mathrm{pH}$ - Wert Abnahme im Liquor cerebrospinalis, welche durch einen erhöhten $\mathrm{pCO}_{2}$ hervorgerufen wird, reagieren. Allerdings sind diese zentralen Chemorezeptoren nicht in der Lage, auf Veränderungen im $\mathrm{pO}_{2} \mathrm{zu}$ reagieren, dies geschieht ausschließlich durch die peripheren Chemorezeptoren (Eckert et al., 1993).

\subsection{Das medulläre respiratorische Netzwerk}

Das neuronale Netzwerk, das für die Ausbildung des zentralnervösen Atemrhythmus verantwortlich ist, befindet sich in der Formatio reticularis des Hirnstamms. Die respiratorischen Muskeln werden von spinalen Motoneuronen innerviert. Diese Motoneurone wiederum erhalten ihre Informationen von Gruppen respiratorischer Neurone, die in der bilateral angeordneten dorsalen respiratorischen Gruppe (DRG) und der ventralen respiratorischen Gruppe (VRG) lokalisiert sind (Richter, 1997; Richter and Spyer, 2001). Nur die VRG ist für die Rhythmogenese verantwortlich. Sie befindet sich im ventrolateralen Bereich der Medulla oblongata innerhalb des lateralen tegmentalen Feldes. In ihrer rostrokaudalen Ausrichtung erstreckt sich die VRG vom Nucleus retrofacialis bis zum ersten zervikalen Rückenmarkssegment und bildet somit eine Zellsäule 
entlang des Nucleus ambiguus (NA) (Richter and Spyer, 1990; Richter, 1997; Richter and Spyer 2001). Die VRG lässt sich funktionell in mehrere Bereiche unterteilen. Im am weitesten rostral gelegenen Teil der VRG sammeln sich vorwiegend expiratorische Neurone, die in ihrer Gesamtheit als Bötzinger Komplex bezeichnet werden. Kaudal des Bötzinger Komplex liegt ein weiteres Kerngebiet, der Prä-Bötzinger Komplex (PBC), welcher eine entscheidende Rolle bei der Entstehung des Atemrhythmus spielt. Sämtliche Typen respiratorisch aktiver Neurone, die für die Entstehung des Atemrhythmus wichtig sind, sind dort nachgewiesen worden (Richter, 1997; Richter and Spyer, 2001). Kaudal des PBC schließt sich die kaudale VRG an, die sich von der Höhe Obex bis in die ersten Zervikalsegmente des Rückenmarks erstreckt (Richter, 1997). Die DRG dagegen befindet sich in der dorsomedialen Medulla, im Bereich der ventrolateralen Anteile des Nucleus tractus solitarius (NTS), sowie der angrenzenden Formatio reticularis, auf Obexhöhe. Sie enthält in erster Linie inspiratorische Neurone, deren Funktion in der Vermittlung oligosynaptischer vagaler Reflexe besteht.

Der PBC gilt als der Ursprung des respiratorischen Rhythmus bei Säugetieren. Er besteht aus einem bilateral angeordneten Netzwerk von rhythmusgenerierenden Neuronen innerhalb der ventrolateralen Medulla (Reckling and Feldmann, 1998; Smith et al., 1991; 2000; Johnson et al., 2001).

Es wird angenommen, dass diese Region einen "Kern" enthält, der für die Rhythmogenese verantwortlich ist. Zur Zeit werden drei unterschiedliche Modelle des Zustandekommens des Atemrhythmus diskutiert. 


\section{Die "conditional network-bursting theory"}

Dieser Theorie liegt zu Grunde, dass die rhythmische Abwechslung phasischer Aktivitäten das Resultat von zwei miteinander interagierenden Prozessen ist. Erste Grundlage ist die synaptische Interaktion zwischen bestimmten Arten von Neuronen (Richter and Spyer., 1990; Richter et al., 1992). Zweite Voraussetzung ist die dynamische Anpassung von inneren bursting Eigenschaften der beteiligten Neurone (Richter et al., 1992; Ramirez and Richter, 1996). Diese Theorie betont, dass die eigenen Leitfähigkeiten der Zellen über synaptische Verbindungen kontrolliert werden. Nur wenn die Stärke dieses sogenannten "funktionellen synaptischen Voltage clamp" abnimmt - also nur während eines kurzen Zeitraums - erlangen diese genannten Eigenschaften Gültigkeit. Aus diesem Grund findet man zelluläres "Bursting" nur zu Beginn inspiratorischer und post-inspiratorischer Phasen vor (Richter and Spyer, 2001).

\section{Die "pacemaker theory"}

Diese Theorie postuliert, dass der respiratorische Rhythmus primär von Schrittmacher-Zellen ausgeht, welche rhythmische "Bursts" auf inspiratorisch folgende Neurone übertragen und damit den inspiratorischen Rhythmus antreiben. Begründet wird diese Aussage mit der Beobachtung, dass bei in vitro Präparaten eine rhythmische Aktivität erhalten bleibt, obwohl jede inhibitorische synaptische Transmission blockiert wird (Funk and Feldman, 1995). Das wiederum führte zu der Schlussfolgerung, dass inhibitorische synaptische Interaktionen nicht entscheidend sind für die Entstehung des Atemrhythmus; ihre Funktion besteht vielmehr darin, die Aktivität der daran beteiligten Neurone zu modifizieren (Ramirez et al., 1997; Richter and Spyer, 2001). 


\section{Das "hybrid-pacemaker-network" Modell}

In diesem Modell wurde die "pacemaker theory" durch ein Computermodell erweitert. Zusätzlich zu endogenen Schrittmachern beinhaltet diese Erweiterung Daten verschiedener Interaktionen zwischen respiratorischen Neuronen (Smith et al., 2000; Richter and Spyer, 2001).

In jedem Fall gilt als gesichert, dass der respiratorische Rhythmus seinen Ursprung im PBC hat. Innerhalb dieser funktionell und strukturell definierten Region wurden Neuronen mit unterschiedlichen Eigenschaften identifiziert (Reckling and Feldman, 1998). Eben diese sind notwendig für das Zustandekommen des respiratorischen Rhythmus (Liu et al., 2001). Verschiedene im PBC lokalisierten Neurone zeigen inspiratorische, expiratorische und phasenübergreifende Aktivitäten. Tatsächlich gibt es drei verschiedene Klassen von Neuronen: 1. Inspiratorische Neurone (I - Neurone), die während der Phase der Inspiration aktiv sind; 2. post-inspiratorische Neurone (PI - Neurone), die während der ersten, passiven Ausatmungsphase - der sogenannten Postinspiration - aktiv sind, und 3. expiratorische Neurone ( $E_{2}-$ Neurone), die während der zweiten aktiven Expirationsphase aktiv sind. Die erste Klasse der I - Neurone kann abermals anhand unterschiedlichen Verhaltens in vier Typen unterteilt werden: Die Prä--Neurone, die kurz vor und zu Beginn der Inspiration aktiv sind; die sogenannten Früh-I-Neurone zeigen dagegen Aktivität während der frühen Phase der Inspiration. Neben Neuronen, die während der terminalen Phase (Spät--Neurone) aktiv sind, gibt es Neuronen, die während der gesamten Inspirationsphase entladen, und zwar mit einer "rampenförmig" ansteigenden Frequenz (Rampen--Neurone) (Richter, 1997; Hilaire et al., 1999). 


\section{3 Die Entwicklung des respiratorischen Systems}

Während bei der adulten Ratte eine ausgeprägte synaptische Interaktion innerhalb des gesamten Netzwerks der respiratorischen Neurone für die Bildung des Atemrhythmus als entscheidend angesehen wird, scheinen diese Mechanismen beim Neugeborenen weniger stark ausgebildet zu sein. Mit Hilfe von in vitro Experimenten am Hirnstamm-Rückenmark Präparat der embryonalen Ratte konnte gezeigt werden, dass das medulläre respiratorische Netzwerk bereits pränatal entwickelt ist und neuronale Aktivität aufweist. Ab dem 17. Embryonaltag (E17) ist ein spontaner respiratorischer Rhythmus nachweisbar. Allerdings ist dieses fötale System zu diesem Zeitpunkt nicht in der Lage, einen stabilen, gleichmäßigen Rhythmus, der in Form von Entladungsfrequenz und Entladungsamplitude dem neonatalen System gleicht, zu generieren (Hilaire and Duron, 1999). Ab E20 bis zur Geburt stabilisiert sich das respiratorische System.

Es hat sich herausgestellt, dass inhibitorische Einflüsse zu diesem Zeitpunkt innerhalb des Netzwerks für die Entstehung des respiratorischen Rhythmus nicht zwingend notwendig sind. Außerdem sind Neurone in diesem Stadium noch nicht in der Lage, sämtliche möglichen lonenleitfähigkeiten zu benutzen (Richer and Spyer, 2001). Verschiedene endogene Substanzen modulieren die respiratorische Aktivität, indem sie direkt auf die rhythmischen Neurone einwirken. Bei erwachsenen Ratten dagegen spielen inhibitorische Verbindungen innerhalb des medullären Netzwerks eine wichtige Rolle bei der Entstehung des Atemrhythmus (Richter, 1997; Richter and Spyer, 2001). Der adulte Atemtyp entwickelt sich innerhalb der ersten drei postnatalen Wochen. Die meisten Mechanismen, die im 
neonatalen Tier modulierend wirken, existieren vermutlich auch in erwachsenen Tieren, es ist jedoch schwierig, dies in adäquaten in vivo Experimenten nachzuweisen (Hilaire and Duron, 1999).

\subsection{Serotonin und Serotoninrezeptoren}

Ursprünglich als Blutserumfaktor entdeckt, ist Serotonin (5HT) aus der Familie der biogenen Amine funktionell in viele verschiedene biologische Prozesse eingebunden. Es entsteht durch die Decarboxylierung der Aminosäure Tryptophan. 5HT kann unter anderem Veränderungen im Zytoskelett hervorrufen und dadurch die Bildung von interzellulären Kontakten beeinflussen. Darüber hinaus spielt Serotonin bei der Zellproliferation, sowie bei der Migration und Reifung einer Vielzahl von Zelltypen, darunter Zellen der Lunge, Niere, Endothelzellen, Mastzellen, Neurone und Astrozyten, eine wichtige Rolle (Azmitia, 2001).

Im Zentralnervensystem (ZNS) sind bisher sieben Familien von Serotoninrezeptoren beschrieben, die mindestens 14 verschiedene Rezeptorproteine beinhalten (Julius, 1998; Azmitia, 2001).

Diese 14 verschiedenen Rezeptorsubtypen wurden durch molekularbiologische, pharmakologische und funktionelle Unterschiede klassifiziert. (Hoyer, 1997; Kennett, 1997; Oh et al., 2001). Die meisten Serotoninrezeptoren gehören zu der

Familie der G-Protein gekoppelten Rezeptoren. Die Rezeptoren der 5HT 3 Rezeptorfamilie dagegen stellen eine Ausnahme dar, denn sie gehören zu der Familie der ligandengesteuerten lonenkanäle, d.h. ihre Wirkung wird nicht über G-Proteine vermittelt (Gerhardt et al., 1997; Gingrich et al., 2001). Die 
Untereinheiten der 5HT 3 Rezeptoren bilden als Pentamere einen Kationenkanal, der permeabel für $\mathrm{Na}^{+}-, \mathrm{K}^{+}$- und $\mathrm{Ca}^{++}$-lonen ist und somit depolarisierend wirkt (Kennett, 1997).

Die Rezeptoren der 5HT 1 und 5HT 5 Rezeptorfamilie sind über $G_{\alpha}$-Proteine negativ an die Adenylatcyclase gekoppelt. Die Rezeptoren der 5HT 4, 5HT 6 und 5HT 7 Rezeptorfamilien dagegen sind über $\mathrm{G}_{\mathrm{s}}$-Proteine positiv an die Adenylatcylase gekoppelt, wobei ATP zu cAMP als intrazellulärem Botenstoff umgewandelt wird. Die Rezeptoren der 5HT 2 Rezeptorfamilie sind über die $\mathrm{G}_{\mathrm{q}}$-Proteine positiv an die Phospholipase $\mathrm{C}$ gekoppelt. Durch die Aktivierung der Phospholipase wird diese zur Hydrolyse von membrangebundenen 1-Phosphatidyl-1 $\mathrm{D}$-myo-Inositol-(4,5)- $\mathrm{P}_{2} \quad\left(\mathrm{PIP}_{2}\right) \quad$ aktiv. Dabei entstehen Inositot(1,4,5)- $\mathrm{P}_{3}\left(\mathrm{IP}_{3}\right)$ und 1,2-Diacylglycerin (DAG) als intrazelluläre Botenstoffe.

Eine besondere Stellung unter den Rezeptoren der 5HT 2 Rezeptorfamilie nimmt der 5HT 2B Rezeptor ein, denn er ist von entscheidender Bedeutung während der embryonalen Entwicklung. Die erste Expression dieses Rezeptors ist schon 8-9 Tage postcoitum nachzuweisen (Choi et al., 1997). Neben der Aktivierung der Phospholipase $C$ über die $\alpha$ Untereinheit des $G_{q}$-Proteins, aktiviert die Bindung von $5 \mathrm{HT}$ an den $5 \mathrm{HT}$ 2B Rezeptor weitere intrazelluläre Signaltransduktionsmechanismen. So wird neben der Phospholipase A2 auch die NO-Synthase aktiviert. Darüber hinaus verursacht die Aktivierung des 5HT 2B Rezeptors die Aktivierung des Protooncogenprodukts p21 ${ }^{\text {ras }}$ und der MAP Kinasen p42 ${ }^{\text {mapk} / p 44}{ }^{\text {mapk }}$. Über die Aktivierung der Tyrosin Kinase c-Src und der Rezeptor Tyrosin Kinase des PDGF (patelet-derived growth factor) Rezeptors werden mitogene Signale vermittelt (Nebigil et al., 2000). 
Über imunhistochemische Methoden konnten Duxon et al. den Nachweis erbringen, dass der 5HT 2B Rezeptor im ZNS der Ratte vorhanden ist (Duxon et al., 1997). Außerdem zeigt die KO Maus für diesen Rezeptor einen charakteristischen Phänotyp (Nebigil et al., 2000a; 2001b).

Die vielfältigen Wirkungen des Serotonin im ZNS werden vor allem durch die postsynaptisch lokalisierten $5 \mathrm{HT}$ Rezeptoren vermittelt. Aufgrund der immensen Anzahl von Möglichkeiten der Lokalisation, der Signaltransduktionsmechanismen und der unterschiedlichen pharmakologischen Eigenschaften ist es immer noch sehr schwer, die genaue Funktion und das Zusammenspiel der postsynaptisch lokalisierten 5HT Rezeptoren zu erklären. Nach wie vor bleiben zahlreiche Lücken im Verständnis der Anatomie und Physiologie von Serotonin und seinen Funktionen als Neurotransmitter, Neuromodulator und als Hormon (Murphy et al., 1998; Gingrich et al., 2001).

\subsection{Das Serotonerge System}

Das Serotonerge System innerviert nahezu sämtliche Regionen des Gehirns und stellt das am weitesten ausgedehnte und komplexeste unter den bislang bekannten Transmittersystemen des ZNS dar. Während serotonerge Zellkörper ausschließlich im Hirnstamm lokalisiert sind, existiert darüber hinaus auch ein weit verzweigtes Axonnetz. Serotonerge Neurone stellen den größten Anteil des im Gehirn produzierten Serotonins her und erreichen über ihre Terminalen nahezu das gesamte ZNS (Julius, 1998; Jacobs and Azmitia, 1992). Diese weite Verteilung ermöglicht dem serotonergen System, seinen hauptsächlich 
modulierenden Einfluss nicht nur auf das respiratorische System, sondern auch auf eine Vielzahl weiterer physiologischer Vorgänge auszuüben (Jacobs and Azmitia, 1992). Es zeigen sich starke lokale Unterschiede in der Innervationsdichte des serotonergen Systems. Die Zielneurone werden einerseits durch eine Ausschüttung von Serotonin in den Extrazellulärraum, andererseits durch direkte synaptische Übertragung beeinflusst. Bedingt durch die große Anzahl verschiedener Serotoninrezeptoren kann die Reaktion der entsprechenden Zielzelle in Abhängigkeit der beteiligten Rezeptortypen sehr variabel ausfallen (Jacobs and Azmitia, 1992). Die enge Nachbarschaft der serotonergen Kerne zu den autonomen Zentren des ZNS deutet auf eine Beteiligung des Serotonins an verschiedenen autonomen und neuroendokrinen Prozessen hin (Azmitia et al., 1991; Jakobs und Fornal, 1993).

Ursprünglich wurden die serotonergen Kerngebiete mit Hilfe histochemischer Markierungsmethoden in Zellgruppen B1-B9 eingeteilt (Dahlström and Fuxe, 1964). Da diese Zellgruppen in engem Zusammenhang mit den Raphekernen stehen, werden sie heute dementsprechend benannt. Aufgrund ihrer Embryonalentwicklung werden die serotonergen Kerngebiete in zwei Hauptgruppen aufgeteilt: eine rostrale Gruppe im Mittelhirn und eine kaudale, rhombenzephale Gruppe. Der Nucleus raphe medianus (B8 und B5) bildet gemeinsam mit dem Nucleus raphe dorsalis (B6 und B7), den lateral liegenden Neuronen der Gruppe B9 und dem Nucleus caudalis linearis (B8) die rostrale (superiore) Gruppe. Die kaudale (inferiore) Gruppe besteht aus dem Nucleus raphe obscurus (B2), dem Nucleus raphe pallidus (B1 und B4) und dem Nucleus raphe magnus (B3) (Jacobs and Azmitia, 1992). Zu der kaudalen Gruppe gehören 
außerdem serotonerge Zellkerne, die im ventrolateralen medullären Bereich lokalisiert sind und dem Nucleus reticularis paragigantocellularis lateralis und dem Nucleus interfascicularis hypoglossi zugeordnet werden können. Vervollständigt wird die kaudale Gruppe durch Neurone, die innerhalb der Area postrema lokalisiert sind (Halliday et al., 1995).

\subsection{Serotonerge Modulation der respiratorischen Aktivität}

Die Entwicklung und Kontrolle des respiratorischen Netzwerks steht unter modulatorischem Einfluss verschiedener endogener Wirkstoffe. Monoamine, wie Noradrenalin, Adrenalin, Histamin und Serotonin, beispielsweise haben modulierende Effekte (Jacobs und Azmitia, 1992).

Serotonin ist einer der ersten Neuromodulatoren, der während der Ontogenese exprimiert wird. Die Entwicklung des serotonergen Systems beginnt ab dem 12. Embryonaltag. Da dieses System so frühzeitig im embryonalen Nervensystem vorhanden ist, kann man davon ausgehen, dass 5HT eine Wirkung als morphogenetischer Faktor hat (Lauder, 1990; Hilaire and Duron, 1999). 5HT kann sowohl biochemisch als auch morphologisch die Differenzierung von Raphe Neuronen beeinflussen (Lauder, 1990).

Endogenes Serotonin hat bereits einen sehr starken modulatorischen Einfluss auf den fötalen Rhythmusgenerator. Ab dem 17. Embryonaltag ist das respiratorische Netzwerk der Ratte in der Lage, rhythmische Aktivität zu erzeugen (Hilaire and Duron, 1999; Pestean, 1999; Bou-Flores, et al., 2000); ab dem 18. Embryonaltag wird $5 \mathrm{HT}$ als unentbehrlich für die Rhythmogenese angesehen. Werden 
bestimmte 5HT Rezeptoren blockiert, hat dies einen Stop des respiratorischen Rhythmus zur Folge. Eine Aktivierung dieser Rezeptoren führt zu einer Beschleunigung des respiratorischen Atemrhythmus (Di Pasquale et al., 1994; Hilaire and Duron, 1999; Bou-Flores et al., 2000).

Zum Zeitpunkt der Geburt wird die Aktivität der respiratorischen Motoneurone durch endogene Substanzen wie Serotonin direkt beeinflusst. 5HT kann einerseits über postsynaptische Rezeptoren die Feuerungsrate respiratorischer Motoneurone, andererseits den Input, den diese Motoneurone erhalten, über präsynaptische Rezeptoren beeinflussen. Zudem wirkt 5HT direkt auf das medulläre respiratorische Netzwerk. Das bedeutet, dass der endogene $5 \mathrm{HT}$ Spiegel die Aktivität des gesamten Netzwerks während der Entwicklung kontrolliert und darüber die Reifung des respiratorischen Netzwerks beeinflusst (Hilaire and Duron, 1999).

Serotonin modifiziert die Erregbarkeit von respiratorischen Neuronen (Lalley, 1994; Lalley et al., 1994 a,b,c; Lalley et al., 1995). Da Serotonin direkt sowohl auf den Rhythmusgenerator, als auch auf die respiratorischen Motoneurone wirkt, vermittelt es vielfältige Effekte auf die Respiration (Hilaire et al., 1997; Hilaire and Duron, 1999; Morin et al., 1990). Die Mechanismen dieser funktionalen Adaptation des respiratorischen Netzwerks sind bis jetzt nicht vollständig geklärt, da $5 \mathrm{HT}$ sowohl exzitatorisch als auch inhibitorisch modulierende Effekte über die Vielzahl der Serotonin Rezeptorsubtypen vermittelt.

Beispielsweise beschleunigt $5 \mathrm{HT}$ die rhythmische Nervenaktivität im isolierten Hirnstamm-Rückenmark Präparat, in dem die Funktionen des respiratorischen Netzwerks erhalten sind (Morin et al., 1990; Lindsay and Feldman, 1993; Al-Zubaidy et al., 1996; Ballanyi et al., 1999). Im Gegensatz dazu wurde ebenfalls 
beobachtet, dass 5HT auch inhibierende Effekte haben kann (Monteau et al., 1990; Morin et al., 1992).

Als sehr bedeutend in der Vermittlung der modulatorischen Wirkung von 5HT werden einerseits der 5HT $1 \mathrm{~A}$ Rezeptor und andererseits die Rezeptoren der 5HT 2 Rezeptor Familie angesehen. Werden beispielsweise in der embryonalen Ratte die 5HT 1A Rezeptoren über spezifische Antagonisten blockiert, hat dies einen Stop der respiratorischen Aktivität zur Folge (Morin et al., 1990; 1991). Wurden Agonisten für den 5HT 2 Rezeptor gegeben, so verstärkte sich die inspiratorische Aktivität. Diese Verstärkung, bedingt durch die Gabe von 5HT, konnte durch $5 \mathrm{HT}$ 2 Rezeptor Antagonisten, jedoch nicht durch 5HT 1A Rezeptor Antagonisten blockiert werden (Onimaru et al., 1998).

\subsection{Zielsetzung dieser Arbeit}

Im Rahmen dieser Arbeit sollten die Wirkungen bestimmter 5HT Rezeptorsubtypen auf respiratorische Motoneurone und Interneurone des PBC untersucht werden. Der Schwerpunkt lag dabei auf den Effekten, die über 5HT 2 Rezeptoren vermittelt wurden. Über die gezielte Gabe von Agonisten und Antagonisten konnte die Reaktion des rhythmisch aktiven Netzwerks in Form der Aktivität von respiratorischen Interneuronen und Motoneuronen registriert werden. Mit den zur Verfügung stehenden pharmakologischen und elektrophysiologischen Mitteln sollte eine Auftrennung zwischen 5HT 2A und 5HT 2B Rezeptoren vorgenommen werden.

Es wird gezeigt, dass sowohl 5HT 2A als auch 5HT 2B Rezeptoren modulierend auf den Atemrhythmus des neonatalen rhythmischen Netzwerks der Ratte wirken 
wobei die Aktivierung dieser Rezeptorsubtypen ähnliche, synergistische Effekte auf die untersuchten Neuronenpopulationen des Nucleus hypoglossus und des PBC zur Folge hat.

Die Blockade dieser Rezeptorsubtypen bringt jedoch einen entscheidenden Unterschied in ihrer Wirkungsweise zu Tage: Werden die 5HT 2A Rezeptoren durch spezifische Antagonisten blockiert, zeigt sich keine Auswirkung auf den im rhythmisch aktiven Schnittpräparat erhaltenen respiratorischen Rhythmus; eine Blockade der 5HT 2B Rezeptoren über einen spezifischen Antagonisten dagegen hat einen Stop der respiratorischen Aktivität zur Folge. Das bedeutet, dass endogenes Serotonin über $5 \mathrm{HT}$ 2B Rezeptoren eine entscheidende Rolle zur Aufrechterhaltung der respiratorischen Aktivität des neonatalen Netzwerks spielt.

Im Rahmen dieser Arbeit wird der erste Beweis erbracht, dass 5HT 2B Rezeptoren im ZNS eine funktionelle Rolle spielen. 


\section{Material und Methoden}

\subsection{Versuchstiere und Präparation}

Für die Experimente wurden neugeborene Sprague-Dawley Ratten (Charles River, Deutschland) verwendet. Zur Herstellung des Präparats wurden Ratten verschiedener Altersstufen (Tag der Geburt bis postnataler Tag 5) verwendet.

\subsubsection{Präparation des spontan rhythmisch aktiven Schnittpräparats}

Zur Herstellung eines spontan rhythmisch aktiven Schnittpräparats des Hirnstamms wurden neugeborene Ratten unter Äthernarkose dekapitiert. Die Schädelkalotte wurde entfernt, so dass das Gehirn frei von dorsal zugänglich wurde. Der Hirnstamm wurde von rostral nach kaudal vorsichtig aus dem Schädel herauspräpariert. Dabei wurden die Hirnnerven mit Hilfe einer Federschere möglichst nahe an der Schädelbasis abgeschnitten. Der Hirnstamm wurde vorsichtig vom Cerebellum abgetrennt. Das Präparat wurde mit der ventralen Seite nach oben fixiert und rostral auf Höhe der Pons transversal durchtrennt. Kaudal wurde das Präparat in Höhe der Spinalnerven des zweiten Zervikalsegments abgeschnitten. Der resultierende Gewebeblock wurde mit Hilfe eines Sekundenklebers (Pattex Blitz-Gel) mit der rostralen Seite auf den PVC-Block einer Vibratomkammer (Camden Instruments, UK) festgeklebt und mit artifizieller cerebrospinaler Lösung (ACSF) überspült. Anschließend wurden transversale Schnitte mit einer Dicke von $200 \mu \mathrm{m}$ angefertigt. Begonnen wurde mit dem 
kaudalen Ende. Die Schnittührung wurde unter einem Dissektionsmikroskop beobachtet und die einzelnen Schnitte lichtmikroskopisch kontrolliert. Nach Erreichen einer transversalen Ebene dicht kaudal des PBC, wurde ein 450-750 $\mu \mathrm{m}$ dicker Schnitt angefertigt, der den PBC sowie den Nucleus hypoglossus zusammen mit seinen Wurzeln enthielt (siehe Abb. 2.1).

Die Schnitte wurden in eine Messkammer überführt. Dort wurden sie entweder auf einem gespannten Netz mit Insect Pins (FST, Heidelberg, Deutschland), oder mit Hilfe eines mit Nylonfäden bespannten Rahmens fixiert. Durch die Platzierung auf einem Netz wurde eine optimale Umspülung des Schnittpräparats von allen Seiten gewährleistet. Die Perfusionslösung - Artifizielle cerebrospinale Flüssigkeit (ACSF, Zusammensetzung siehe 2.6) war auf $27^{\circ} \mathrm{C}$ temperiert und durch die konstante Begasung mit $95 \% \mathrm{O}_{2}$ und $5 \% \mathrm{CO}_{2}$ wurde der pH-Wert auf $\mathrm{pH} 7,4$ eingestellt. Der Kaliumgehalt der Lösung wurde von $3 \mathrm{mM}$ auf $8 \mathrm{mM} \mathrm{K}^{+}$angehoben, um die spontane rhythmische Aktivität des Hirnstammschnittes zu erhalten (Greer et al., 1992; Smith et al. 1991). Das Summenpotential der Aktivität der Hypoglossus Motoneurone (XII Motoneurone) wurde mit Hilfe einer Saugelektrode, die an den Wurzeln des $\mathrm{N}$. hypoglossus angebracht wurde, aufgenommen. 
A

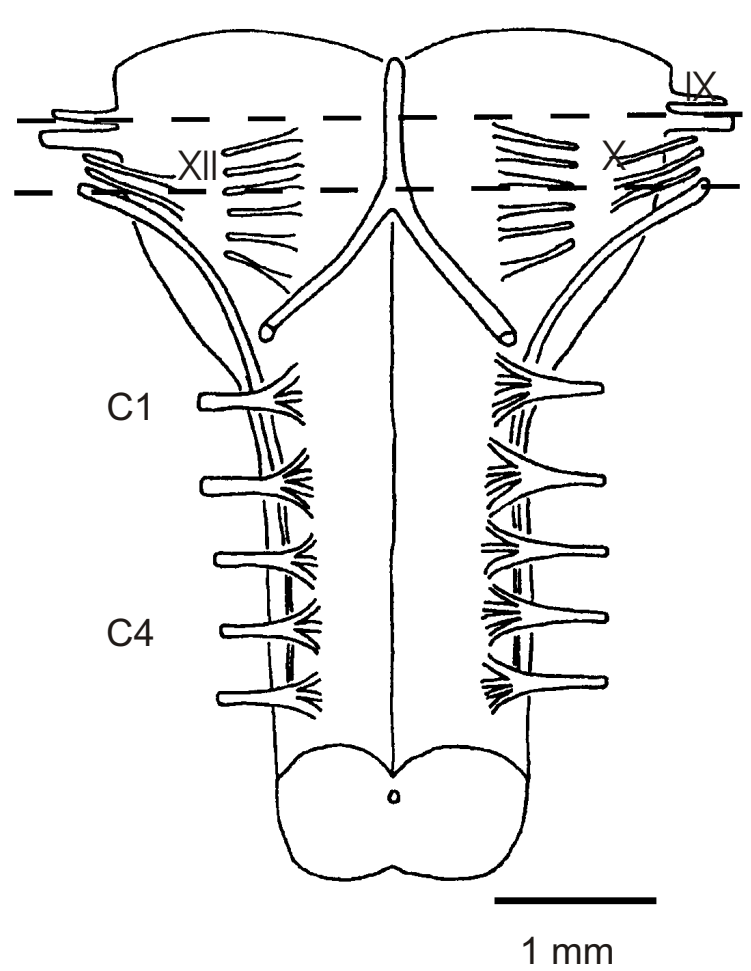

B
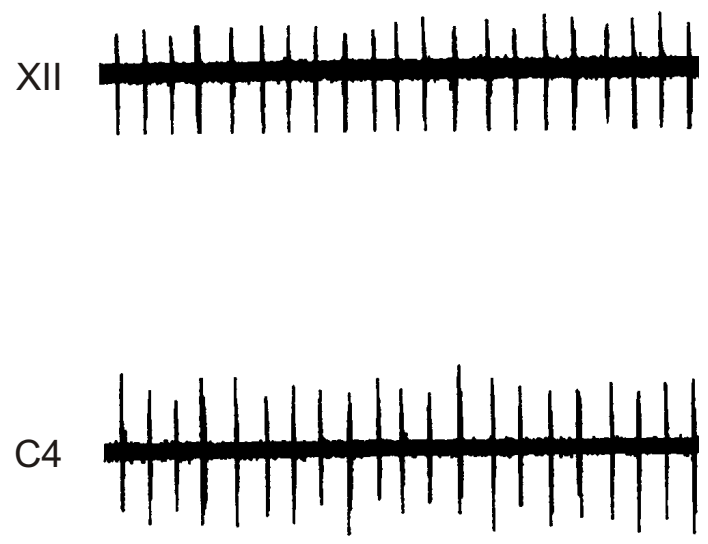

$1 \min$

C

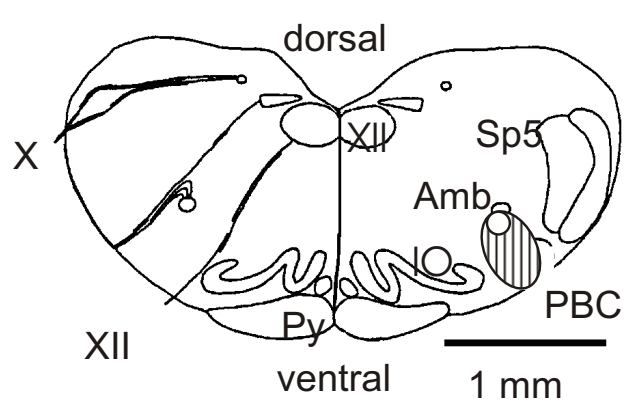

D

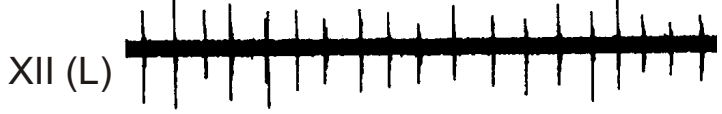

XII (R)

$1 \min$

Abb. 2.1: A: Ventrale Ansicht des Hirnstamms einer neugeborenen Ratte. Die gestrichelten Linien zeigen die horizontalen Schnittebenen des spontan rhythmisch aktiven Schnittpräparats an. C1 und C4: Vorderwurzeln des 1. bzw. 4. zervikalen Spinalnerven

B: Mit Hilfe einer Saugelektrode konnte der respiratorische Rhythmus über die Wurzeln des N. hypoglossus (XII) und an den Vorderwurzeln des 4. zervikalen Spinalnerven abgeleitet werden C: Die rostrale Ansicht des spontan rhythmisch aktiven Schnittpräparats. PBC: Prä- Bötzinger Komplex, Amb: Nucleus ambiguus. IO: Nucl. olivaris inferior. Py: Pyramis. SP5:Tractus spinalis trigemini. X: Wurzeln des $\mathrm{N}$. vagus. XII: Nucl. hypoglossus

D: Aufzeichnungen der Aktivitäten der jeweiligen linken XII (L) und rechten XII (R) Wurzeln des N. hypoglossus. 


\subsection{Ableitungen}

Bei den verschiedenen Ableitungen kamen unterschiedliche Elektrodentypen zum Einsatz. Alle wurden aus Borsilikatglas Kapillaren (Harvard Apparatus LTD, Edenbridge, UK) mit Hilfe eines Pipettenziehgeräts (DMZ Universal Puller, Zeitz; Augsburg, Deutschland) hergestellt.

\subsubsection{Ableitung des $\mathrm{N}$. hypoglossus}

Das Summenpotential der XII Motoneurone wurde mit Hilfe von Saugelektroden aufgenommen. Bei diesen Elektroden wurde die Spitze auf einen Öffnungsdurchmesser von 10-20 $\mu \mathrm{m}$ abgebrochen und rundgeglüht. Das Signal der Wurzel wurde 1000-fach verstärkt, gefiltert (Hochpassfilter 2,5kHz; Tiefpassfilter $200 \mathrm{~Hz}$ ) und mit einer Zeitkonstante von 20-30ms integriert.

\subsubsection{Patch clamp Experimente}

Für Patch clamp Elektroden bei Messungen im Whole cell Modus wurden Glaskapillaren mit innerem Filament verwendet. Diese hatten einen durchschnittlichen Spitzendurchmesser von $2 \mu \mathrm{m}$ und einen Spitzenwiderstand von $4-6 \mathrm{M} \Omega$.

Die Patch clamp Methode wird angewandt, um Zellen in einem definierten elektrischen Zustand zu halten. Es gibt verschiedene Konfigurationen der Methode. Im Rahmen dieser Arbeit wurde ausschließlich mit dem Whole cell 
Modus gearbeitet. Bei dieser Konfiguration wird das Spannungs- bzw. Strommuster einer ganzen Zelle untersucht.

Das Membranpotential wurde mit einem Einzelzell-Elektroden Voltage clamp Verstärker (SEVC-1, NPI, Tamm, Deutschland) aufgenommen. Dazu wurden verschiedene Modi verwendet. Bis zum Erreichen der Whole cell Konfiguration wurde im Bridge mode bei abgeglichener Brücke abgeleitet. Nach Erreichen der Whole cell Konfiguration wurde erneut die Brücke abgeglichen und der Current clamp Modus hergestellt. Um korrekt in diesen Modus zu gelangen, wurde den Empfehlungen des Herstellers Folge geleistet. Die vorgegebenen Rechteckpulse wurden bei niedriger Frequenz und mittels eines zusätzlichen Oszillators kontrolliert. Die Ableitungen erfolgten bei einer Switching frequency von $30-40 \mathrm{kHz}$. Bei dieser Einstellung wurde der Strom der durch die Membran fließt fest vorgegeben und das Potential blieb variabel.

Patch clamp Elektroden wurden mit Pipettenlösung (siehe 2.6) gefüllt, an einem Mikromanipulator (DC3001, WPI, Berlin, Deutschland) befestigt und mit einem leichten Überdruck $(30 \mathrm{mmHg})$ auf der Flüssigkeitssäule in der Pipette langsam in das Gewebe eingeführt. Der Überdruck wurde angelegt, um eine Verschmutzung der Pipettenspitze zu verhindern.

Um den elektrischen Widerstand der Pipettenspitze zu überwachen, wurden hyperpolarisierende negative Pulse $-40 \mathrm{nA}, 20 \mathrm{~ms}$, in einem Intervall von $50 \mathrm{~ms}$ ) angelegt. Wurde eine Vergrößerung in der Spannungsantwort (gleichzusetzen mit einer Widerstandserhöhung) der Pipettenspitze registriert, wurde der positive Druck von der Pipette genommen. In den meisten Fällen erhöhte sich der Widerstand durch das spontane Anlegen der Zellmembran an die Pipettenwände. Dann wurde ein leichter Unterdruck angelegt, bis sich die Ströme über der 
Membran so weit verringerten, dass ein Widerstand von mehreren Gigaohm (G $\Omega$ ) entstand. Um nun die Whole cell Konfiguration zu erreichen, wurden entweder ein ruckartiger Unterdruck angelegt, oder ein kurzer negativer DC Strompuls (0.3$0.5 \mathrm{nA}$, Dauer $30 \mathrm{~ms}$ ) gegeben.

Die analysierten Zellen zeigten Aktionspotentiale mit einem klaren Overshoot und hatten ein stabiles Membranpotential. Der Membranwiderstand wurde mit Hilfe hyperpolarisierender Strompulse (20-70pA bei einer Dauer von 200-500ms) und der resultierenden Spannungsantwort bestimmt.

Respiratorische Neurone wurden funktionell identifiziert. Dazu wurden die Membranpotentialänderungen in Abhängigkeit zu der Phase der rhythmischen respiratorischen Aktivität der synchron abgeleiteten Hypoglossus Wurzel registriert.

\subsubsection{Aufzeichnung der Daten}

Der SEVC-1 Einzell-Elektroden Voltage clamp Verstärker war über ein ITC-16 Interface (Instrutech, Great Neck, New York, USA) an einen Atari Mega-St Computer angeschlossen. Der Verlauf der Experimente wurde mit Hilfe eines Chart recorders (Yokogawa, Amersfort, Niederlande) dokumentiert. Die Strom- und Spannungssignale wurden verstärkt und über eine MacLab/4s Digitalisierungseinheit (AD Instruments, Castle Hill, Australien) zu einem Macintosh Computer (Apple Computer inc., Cupertino, Kalifornien, USA) weitergeleitet, aufgezeichnet und digitalisiert. 


\subsection{Iontophorese}

Die bei der Iontophorese eingesetzten Elektroden hatten durchschnittliche Spitzenöffnungen von 0.5-1 $\mu \mathrm{m}$ und wurden mit den zu applizierenden Pharmaka gefüllt. Die Konzentration betrug dabei $10 \mathrm{mM}$. Die Applikation der Pharmaka erfolgte über einen konstanten positiven Strom von 30-60nA, der über einen Zeitraum von 10-120s angelegt wurde. Für die lontophorese wurde eine MVCS 02 lontophoreseeinheit (NPI, Tamm, Deutschland) verwendet. Die gewünschten Stoffe sollten möglichst nah an der abgeleiteten Zelle appliziert werden, um den unmittelbaren Effekt beobachten zu können. Aus diesem Grund wurden vor Beginn des Experiments die Spitzen der Patch und lontophorese Pipetten unter optischer Kontrolle mit Hilfe eines Stereomikroskops bis zu einem Abstand von 10-20 $\mu \mathrm{m}$ zueinander gebracht. (siehe Abb. 2.2) Beide Elektroden, die Iontophorese und die Patch Elektrode, waren an motorisierten Mikromanipulatoren (DC3001 mit MS 314 Kontrolleinheit, WPI, Berlin, Deutschland) befestigt. Anschließend wurde die Iontophorese Elektrode um einen definierten Abstand zurückgenommen $(1 \mathrm{~mm})$. War eine stabile Whole cell Ableitung etabliert, wurde die lontophorese Elektrode sehr vorsichtig in ihre ursprüngliche Position gebracht. Hatte dies keine negativen Auswirkungen auf die Ableitung, konnte der gewünschte Stoff in unmittelbarer Nachbarschaft der abgeleiteten Zelle (Distanz 50 $\mu \mathrm{m}$ ) iontophoretisch appliziert werden (siehe Abb. 2.3), 


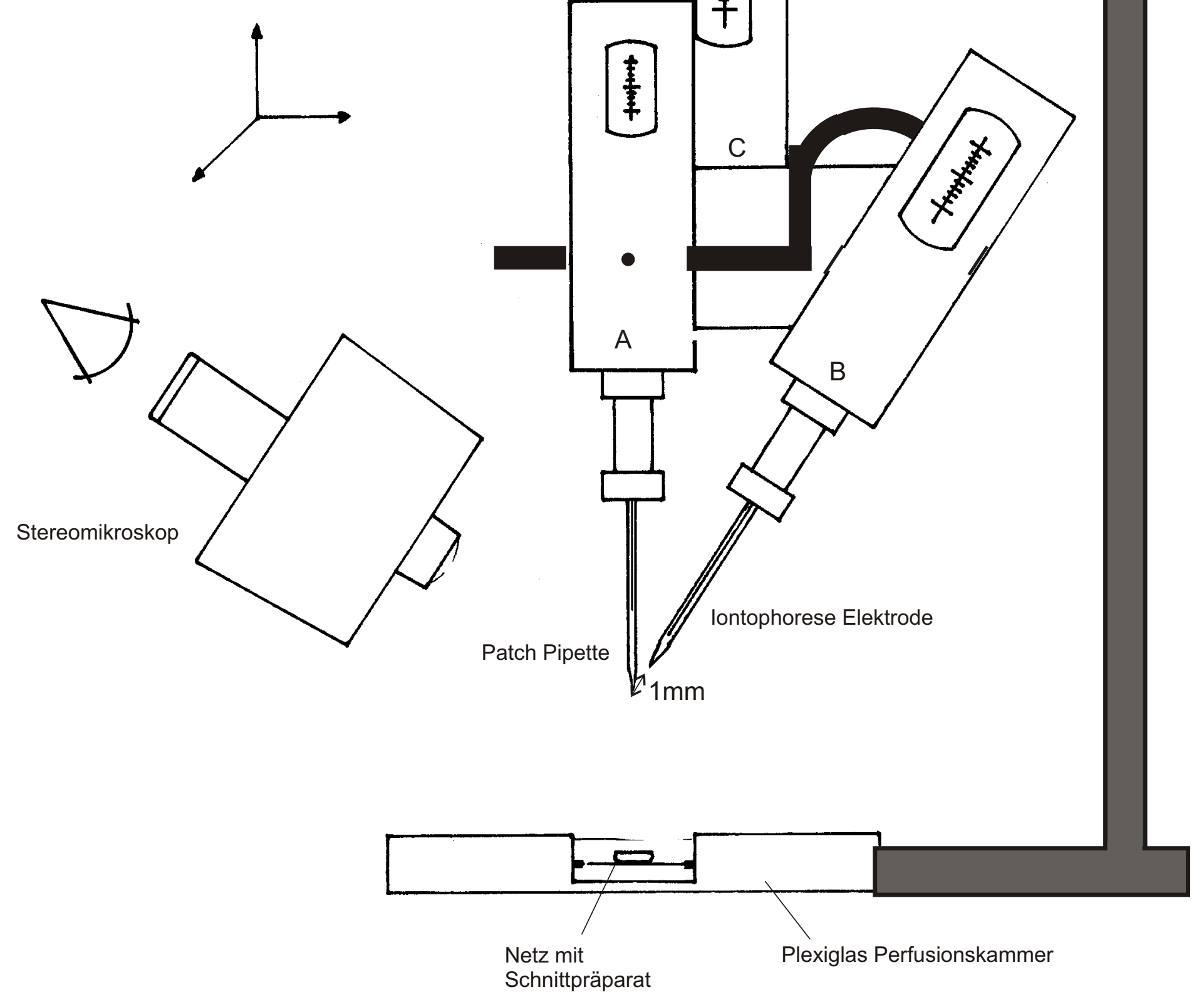

Abb. 2.2: Schematische Darstellung der Positionierung der motorisierten Mikromanipulatoren DC3001 (WPI, Berlin, Deutschland). Das System wurde mit manuellen Mikromanipulatoren so modifiziert, dass die beiden Elektroden vor Beginn des Experiments bis zu einem Abstand von 10-20 $\mu$ m zueinander gebracht werden konnten. Anschließend konnte die lontophorese Elektrode um $1 \mathrm{~mm}$ zurückgenommen werden.
A: Mikromanipulator für die Patch clamp Elektrode;
B: Mikromanipulator für die lontophorese Elektrode;
C: Mikromanipulator an dem die voreingestellten Ptach clamp und lontophorese Elektroden befestigt waren und bewegt wurden. War eine Ganzzell Ableitung etabliert, wurde die lontophorese Elektrode wieder in die ursprüngliche Position gebracht. Modifiziert nach Pestean 1999. 


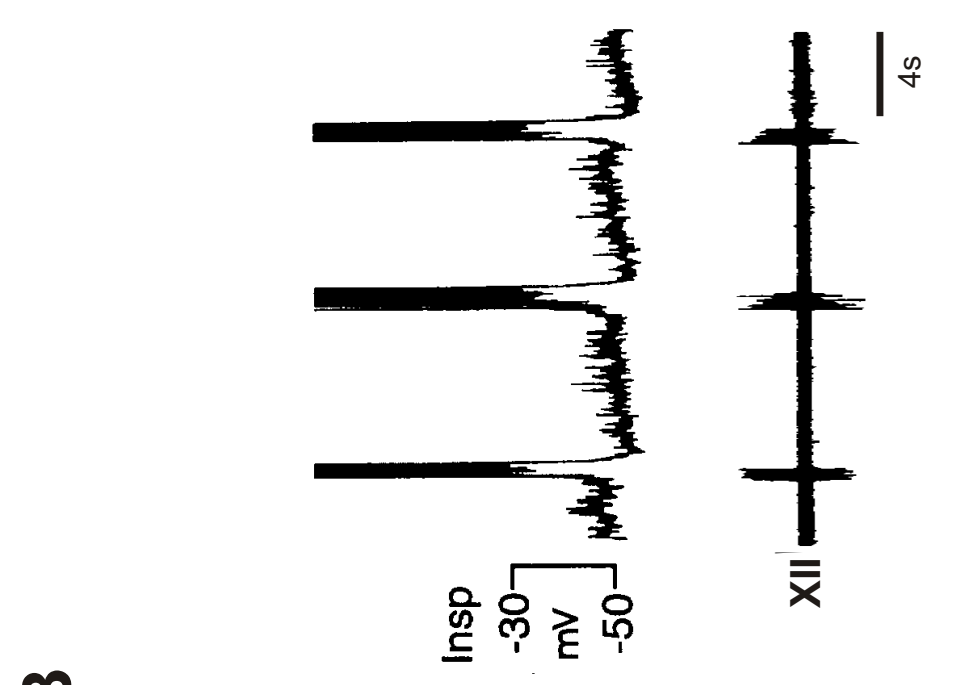

$m$

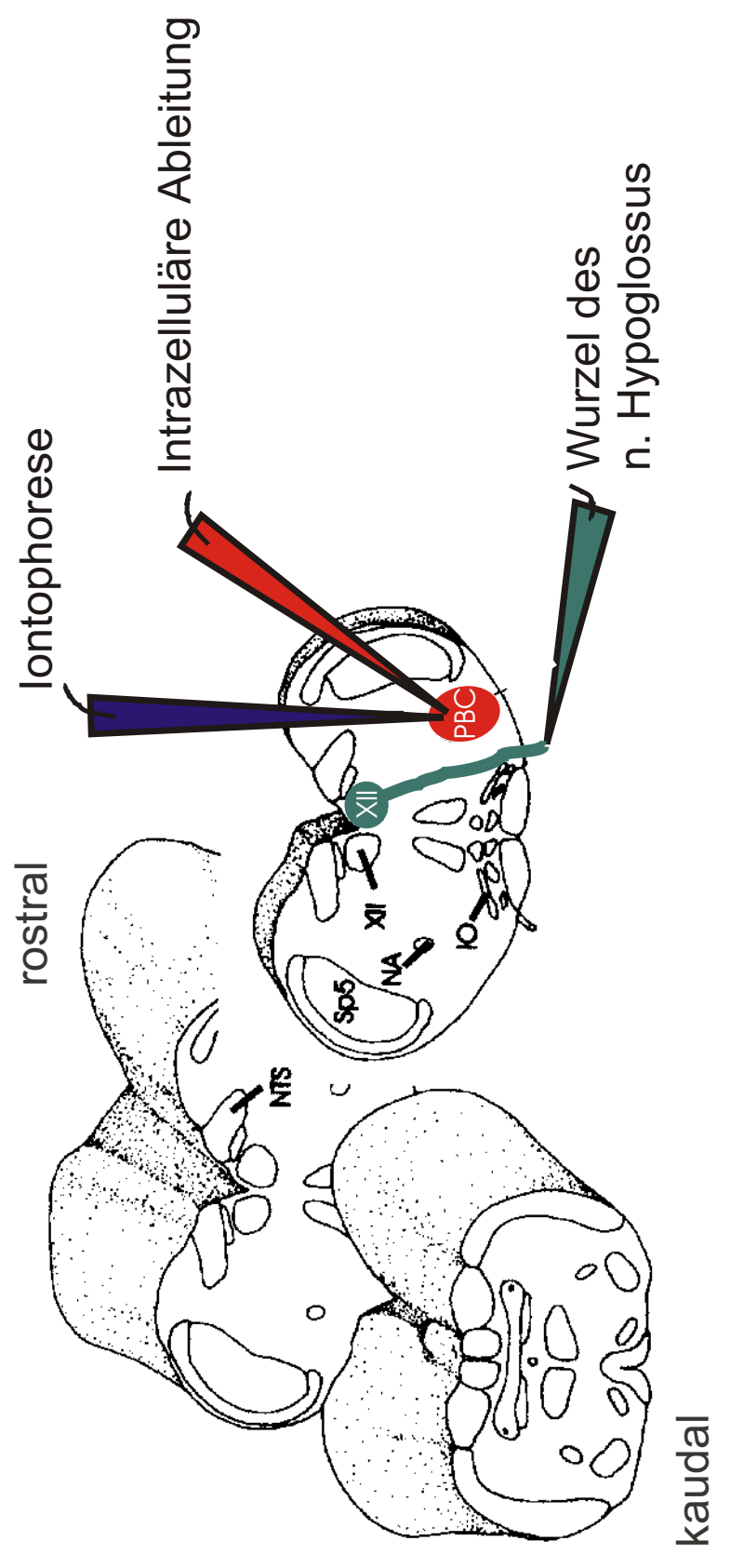

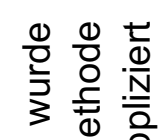

$\frac{\infty}{\pi} \sum^{\infty} \frac{2}{\sigma} \frac{\dot{\bar{c}}}{\sigma}$

范 은

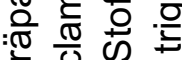

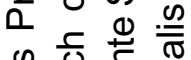

i 월

음 के

西 市边

$\geq 0$ 을

荙药焉

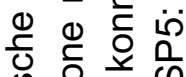

号 气

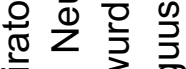

후의

की ट 항

(1) त

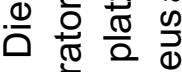

के क्वे

는 인

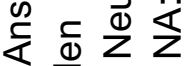

ब) 윽

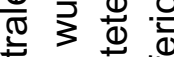

क.

음

त्ञ

市

:

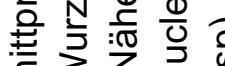

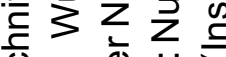

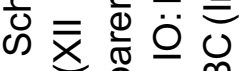

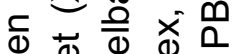

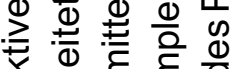

ब

등

을

के

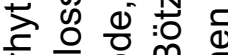

등ㅇㅇㅇ

당

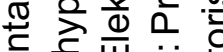

히뭉

के z⿺辶

ब $\&$ \&

은 워응 क

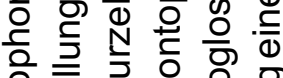

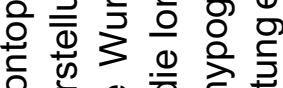

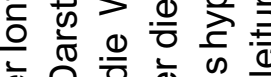

बे

웡

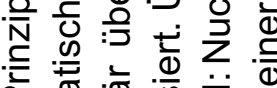

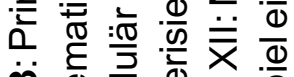

iู ब

N $\frac{1}{0}$ ह

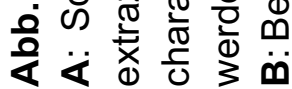




\subsection{Lokale Mikroinjektion}

Verschiedene Stoffe wurden direkt, entweder in den PBC oder in den Nucleus hypoglossus, injiziert, um deren Wirkung zu untersuchen. Die daraus resultierende Reaktion des Systems wurde mit Hilfe der Ableitung des Summenpotentials des N. hypoglossus registriert.

Für die lokale Mikroinjektion verschiedener Stoffe in das Gewebe des rhythmisch aktiven Hirnstammschnittpräparats wurden dünne Borsilikatglaskapillaren mit Filament (Hilgenberg, Malsfeld, Deutschland) verwendet. Diese wurden wie bei der Herstellung der Saugelektroden abgebrochen. Der Spitzendurchmesser betrug $5-10 \mu \mathrm{m} .1-2 \mu \mathrm{l}$ der $10 \mu \mathrm{M}$ Lösungen wurden luftblasenfrei in die Pipette eingefüllt. An der Pipette wurde ein Silikonschlauch befestigt, der am anderen Ende mit einer Spritze verbunden war. Mit Hilfe dieser Spritze wurde Druck auf das gesamte System ausgeübt. Die Kontrolle der injizierten Menge erfolgte optisch mit Hilfe eines Stereomikroskops. So konnte die Bewegung des Meniskus der Flüssigkeitssäule in der Pipette beobachtet und mit Hilfe eines im Okular positionierten Maßstabs gemessen werden. Das injizierte Volumen betrug 20-50nl. Da die zu injizierenden Stoffe in einer Konzentration von $10 \mu \mathrm{M}$ eingesetzt wurden, wurden somit 0,2-0,5pmol der Stoffe appliziert (siehe Abb. 2.4). Um mögliche Artefakte aufgrund der mechanischen Belastung des Gewebes durch die Injektion abschätzen zu können, wurde vor jeder lokalen Mikroinjektion mit einem 5HT Rezeptoragonisten eine Kontrollinjektion mit ACSF in die jeweilige Region des rhythmisch aktiven Hirnstammschnittpräparats vorgenommen. 


\section{Stereomikroskop}

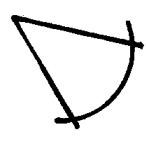
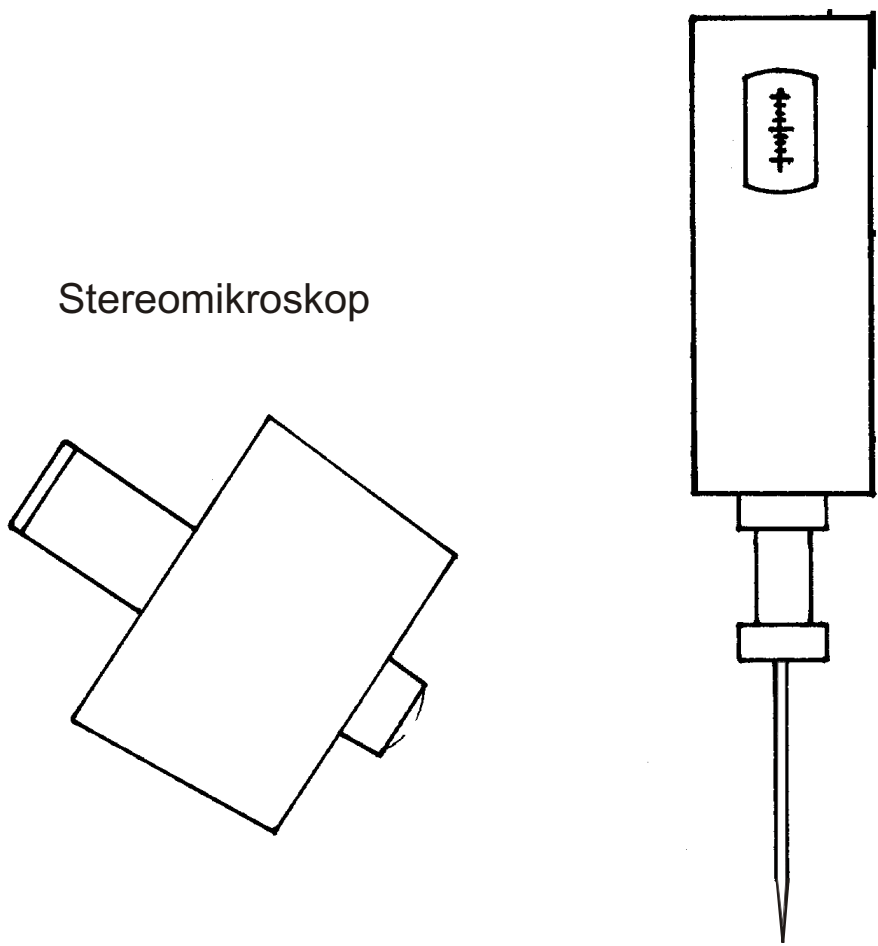

Mikromanipulator DC 3001

Mikroinjektionselektrode

B

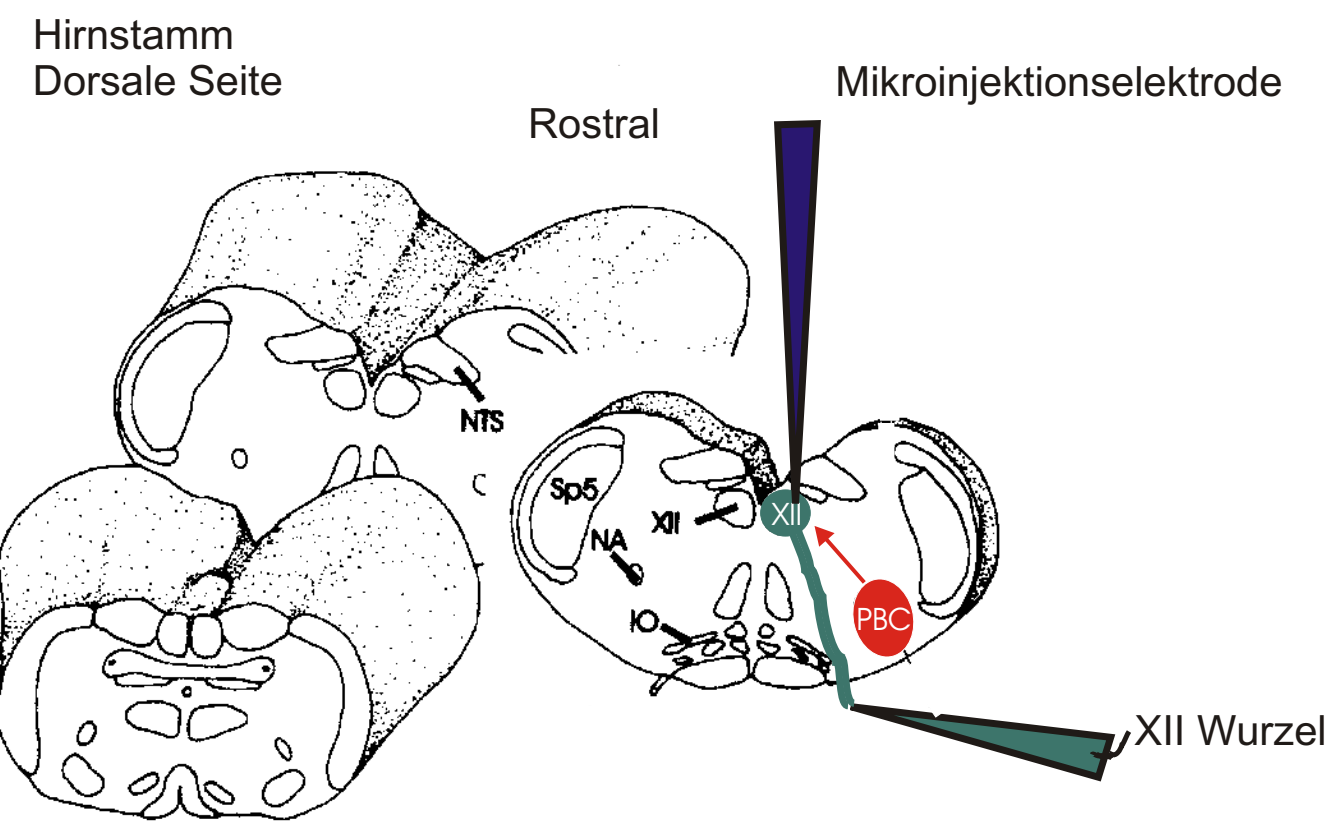

Kaudal

Abb. 2.4: Schematische Darstellung der Druckinjektion

A: Die abgebrochenen und mit den Lösungen befüllte Kapillare wurde an einem motorisiertem Mikromanipulator DC3001 befestigt und vorsichtig in das Gewebe eingeführt. Die Bewegung des Meniskus der Flüssigkeitssäule in der Kapillare wurde mit Hilfe eines Stereomikroskops kontrolliert. Nicht abgebildet sind der Silikonschlauch und die daran befestigte Spritze um Druck auf das gesamte System auszuüben.

B: Darstellung des spontan rhythmisch aktiven Schnittpräparats (rostrale Ansicht). Die respratorische Aktivität des Präparats wurde extrazellulär über die Wurzel des N.hypoglossus abgeleitet (XII-Wurzel). Injiziert wurde entweder in den Nucleus hypoglossus (XII) oder in der Prä-Bötzinger Komplex (PBC). IO: Nucleus olivaris inferior, NA: Nucleus ambiguus, SP5: Tractus spinalis trigemini, NTS: Nucleus tractus solitarius 


\subsection{Badapplikation}

Zur Untersuchung der Wirkung bestimmter Stoffe auf das im Schnittpräparat enthaltene neuronale Netzwerk, wurden diese über die Perfusionslösung appliziert. Dazu wurden die gelösten Stoffe in einer Endkonzentration von

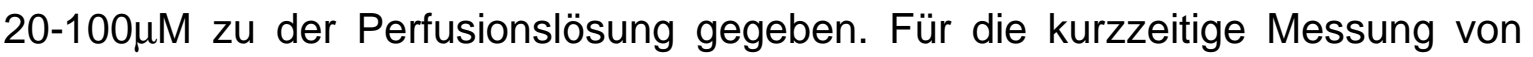
Effekten - beispielsweise von Rezeptoragonisten - wurde genau ein Messkammervolumen $(7,5 \mathrm{ml})$ mit dem gelösten Stoff appliziert. Bei einer Flussgeschwindigkeit von 2,7ml/min entsprach das einer Applikationsdauer von 2,5-3,0 Minuten. Wurde dagegen der Effekt von Antagonisten auf das Präparat untersucht, so wurden diese über einen längeren Zeitraum (> 20min) in der gewünschten Konzentration der Perfusionslösung zugesetzt. Die Applikation von über 20min entsprach einem Volumen von über 100ml. 


\subsection{Chemikalien und Lösungen}

Tab. 2.1 Verwendete Serotonergika mit den Funktionen und den je nach Anwendung verwendeten Konzentrationen

\begin{tabular}{|c|c|c|c|c|}
\hline \multirow[b]{2}{*}{ Funktion } & \multirow[b]{2}{*}{$\begin{array}{c}\text { Verwendeter } \\
\text { Agonist/Antagonist }\end{array}$} & \multicolumn{3}{|c|}{ Eingesetzte Konzentration } \\
\hline & & Badapplikation & lontophorese & Mikroinjektion \\
\hline 1A Agonist & 8-OH DPAT & - & $10 \mathrm{mM}$ & - \\
\hline 1A Antagonist & WAY 100635 & $50 \mu \mathrm{M}$ & - & - \\
\hline 2A Agonist & $\alpha$-Methyl- $5 \mathrm{HT}$ & $50 \mu \mathrm{M}$ & $10 \mathrm{mM}$ & $10 \mu \mathrm{M}$ \\
\hline 2A Antagonist & Ketanserin & $30-70 \mathrm{mM}$ & - & - \\
\hline 2B Agonist & BW 723C86 & $30-50 \mu \mathrm{M}$ & - & $10 \mu \mathrm{M}$ \\
\hline 2B Antagonist & LY 272015 & $25-100 \mu \mathrm{M}$ & - & - \\
\hline
\end{tabular}

Der 5HT 2B Rezeptor Antagonist LY 272015 wurde von Eli Lilly GmbH (Bad Homburg, Deutschland), TTX wurde von Alomone Labs (Israel) bezogen. Alle weiteren Serotonin Rezeptor Agonisten und Antagonisten wurden, wie alle anderen verwendeten Chemikalien, von Sigma oder RBI/Sigma (Deisenhofen, Deutschland) bezogen.

Die bei der lontophorese verwendeten Lösungen hatten eine Konzentration von

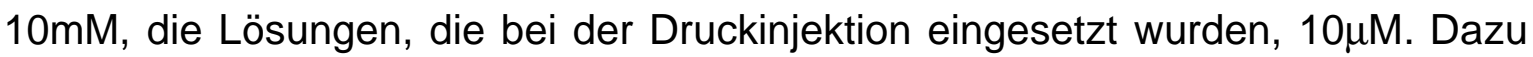
wurden die entsprechenden Chemikalien in ACSF gelöst. 
Die ACSF, die für die normale Perfusion verwendet wurde, hatte folgende Zusammensetzung (in $\mathrm{mM}$ ):

$\begin{array}{lr}\mathrm{NaCl} & 118,0 \mathrm{mM} \\ \mathrm{KCl} & 3,0 \mathrm{mM} \\ \mathrm{CaCl}_{2} & 1,5 \mathrm{mM} \\ \mathrm{MgCl}_{2} & 1,0 \mathrm{mM} \\ \mathrm{NaHCO}_{3} & 2,0 \mathrm{mM} \\ \mathrm{NaH}_{2} \mathrm{PO}_{4} & 1,2 \mathrm{mM} \\ \text { D-Glucose } & 35,0 \mathrm{mM}\end{array}$

Der erforderliche $\mathrm{pH}$-Wert von $\mathrm{pH} 7,4$ wurde durch das kontinuierliche Begasen mit $95 \% \mathrm{CO}_{2}$ mit $5 \% \mathrm{O}_{2}$ eingestellt.

Pipettenlösung für die Elektrophysiologie:

Pipettenlösung mit niedriger $\mathrm{Cl}^{-}$Konzentration:

$\begin{array}{lr}\text { K-Gluconat } & 140,0 \mathrm{mM} \\ \mathrm{CaCl}_{2} & 1,0 \mathrm{mM} \\ \mathrm{NaCl} & 1,0 \mathrm{mM} \\ \text { HEPES } & 10,0 \mathrm{mM} \\ \mathrm{K}_{4} \mathrm{BAPTA} & 11,0 \mathrm{mM} \\ \mathrm{MgCl}_{2} & 1,0 \mathrm{mM} \\ \mathrm{Na}_{2} \text {-ATP } & 1,0 \mathrm{mM}\end{array}$


Der erforderliche $\mathrm{pH}$-Wert von $\mathrm{pH} 7,4$ wurde mit $1 \mathrm{M} \mathrm{KOH}$-Lösung eingestellt; anschließend wurde die Osmolarität kontrolliert. Die erforderliche Osmolarität lag bei 250 mosmol.

TTX wurde in einer Endkonzentration von $0,4 \mu \mathrm{M}$ in ACSF gelöst eingesetzt. Um eine Zelle isoliert zu untersuchen, wurde eine Kombination von verschiedenen Inhibitoren der synaptischen Übertragung in Kombination mit TTX in folgenden Konzentrationen eingesetzt:

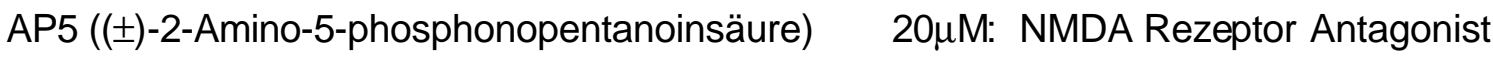

CNQX (5-Cyano-7-nitroquinoxalin-2,3-dion)

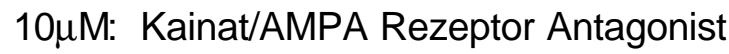

Strychnin

$5 \mu \mathrm{M}:$ Glycin Rezeptor Antagonist

(-)-Bicucullin methbromid

10 $\mu \mathrm{M}: \mathrm{GABA}_{\mathrm{A}}$ Rezeptor Antagonist 


\section{Ergebnisse}

Im Rahmen dieser Arbeit sollten serotonerge Effekte auf respiratorische Interneurone des PBC sowie auf respiratorische Motoneurone des Nucleus hypoglossus (XII Motoneurone), die über bestimmte 5HT Rezeptorsubtypen vermittelt werden, untersucht werden. Der Schwerpunkt lag dabei auf den von der Familie der 5HT 2 Rezeptoren vermittelten Effekten. Mit Hilfe von spezifischen 5HT 2 Rezeptor Agonisten und Antagonisten konnten die jeweiligen Reaktionen, wie beispielsweise Veränderungen im Membranpotential oder in der Aktivität respiratorischer Interneurone und Motoneurone, registriert werden. Dazu wurden drei unterschiedliche Applikationsformen der Agonisten und Antagonisten eingesetzt.

1. Bei der intrazellulären Ableitung respiratorischer Neurone im PBC wurden die Agonisten über die Iontophorese direkt an der Zelle appliziert. Unter Badapplikation des entsprechenden Antagonisten wurde die Wirkung der Agonisten getestet. Über die gleichzeitige Blockade der synaptischen Aktivität konnte das Vorhandensein von aktivierbaren postsynaptisch lokalisierten 5HT Rezeptoren nachgewiesen werden.

2. Durch die lokale Mikroinjektion von 5HT Agonisten und Antagonisten, entweder in den PBC oder den Nucleus hypoglossus, wurde die Wirkung auf Populationen von Neuronen lokal untersucht. Bei Mikroinjektionen in den PBC wurde die Wirkung auf respiratorische Interneurone, bei Mikroinjektionen in den Nucleus Hypoglossus dagegen die Wirkung auf respiratorische Motoneurone untersucht. 
3. Um die Reaktion des gesamten, im rhythmisch aktiven Schnittpräparat enthaltenen, neuronalen Netzwerks auf die entsprechenden 5HT Rezeptor Agonisten und Antagonisten zu untersuchen, wurden diese kontrolliert systemisch über die Perfusionslösung appliziert.

\subsection{Intrazelluläre Ableitungen respiratorischer Interneurone}

Bei intrazellulären Ableitungen respiratorischer Neurone, die innerhalb des PBC lokalisiert waren, konnte durch die direkte lontophorese von 5HT Rezeptor Agonisten festgestellt werden, welche Auswirkung der jeweils eingesetzte Rezeptor Agonist auf die Eigenschaften der Zellen hatte. Durch die Whole cell Methode im Current clamp Modus konnten Veränderungen im Membranpotential und des Widerstands über die gesamte Zelle ermittelt werden.

\subsubsection{Iontophorese des 5HT 1A Rezeptor Agonisten 8 OH DPAT}

Durch die lontophorese des 5HT 1A Rezeptor Agonisten 8 OH DPAT auf respiratorische Neurone sollte die Funktion des 5HT 1A Rezeptors genauer untersucht werden.

Die iontophoretische Applikation von 8 OH DPAT resultierte in einer Erhöhung des Eingangswiderstands um 22,8 $\pm 3,6 \%(n=6)$. Das Membranpotential der Zellen stieg um 5,0 $\pm 2,5 \mathrm{mV}(\mathrm{n}=6)$. Bei der Gabe einer Mischung aus verschiedenen Hemmern der synaptischen Übertragung mit TTX $(0,4 \mu M)$, AP5 $(20 \mu M)$, Strychnin $(5 \mu \mathrm{M})$ und Bicucullin $(10 \mu \mathrm{M})$ konnten diese Effekte der iontophoretischen 
Applikation von 8 OH DPAT ebenfalls beobachtet werden $(n=3)$. Da durch die Applikation der Inhibitoren die synaptische Interaktion blockiert war, lassen diese Ergebnisse den Schluss zu, dass die Reaktionen auf die Applikation der Agonisten durch postsynaptisch lokalisierte 5HT Rezeptoren vermittelt wurden (siehe Abb. 3.1).

\subsubsection{Iontophorese des 5HT 2 Rezeptor Agonisten $\alpha$-Methyl 5HT}

Bei iontophoretischer Applikation von $\alpha$-Methyl 5HT auf respiratorische Interneurone des PBC konnte stets eine Depolarisation des Membranpotentials um 4,8 $\pm 3,0 \mathrm{mV}$, verbunden mit einer Reduktion des Membranwiderstands um $29,3 \pm 12,0 \%$ beobachtet werden $(n=18)$ (siehe Abb. 3.2). Bei Blockade der synaptischen Aktivität konnte bei Wiederholung der iontophoretischen Applikation von $\alpha$-Methyl $5 \mathrm{HT}$ eine Depolarisation des Membranpotentials und Reduktion des Eingangswiderstandes festgestellt werden $(n=5)$. Wurde zusätzlich noch der 5HT 2A Rezeptor Antagonist Ketanserin $(50 \mu \mathrm{M}, 20 \mathrm{~min})$ systemisch appliziert, wurde der Effekt des $\alpha$-Methyl 5HT komplett blockiert $(n=3)$.

Die intrazellulären Untersuchungen zeigen funktionelle postsynaptisch lokalisierte 5HT Rezeptoren des Typs 5HT 1A und 5HT 2 an respiratorischen Interneuronen auf. 5HT $1 \mathrm{~A}$ und $5 \mathrm{HT} 2$ Rezeptoren vermitteln synergistisch eine Depolarisation und Stimulation der respiratorischen Neurone. Allerdings ist die depolarisierende Wirkung über 5HT2 Rezeptoren wesentlich ausgeprägter. Ähnliches gilt für XII Motoneurone, an denen eine tonisch exzitiative Wirkung von 5HT über 5HT 2 Rezeptoren beschrieben wurde (Berger et al., 1992; Lalley et al., 1995; Pestean, 1999). 


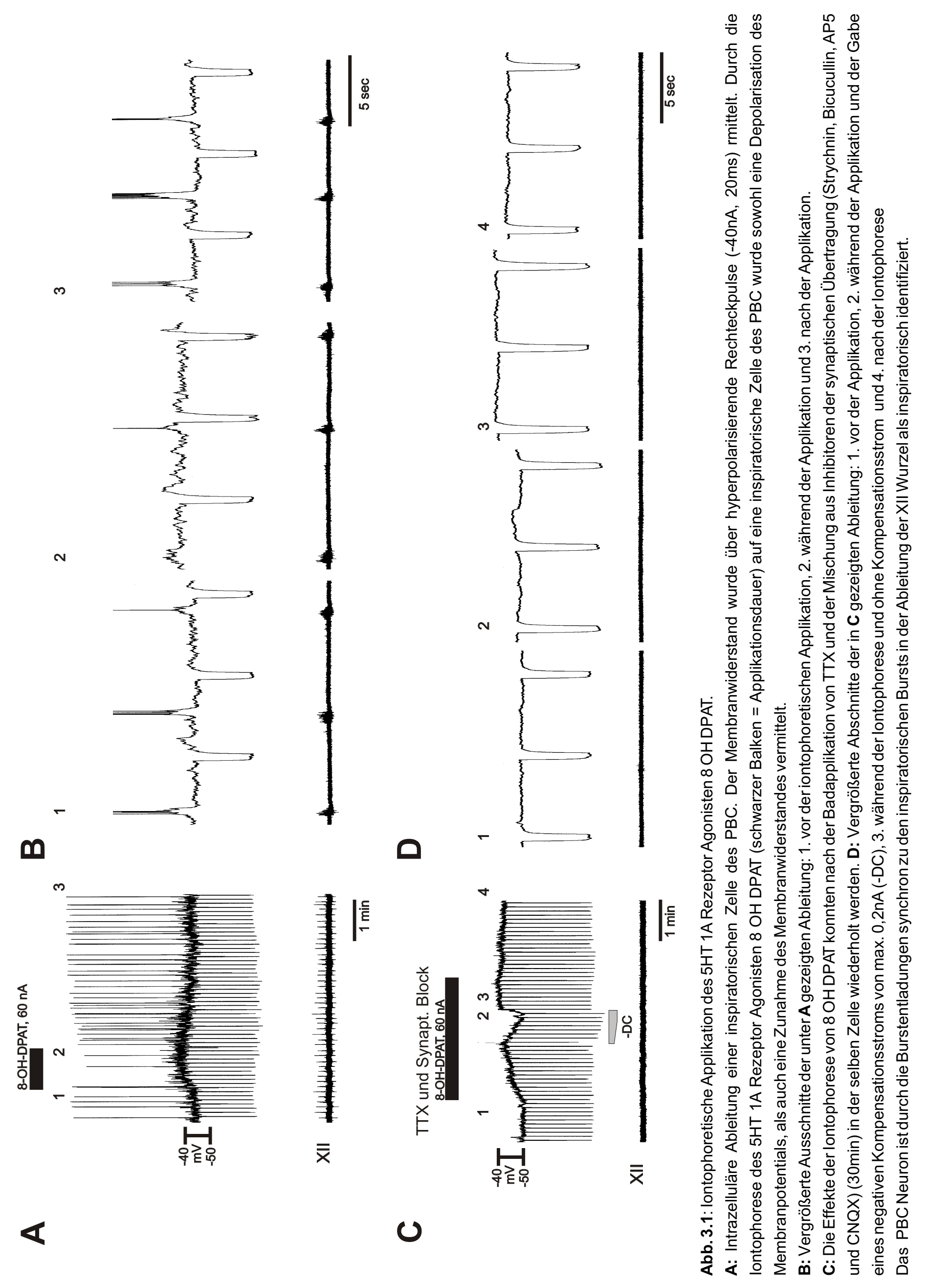




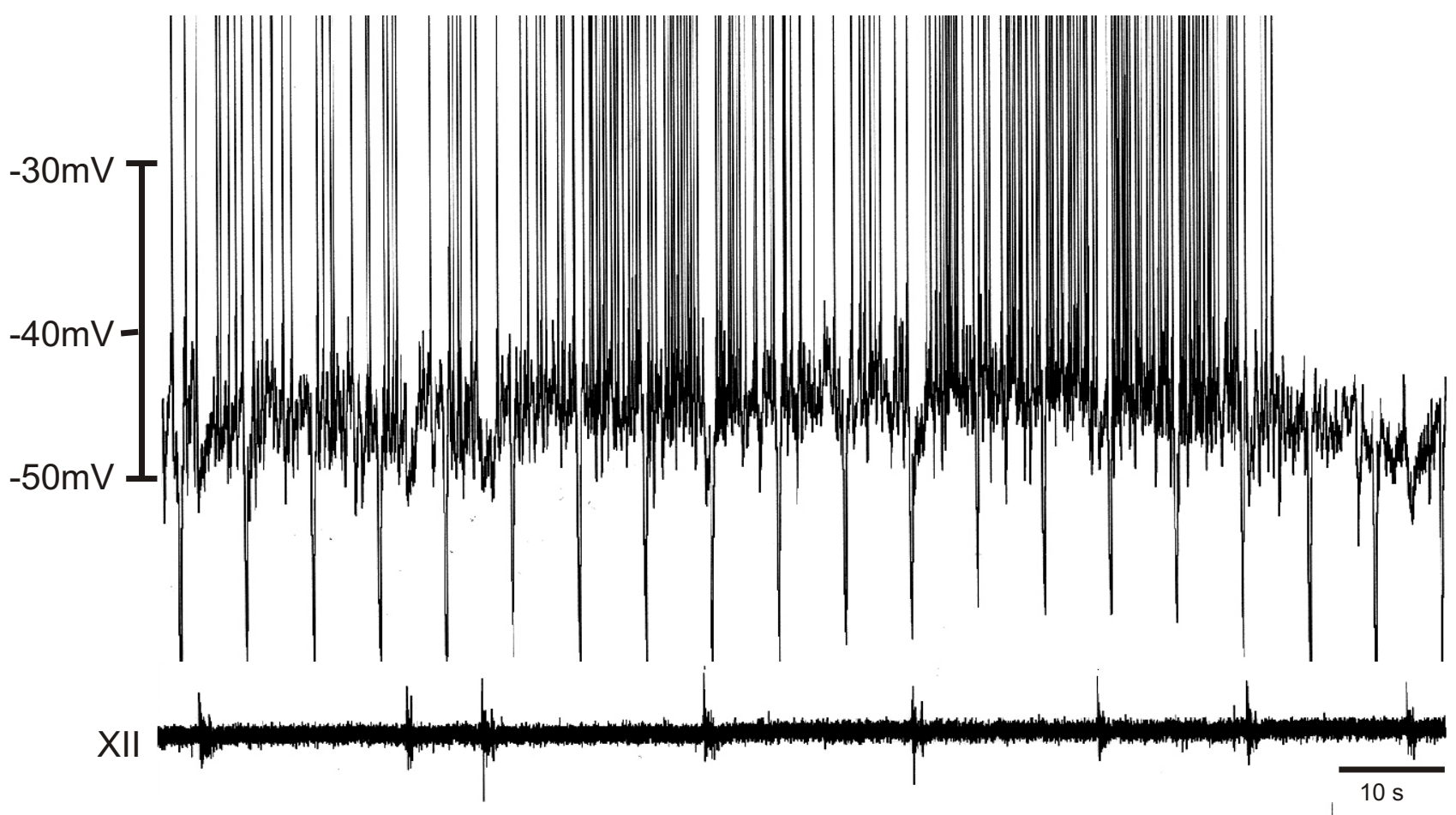

B

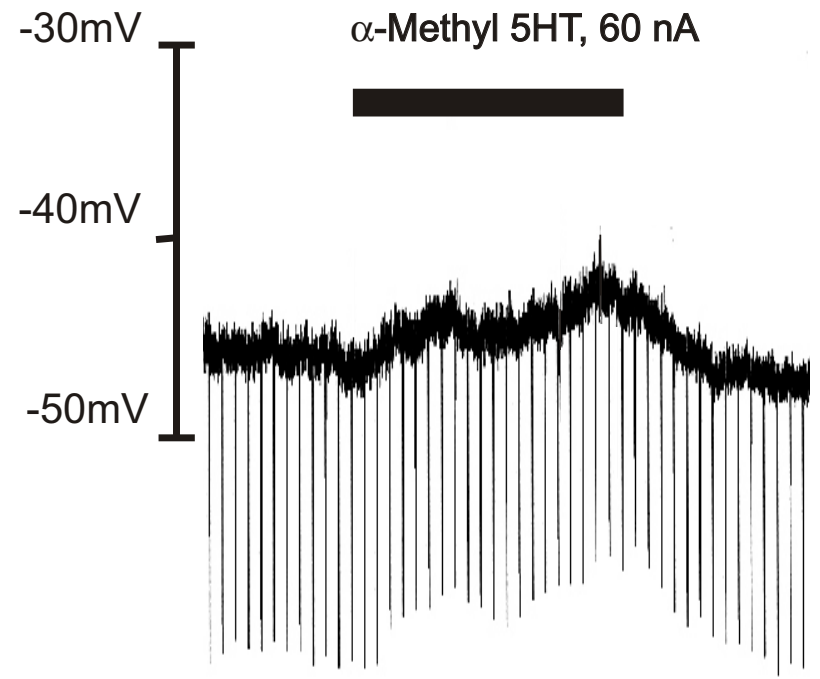

\section{XII}

$20 \mathrm{~s}$

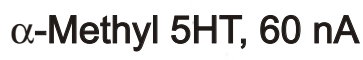

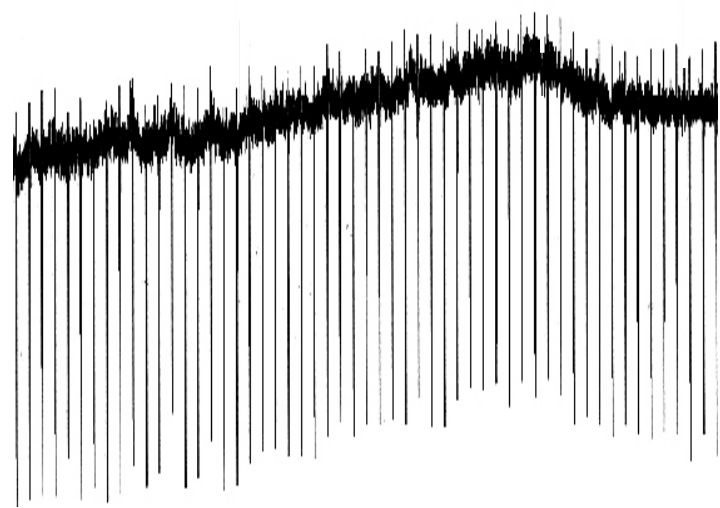

$\overline{20 s}$

Abb. 3.2: Iontophoretische Applikation des 5HT 2 Rezeptor Agonisten $\alpha-M e t h y l ~ 5 H T$.

A: Die lontophorese des 5HT 2 Rezeptor Agonisten $\alpha$-Methyl 5HT auf eine intrazellulär abgeleitete expiratorische Zelle des PBC. Der schwarze Balken zeigt den Applikationszeitraum an. Die direkte Applikation des Agonisten hatte eine Depolarisation und Zunahme der Entladungsaktivität sowie eine Reduktion des Membranwiderstands zur Folge. B: Die Effekte der Applikation von $\alpha$-Methyl 5HT auf die Zelle konnten in Gegenwart von TTX und der Mischung aus Inhibitoren der synaptischen Übertragung (Strychnin, Bicucullin, AP5 und CNQX)(30min) wiederholt werden. C: Iontophorese von $\alpha$-Methyl 5HT unter zusätzlicher Badapplikation des 5HT 2A Rezeptor Antagonisten Ketanserin $(50 \mu \mathrm{M},>20 \mathrm{~min})$. Durch die systemische Applikation von Ketanserin konnte der Effekt des $\alpha$-Methyl $5 \mathrm{HT}$ blockiert werden. Die Depolarisation der Membran ist als Artefakt der lontophorese zu werten, da unmittelbar mit dem Ende der lontophorese die Zellemembran wieder repolarisiert.

Der Membranwiderstand wurde über hyperpolarisierende Rechteckpulse (-40nA, 20ms) ermittelt. 
Deshalb wurde im Folgenden die 5HT 2 Rezeptoren näher untersucht. Dabei wurde der Frage nachgegangen, welche der 5HT 2 Rezeptorsubtypen an der stimulierenden Wirkung von 5HT auf respiratorische Interneurone und Motoneurone beteiligt sind.

\subsection{Mikroinjektionen in den Prä-Bötzinger Komplex und in den Nucleus hypoglossus}

In rhythmischen Schnittpräparaten erzeugte eine Mikroinjektion von 5HT, bzw. verschiedener 5HT Rezeptor Agonisten, in den Nucleus hypoglossus eine konstante und Rhythmus unabhängige Entladungsaktivität in den abgeleiteten Wurzeln des ipsilateralen $\mathrm{N}$. hypoglossus, nicht aber in den Wurzeln des kontralateralen N. hypoglossus. Dies entspricht einer Depolarisation und einer tonischen Exzitation der XII Motoneurone, wie sie bei Einzelzellableitungen von XII Motoneuronen durch die Gabe von 5HT 2 Rezeptor Agonisten ausgelöst wird (Pestean, 1999). Wie die Einzelzellableitungen zeigten, wird diese tonische Exzitation durch postsynaptische 5HT 2 Rezeptoren vermittelt (Berger et al., 1992; Pestean, 1999). Dagegen wurde keine Frequenzveränderung der rhythmischen Burstentladungen festgestellt.

Bei Mikroinjektion von 5HT oder 5HT 2 Rezeptor Agonisten in den PBC dagegen wurde die respiratorische Frequenz erhöht, eine tonisch exzitatorische Aktivität der XII Motoneurone wurde nicht ausgelöst $(n=9)$ (siehe Abb. 3.3). 

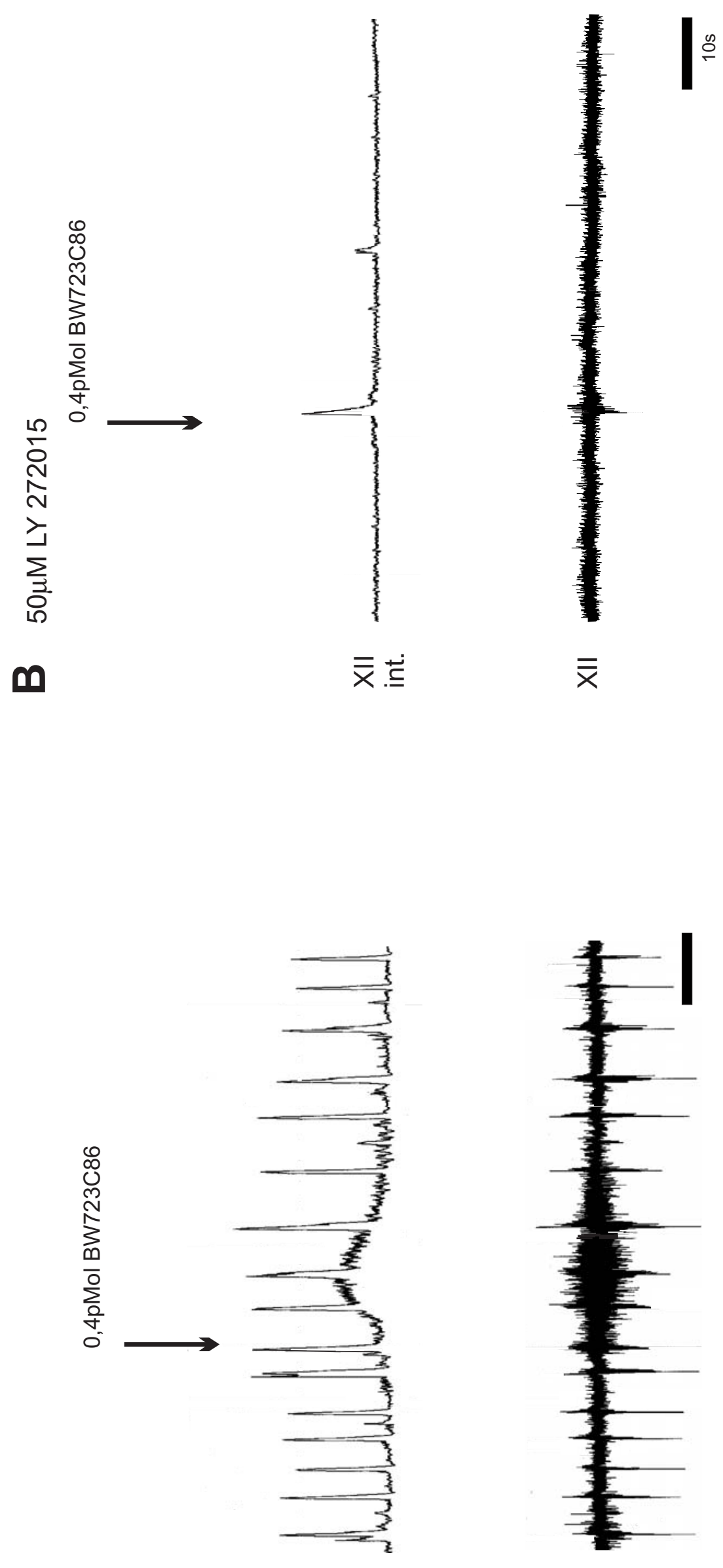

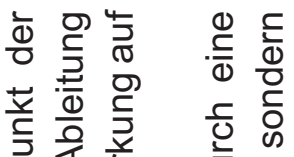

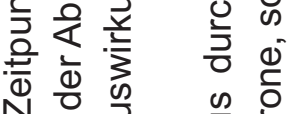
N

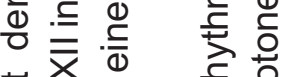

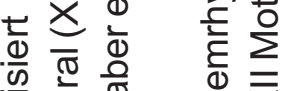
品焉 㐫

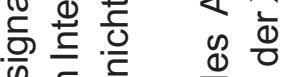
क ह

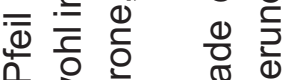

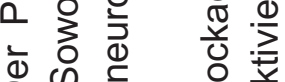
๑ क क्ष 离 渮

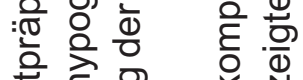
की

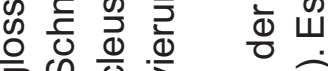

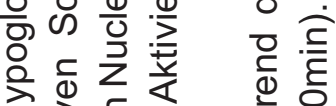

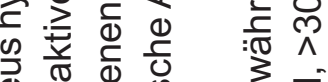
कृ 之. ब है बำ

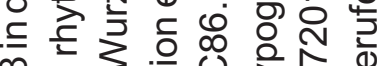

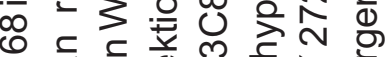

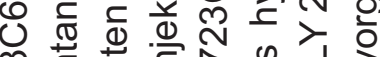

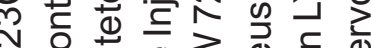

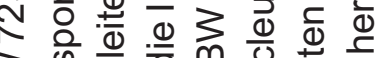

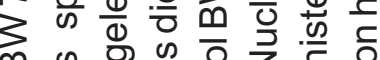
๓

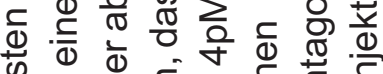

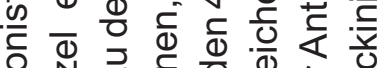

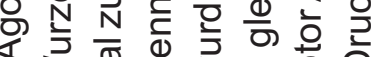

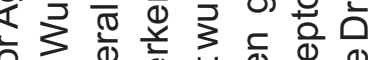

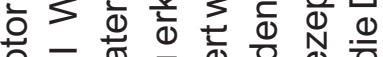

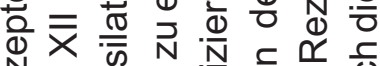

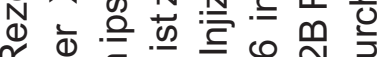
$\propto$ Ф 品 产 $\overline{\bar{x}}$ 믕ำ T

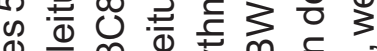

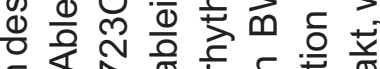

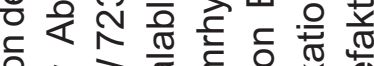

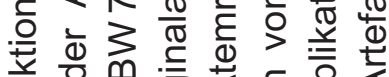

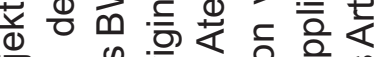
일 \&

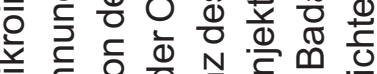

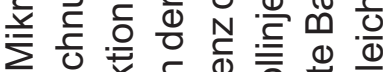

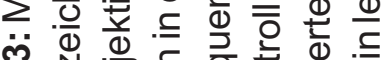
m.

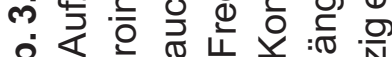

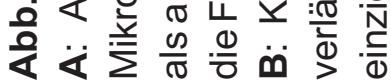


Einzelzellableitungen an respiratorischen Neuronen des PBC (siehe 3.1.1 und 3.1.2) zeigten, dass die Frequenzveränderung der respiratorischen Bursts durch eine über postsynaptische $5 \mathrm{HT} 2$ Rezeptoren vermittelte Depolarisation erklärt werden kann (siehe Abb. 3.1 und 3.2).

Damit erwiesen sich die durchgeführten lokalen Mikroinjektionen als geeignet, um lokale Wirkungen zu erzielen. Eine Diffusion über größere Distanzen innerhalb des rhythmisch aktiven Schnittpräparats konnte ausgeschlossen werden.

\subsubsection{Mikroinjektionen in den Prä-Bötzinger Komplex}

\section{HT 2A Rezeptor vermittelte Effekte}

Die Mikroinjektion des 5HT 2 Rezeptor Agonisten $\alpha$-Methyl 5HT in den PBC resultierte in einer reversiblen Erhöhung der Frequenz der respiratorischen Aktivität um 364,2 $\pm 124,3 \%(n=3)$ (siehe Abb. 3.4). Dieser Effekt konnte durch die systemische Badapplikation des spezifischen 5HT 2A Rezeptor Antagonisten Ketanserin $(50 \mu \mathrm{M}, 20 \mathrm{~min})(\mathrm{n}=3)$ blockiert werden. Da der 5HT 2 Rezeptor Agonist $\alpha$-Me 5HT eine gewisse Spezifität für den 5HT 2A Rezeptor hat und dieser Effekt mit dem spezifischen 5HT 2A Rezeptor Antagonisten Ketanserin blockiert werden konnte, kann eine gewisse Dominanz der 5HT 2A Rezeptoren gegenüber den anderen Subtypen der 5HT 2 Rezeptor Familie, 5HT 2B und 5HT 2C Rezeptoren, auf respiratorischen Neuronen festgestellt werden. 


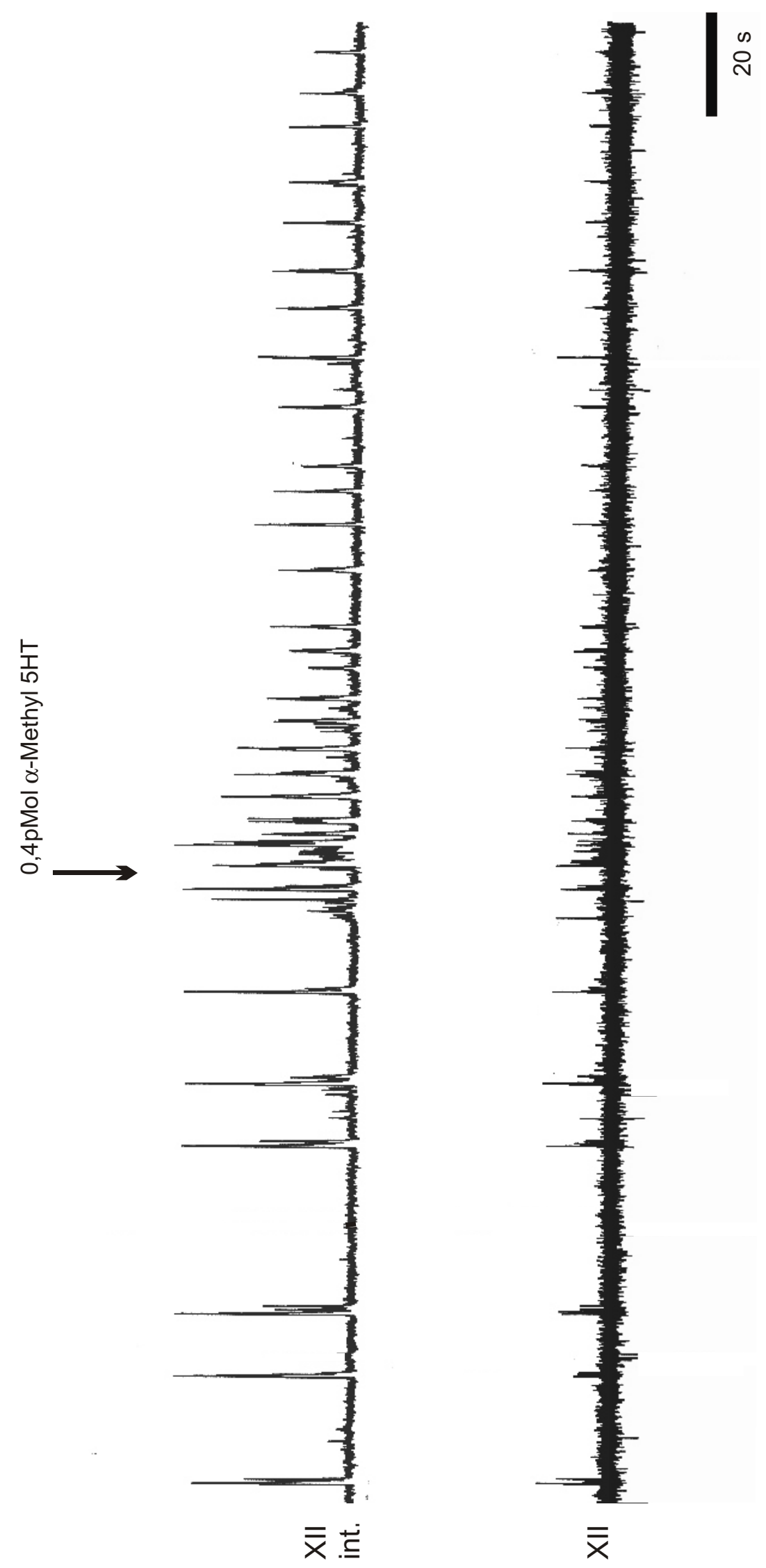

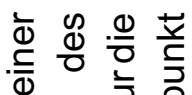

정

N

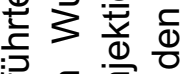

क

त 0 ब

ब

뜽

表

论

फ

बे

紊竞这

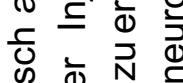

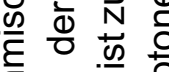

突六总主

$\overline{\bar{\sigma}} \overline{\bar{x}}$

孪 㐫

흥 $\frac{\pi}{\bar{\omega}}$

o $\cong$ 능

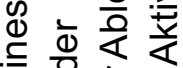

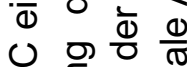

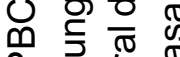

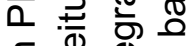

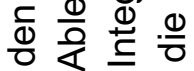

$\subseteq$ ह

누응

잉

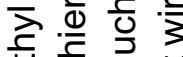

क त

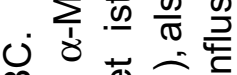

品

․ㅡㄹ

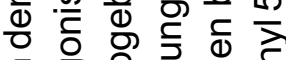

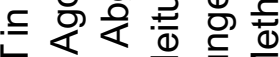

壬就运

फ

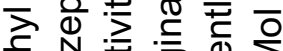

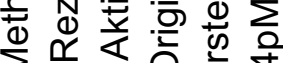

$\sum_{i} \underset{N}{*}$

눙

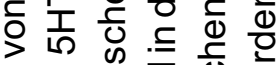

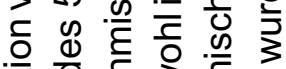

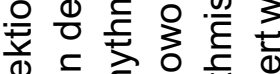

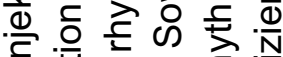

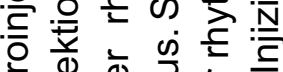

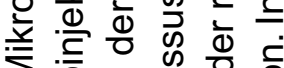

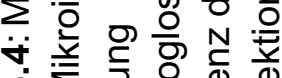
mi ${ }^{2}$ 을

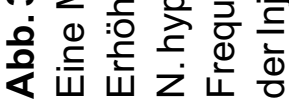




\section{HT 2B Rezeptor vermittelte Effekte}

Die Mikroinjektion des 5HT 2B Rezeptor Agonisten BW 723C86 in den PBC induzierte ebenfalls eine reversible Frequenzerhöhung der respiratorischen Aktivität um $395,1 \% \pm 131,9(n=4)$.

Dieser Effekt konnte durch die Badapplikation des spezifischen 5HT 2B Rezeptor Antagonisten LY $272015(30 \mu \mathrm{M}, 20 \mathrm{~min})$ komplett blockiert werden $(\mathrm{n}=4)$. Nach dem Auswaschen des 5HT 2B Rezeptor Antagonisten LY 272015 für 40 Minuten und einer Wiederholung der Injektion, konnte erneut eine reversible Frequenzerhöhung der respiratorischen Aktivität festgestellt werden. Somit war der Effekt des 5HT 2B Rezeptor Antagonisten LY 272015 voll reversibel (siehe Abb. 3.5).

Damit zeigt sich, dass neben 5HT 2A auch 5HT 2B Rezeptoren auf respiratorischen Neuronen des PBC vorhanden sind. 
A

0,4pMol BW 723C86

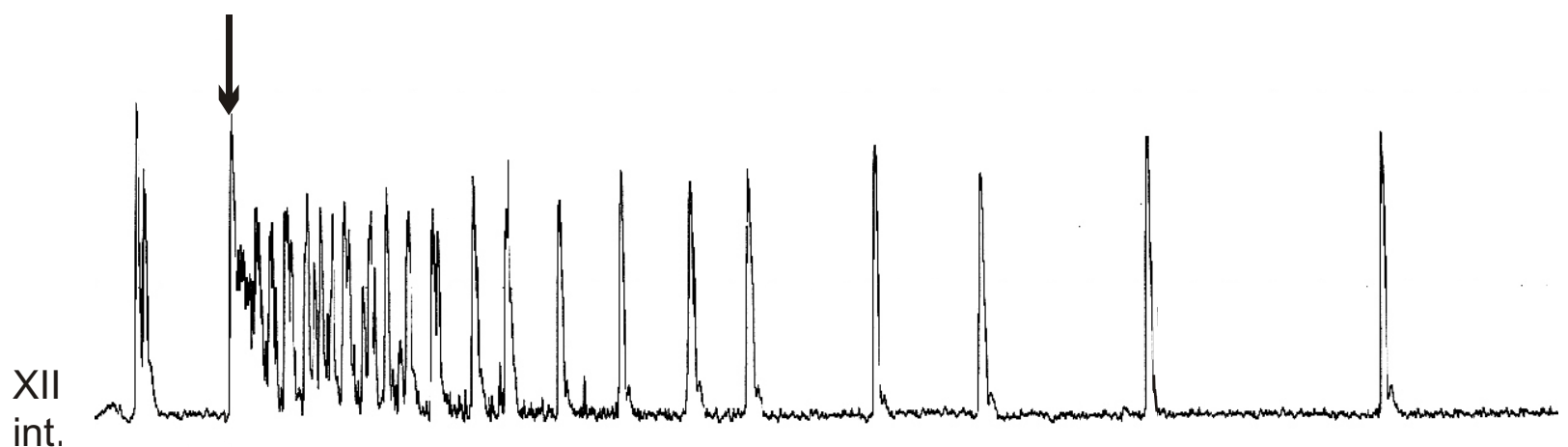

int.

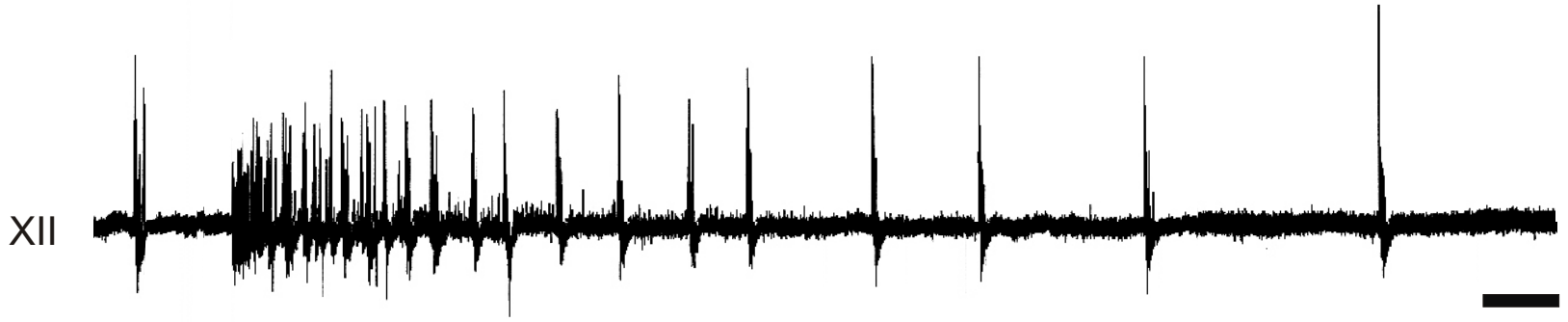

B

LY 272015, 30uM

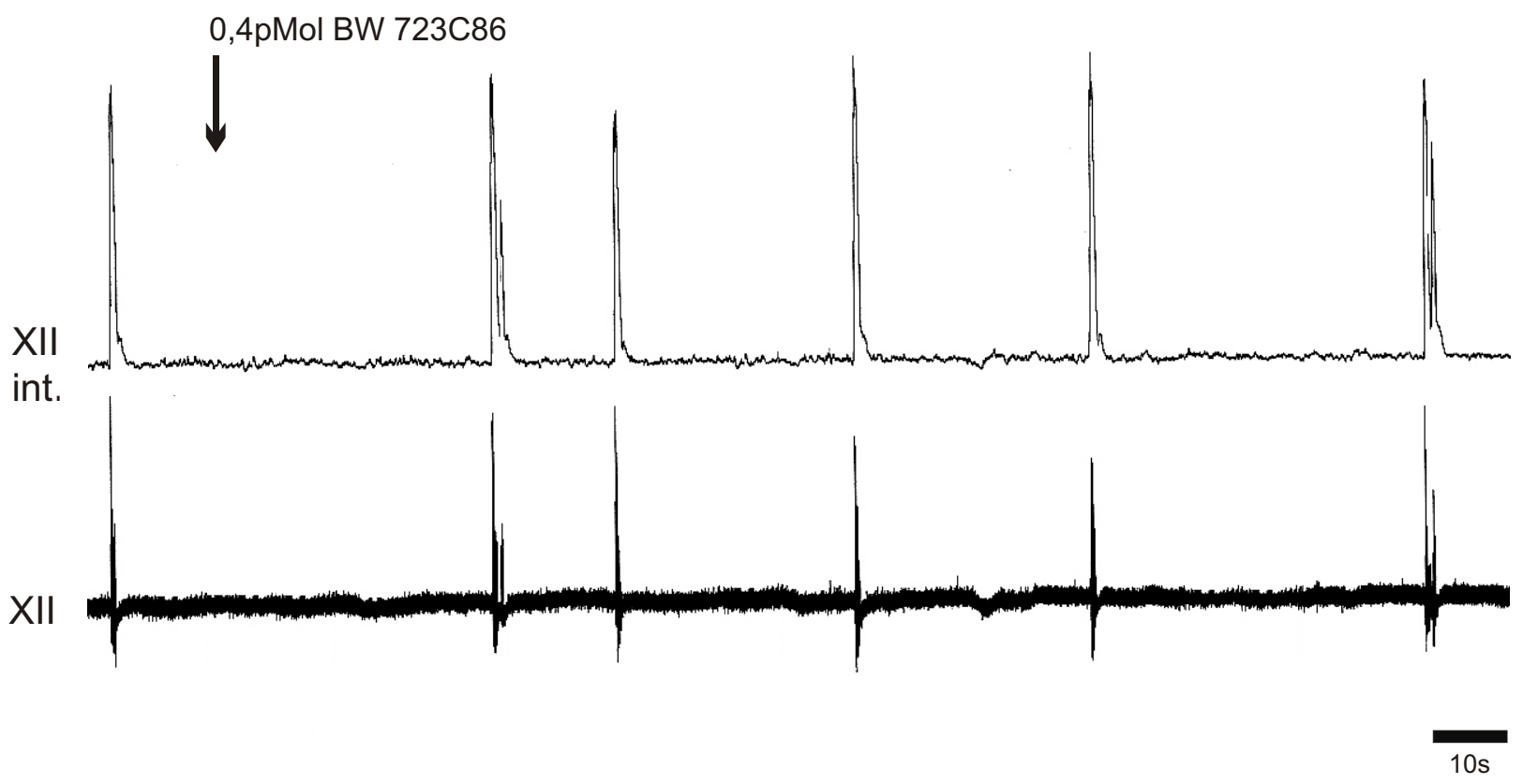

Abb. 3.5:Lokale Mikroinjektion des 5HT 2B Rezeptor Agonisten BW 723C86 in den PBC.

A:Die Mikroinjektion des 5HT 2B Rezeptor Agonisten BW 723C86 in den PBC eines spontan rhythmisch aktiven Schnittpräparats führte zu einer temporären Erhöhung der rhythmischen Aktivität. Abgebildet ist hier die Ableitung der ipsilateral zu der Injektionsstelle gelegenen Wurzel des N. hypoglossus. Die Frequenz der rhythmischen Burstentladungen stieg an, eine tonische Aktivierung der XII Motoneurone fand nicht statt. Demnach konnten Diffusionsprozesse innerhalb des Präparats ausgeschlossen werden. Der Pfeil signalisiert den Zeitpunkt der Injektion. Injiziert wurden 0,4pMol BW723C86.

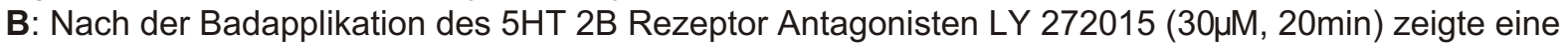
Wiederholung der BW 723C856 Injektion in den gleichen PBC keinen Effekt. Die rhythmische Aktivität des Präparats wurde durch die Gabe des 5HT 2B Rezeptor Antagonisten LY 272015 verlangsamt (siehe dazu auch Abb. 3.10). 


\subsubsection{Mikroinjektionen in den Nucleus hypoglossus}

\section{HT 2A Rezeptor vermittelte Effekte}

Die Mikroinjektion von $\alpha$-Methyl $5 \mathrm{HT}$ in den Nucleus hypoglossus erzeugte eine tonische Aktivität der XII Motoneurone, es zeigte sich keine Veränderung der Frequenz der rhythmischen Burstentladungen $(n=12)$. Dieser Effekt der Aktivierung der XII Motoneurone konnte durch die systemische Badapplikation des Antagonisten Ketanserin $(50 \mu \mathrm{M}, 30 \mathrm{~min})$ komplett blockiert werden $(n=6)$ (siehe Abb. 3.6). Allerdings konnte die systemische Badapplikation des 5HT 2B Rezeptor Antagonisten LY $272015(50 \mu \mathrm{M}, 30 \mathrm{~min})$ die durch $\alpha$-Methyl 5HT induzierte

tonische Aktivierung der XII Motoneurone nicht beeinflussen (siehe Abb. 3.7) $(n=7)$.

Das bedeutet, dass die durch $\alpha$-Methyl 5HT ausgelöste tonische Exzitation der XII Motoneurone über 5HT 2A Rezeptoren vermittelt wird. 


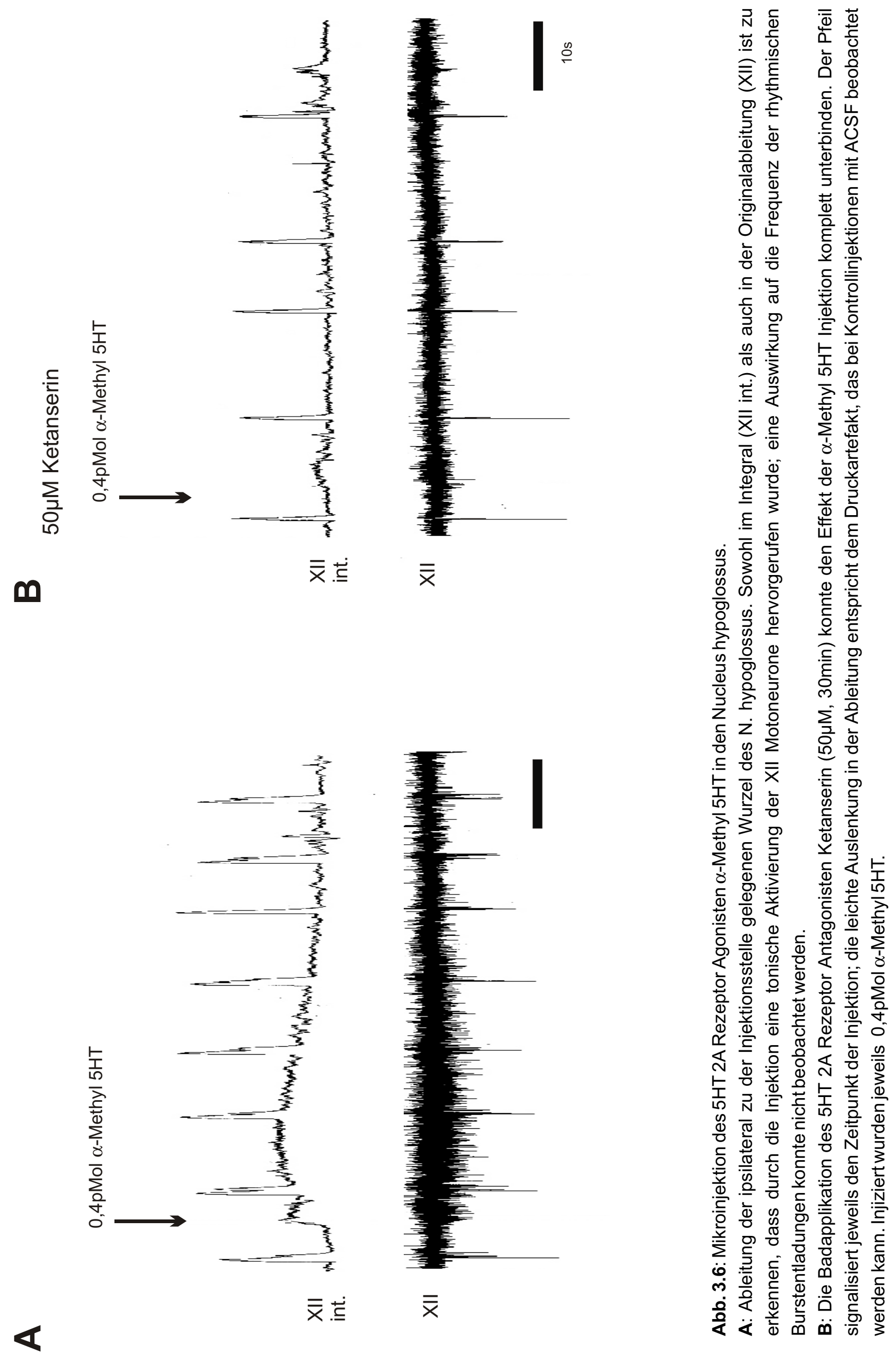


XII XII

B in $50 \mu M$ LY 272015:
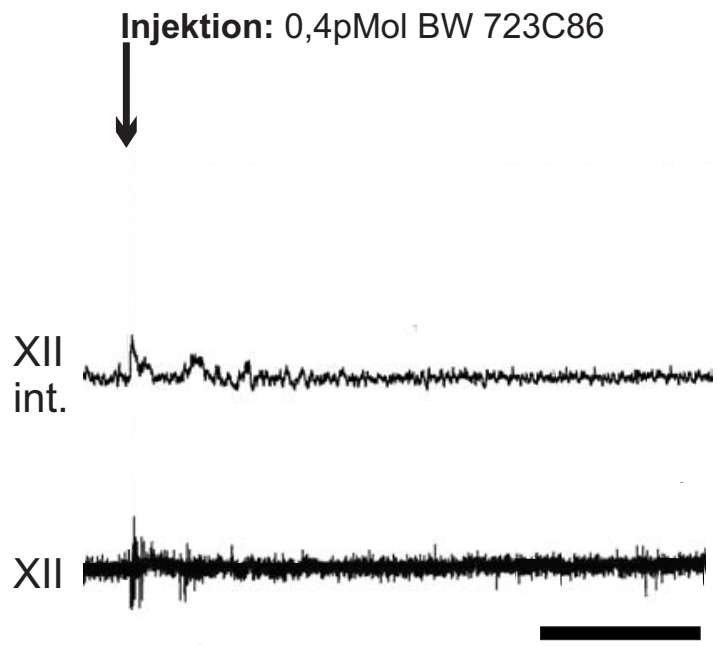

Injektion: 0,4pMol BW 723C86
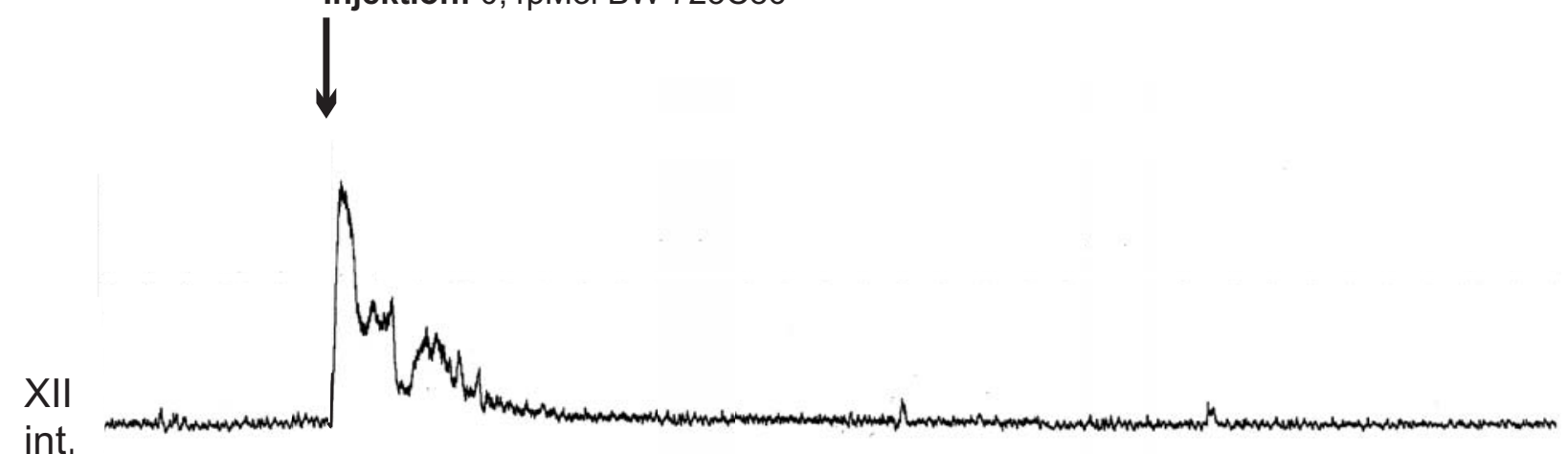

in 50 $\mu$ M LY 272015:

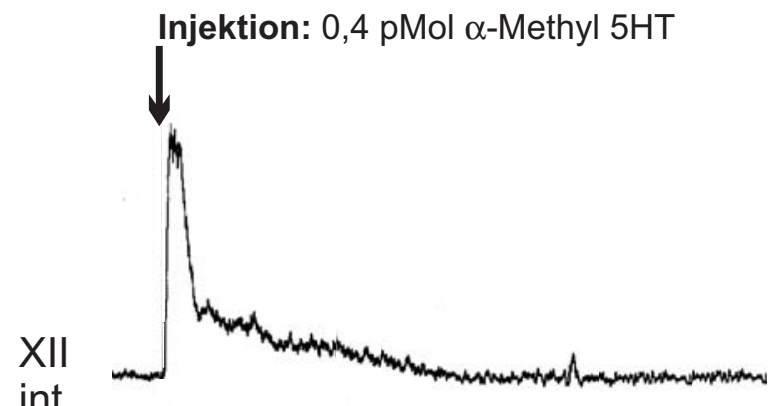

XII

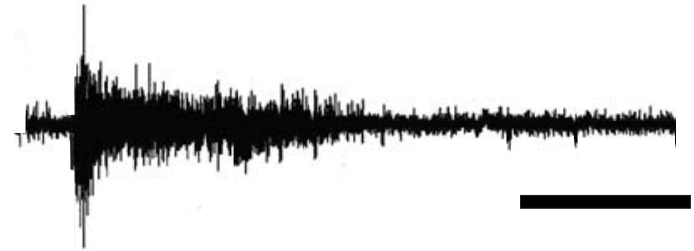

D

int.
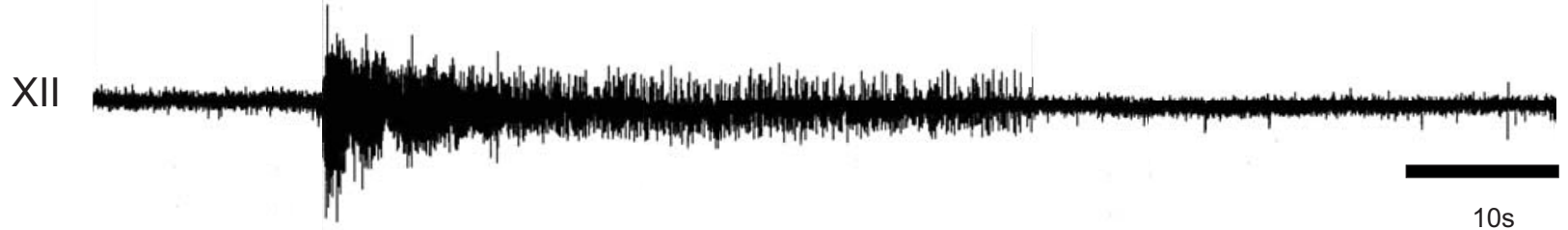
Abb. 3.7: Mikroinjektion des 5HT 2B Rezeptor Agonisten BW 723C68 in den Nucleus hypoglossus (Nucleus XII)

A: Aufzeichnung der Ableitung einer Wurzel des N. hypoglossus eines Schnittpräparats, das keinen spontanen Rhythmus zeigte. Der Pfeil signalisiert den Zeitpunkt der Mikroinjektion des BW 723C86 in den ipsilateral zu der abgeleiteten Wurzel gelegenen Nucleus hypoglossus. Sowohl im Integral der Ableitung (XII int.), als auch in der Originalableitung (XII) ist zu erkennen, dass die Injektion eine tonische Aktivierung der XII Motoneurone zur Folge hatte.

B: Injektion des 5HT 2B Rezeptor Agonisten BW 723C86 in den XII während der Badapplikation

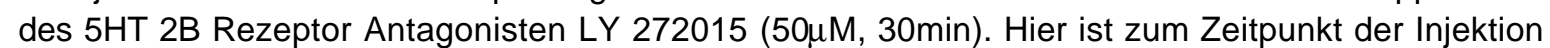
ein Druckartefakt zu erkennen, aber keine tonische Aktivierung der XII Motoneurone.

C: Mikroinjektion des 5HT 2A Rezeptor Agonisten $\alpha$-Methyl-5HT in den Nucleus hypoglossus während der Badapplikation des 5HT 2B Rezeptor Antagonisten. Durch die Injektion erfolgte eine tonische Aktivierung der XII Motoneurone.

D: Nach dem Auswaschen des 5HT 2B Rezeptor Antagonisten LY 272015 (> 30min) hatte eine erneute Injektion des 5HT 2B Rezeptor Agonisten BW 723C86 wieder eine tonische Aktivierung der XII Motoneurone zur Folge.

Alle gezeigten Injektionen erfolgten exakt an der selben Stelle des Nucleus hypoglossus. 


\section{$\underline{5 H T}$ 2B Rezeptor vermittelte Effekte}

Bei Mikroinjektionen des 5HT 2B Rezeptor Agonisten BW 723C86 in den Nucleus hypoglossus konnte eine tonische Aktivität der XII Motoneurone beobachtet werden $(n=17)$ (siehe Abb. 3.7). Diese Effekte waren in Intensität und Dauer mit denen des $\alpha$-Methyl 5HT vergleichbar. Eine Auswirkung auf die Frequenz der rhythmischen Burstentladungen konnte nicht beobachtet werden (siehe Abb. 3.3). Diese tonische Aktivierung der XII Motoneurone konnte durch die systemische

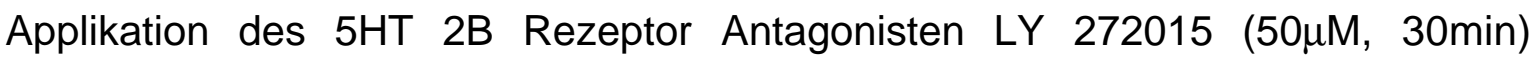
komplett blockiert werden ( $n=14$ ) (siehe Abb. 3.3 und 3.7). Nach dem Auswaschen des Antagonisten konnte bei einer Wiederholung der Mikroinjektion von BW 723C86 erneut eine tonische Aktivierung der XII Motoneurone festgestellt werden ( $n=9$ ) (siehe Abb. 3.7). Dies demonstriert, dass die Effekte des 5HT 2B Rezeptor Antagonisten LY 272015 spezifisch und voll reversibel sind.

Durch die systemische Applikation des 5HT 2A Rezeptor Antagonisten Ketanserin $(50 \mu \mathrm{M}, 30 \mathrm{~min})$ wurde die tonische Aktivierung der XII Motoneurone durch die Mikroinjektion von BW $723 \mathrm{C} 86$ in den Nucleus hypoglossus auf $29,83 \% \pm 32,85 \%$ im Vergleich zu den Effekten vor der Applikation von Ketanserin reduziert $(n=6)$, jedoch nicht blockiert (siehe Abb. 3.8).

Das beweist, dass auf respiratorischen Neuronen des Nucleus hypoglossus neben 5HT 2A auch 5HT 2B Rezeptoren vorhanden sind. 


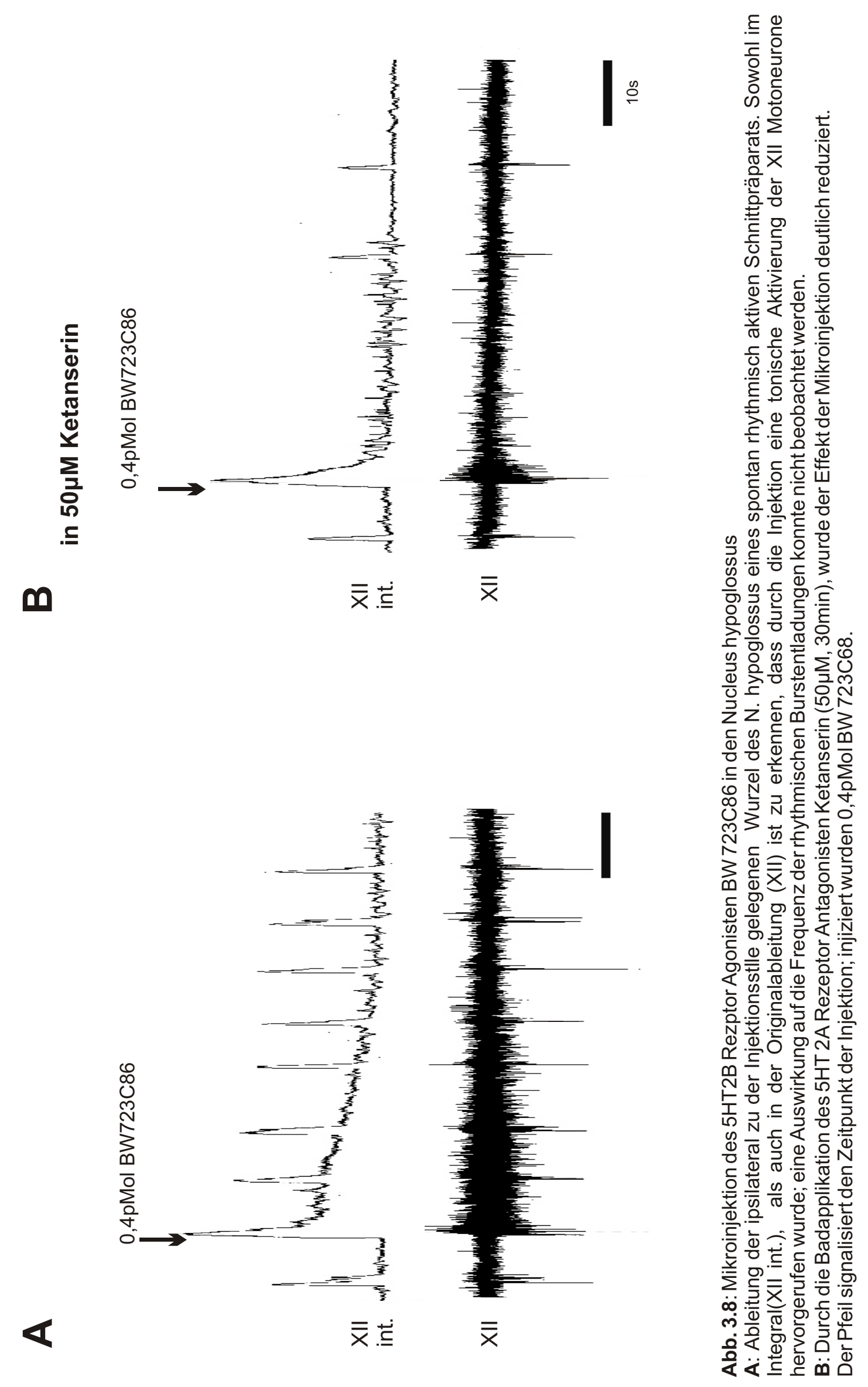




\subsection{Badapplikationen}

Die systemische Badapplikation von 5HT oder 5HT Rezeptor Agonisten hatte sowohl eine tonische Exzitation, als auch eine Veränderung der rhythmischen Aktivität zur Folge (siehe Abb. 3.9).

Wurden dagegen Antagonisten der entsprechenden Rezeptoren systemisch appliziert, konnte beobachtet werden, welche Auswirkungen die Blockade der jeweiligen Rezeptoren auf das, im rhythmischen Schnittpräparat enthaltene, respiratorische Netzwerk hat.

\subsubsection{Badapplikation des 5HT 2B Rezeptor Agonisten BW 723C86}

Bei der Badapplikation des 5HT 2B Rezeptor Agonisten BW 723 C86 in einer Konzentration von 50 $\mu \mathrm{M}$ über 2,5-3,0 Minuten konnte eine tonische Exzitation in Kombination mit einer Depolarisation der XII Motoneurone beobachtet werden $(n=5)$. Diese Depolarisation war vergleichbar mit den Effekten der lokalen

Mikroinjektion in den Nucleus hypoglossus (siehe Abb. 3.9 und 3.3 oder 3.7). Gleichzeitig hatte die Badapplikation eine Frequenzmodulation der rhythmischen Burstentladungen zur Folge (siehe Abb. 3.9). Die Frequenz der Atembursts stieg um $175,3 \pm 35,4 \%$ an $(n=5)$.

Damit ist erwiesen, dass die bei der lontophorese und Mikroinjektion untersuchten lokalen Effekte auch mit der systemischen Badapplikation der Agonisten in

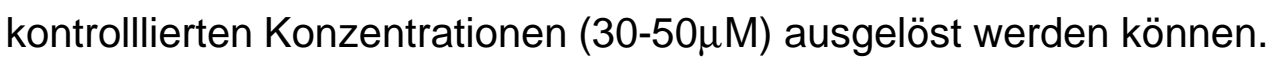




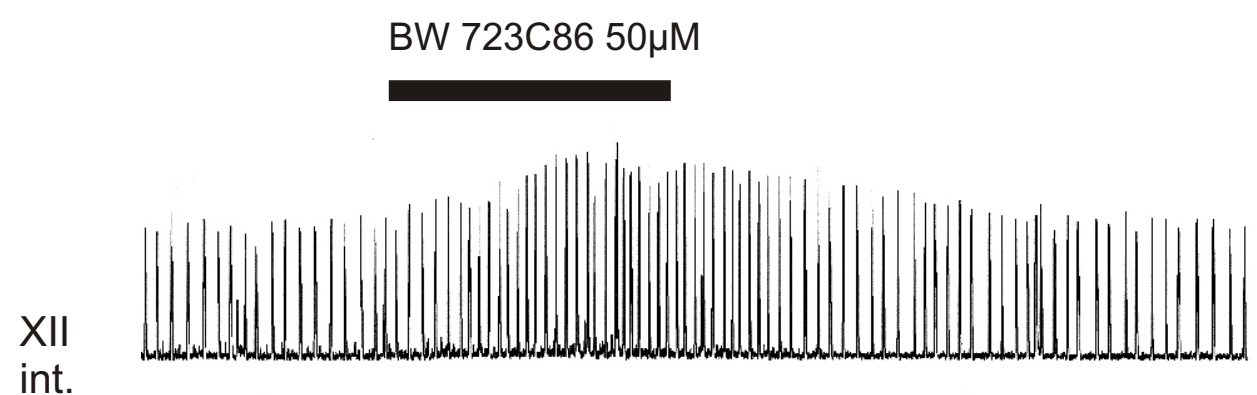

int.

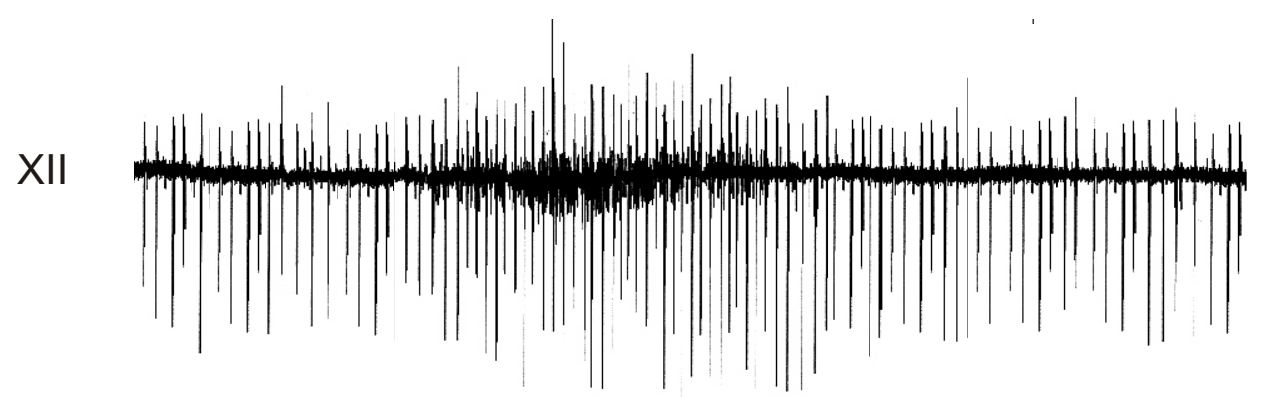

$1 \mathrm{~min}$

B

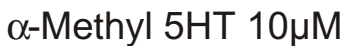

XII

int.

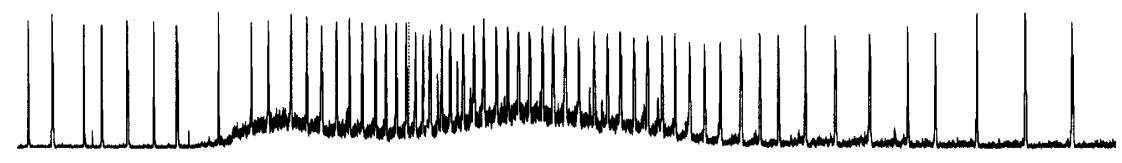

XII

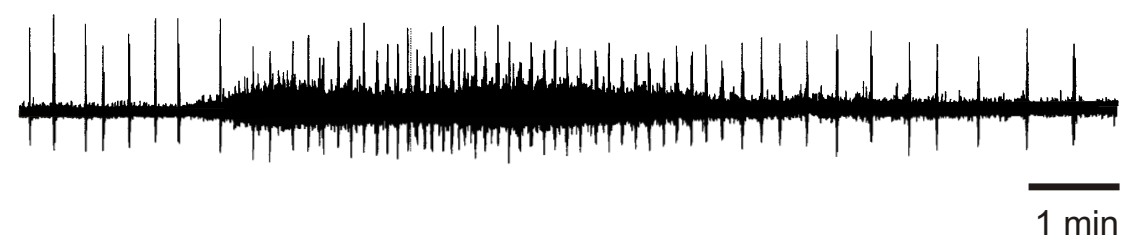

Abb. 3.9: Badapplikationen der 5HT Rezeptor Agonisten BW 723C86 und $\alpha-M e t h y l 5 H T$

A: Ableitung einer Wurzel des N. hypoglossus eines spontan rhythmisch aktiven Schnittpräparats. Der schwarze Balken signalisiert den zeitlichen Verlauf der Applikation. Sowohl in der Originalableitung (XII), als auch im Integral (XII int.) ist zu erkennen, dass die systemische Applikation des 5HT 2B Rezeptor Agonisten eine Steigerung der Frequenz der rhythmischen Atembursts zur Folge hatte. Gleichzeitig kam es zu einer tonischen Entladung des XII.

B:Ableitung einer Wurzel des $\mathrm{N}$. hypoglossus eines weiteren spontan rhythmisch aktiven Schnittpräparats. Der schwarze Balken signalisiert den zeitlichen Verlauf der Badapplikation des 5HT 2A Rezeptor Agonisten $\alpha$-Methyl 5HT. Sowohl in der Originalableitung (XII), als auch im Integral (XII int.) ist eine deutliche tonische Entladung, sowie eine Beschleunigung der Frequenz der Atembursts zu erkennen. 


\subsubsection{Badapplikation des 5HT 2 Rezeptor Agonisten $\alpha$-Methyl 5HT}

Die Badapplikation des 5HT 2 Rezeptor Agonisten $\alpha$-Methyl $5 \mathrm{HT}(10 \mu \mathrm{M})$ für 2,5-3,0 Minutenresultierte in einer tonischen Exzitation der XII Motoneurone in Kombination mit einem Anstieg der Frequenz der rhythmischen Burstentladungen um 284,2 $\pm 37,8 \%(n=3)$ (siehe Abb. 3.9). Im Vergleich zur Badapplikation des 5HT 2B Rezeptor Agonisten BW 723C86 zeigte die Applikation von $\alpha$-Methyl bei

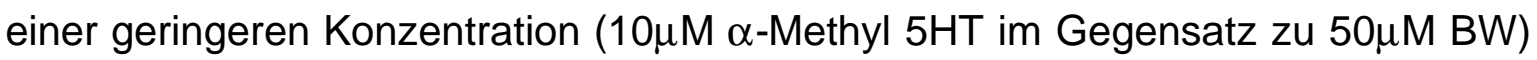
eine wesentlich ausgeprägtere Reaktion.

\subsubsection{Badapplikation des 5HT 2B Antagonisten LY272015}

Bei der systemischen Badapplikation des 5HT 2B Rezeptor Antagonisten

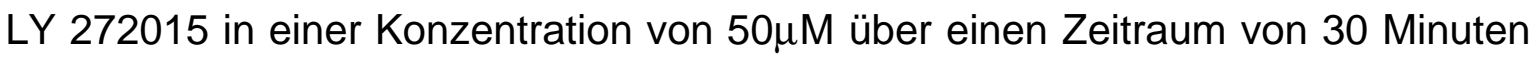
konnte eine kontinuierlichen Reduktion der respiratorischen Aktivität beobachtet werden $(n=7)$. Dabei wurde zunächst eine Verminderung der Amplitude und anschließend eine Verlangsamung der Frequenz festgestellt (siehe Abb. 3.10). Bei Applikation des Antagonisten über mehr als 30 Minuten wurde eine komplette Blockade des Atemrhythmus beobachtet $(n=12)$. Die Effekte dieses Antagonisten waren voll reversibel, d.h. nach dem Auswaschen des Antagonisten für 20-40 Minuten konnte erneut eine respiratorische Aktivität des Präparats festgestellt werden. Diese war in Frequenz und Amplitude der rhythmischen Burstentladungen vergleichbar mit den Werten vor der Applikation des Antagonisten. 
XII int.

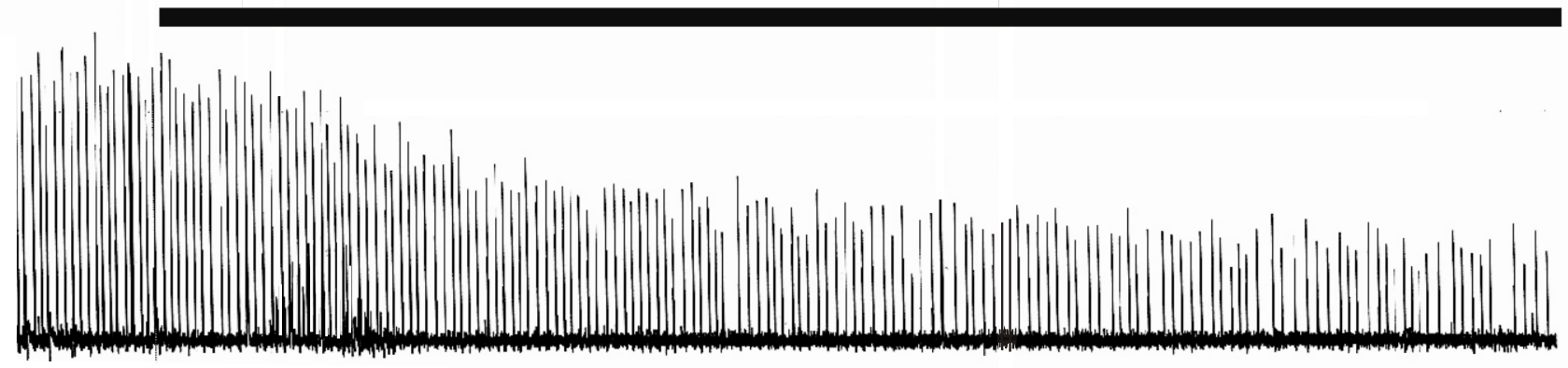

Auswaschen

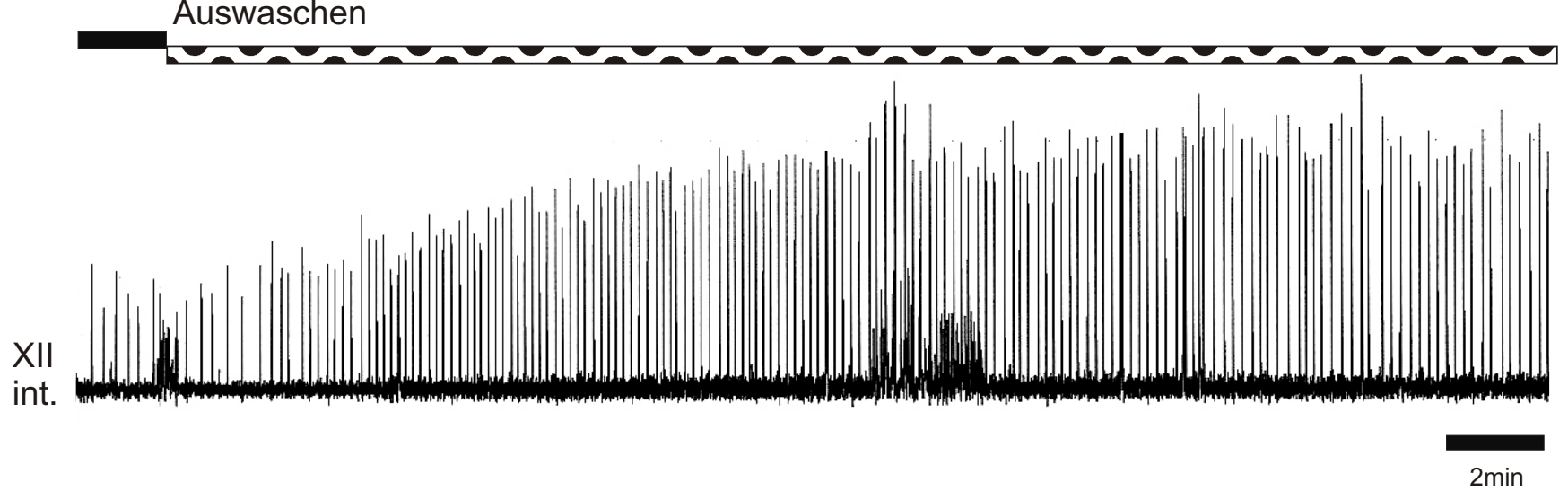

Abb.3. 10: Zeitlicher Verlauf der Blockade des Atemrhythmus durch den 5HT 2B Rezeptor Antagonisten LY272015.

Abgebildet ist hier das Integral der Ableitung einer XII Wurzel eines spontan rhythmisch aktiven Schnittpräparats. Der schwarze Balken zeigt den Verlauf der systemischen Badapplikation des $5 \mathrm{HT}$

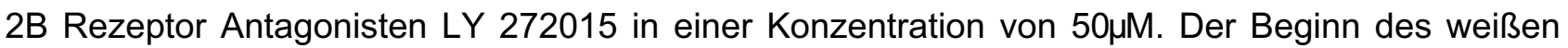
Balkens signalisiert das Auswaschen des Antagonisten. Unmittelbar nach dem Beginn der Applikation des Antagonisten ist als erster Effekt eine Verminderung der Amplitude der rhythmischen Burstentladungen zu erkennen. Nach ca. 15min der Badapplikation ist eine Auswirkung auf die Frequenz der rhythmischen Burstentladungen zu erkennen. Unmittelbar mit dem Auswaschen des Antagonisten beginnt auch eine Erholung des Atemrhythmus. Nach ca. $5 \mathrm{~min}$ ist eine Erhöhung der Frequenz zu beobachten; eine Erhöhung der Amplitude der Bursts beginnt nach ca. $7 \mathrm{~min}$. Nach ca. 20 min zeigt der Atemrhythmus wieder ein Verhalten in Frequenz und Amplitude wie vor der Applikation des Antagonisten. 
Damit wurde gezeigt, dass die Aktivität des 5HT 2B Rezeptors essentiell für die Aufrechterhaltung des respiratorischen Rhythmus ist. Die Tatsache, dass die alleinige Gabe des 5HT 2B Rezeptor Antagonisten zur Blockade der respiratorischen Aktivität führte, lässt den Schluss zu, dass endogen ausgeschüttetes $5 \mathrm{HT}$ im rhythmisch aktiven Schnittpräparat über 5HT 2B Rezeptoren die Neurone des PBC stimuliert. Endogenes 5HT könnte von serotonergen Neuronen stammen, die in den im rhythmisch aktiven Schnittpräparat enthaltenen lokalen Raphekernen (Nucleus raphe magnus, Nucleus raphe obscurus, Nucleus raphe pallidus) lokalisiert sind.

\subsubsection{Badapplikation des 5HT 2A Rezeptor Antagonisten Ketanserin}

Um zu untersuchen, ob eine mit der in 3.3 .3 beschriebenen vergleichbare endogene Wirkung der 5HT 2A Rezeptoren vorliegt, wurde dies über die systemische Badapplikation eines spezifischen 5HT 2A Rezeptor Antagonisten getestet. Bei der Badapplikation des 5HT 2A Rezeptor Antagonisten Ketanserin $(50 \mu \mathrm{M}, 60 \mathrm{~min})$ zeigte sich, dass eine Blockade der 5HT 2A Rezeptoren keine Wirkung auf den respiratorischen Rhythmus hatte $(n=8)$ (siehe Abb. 3.11). 


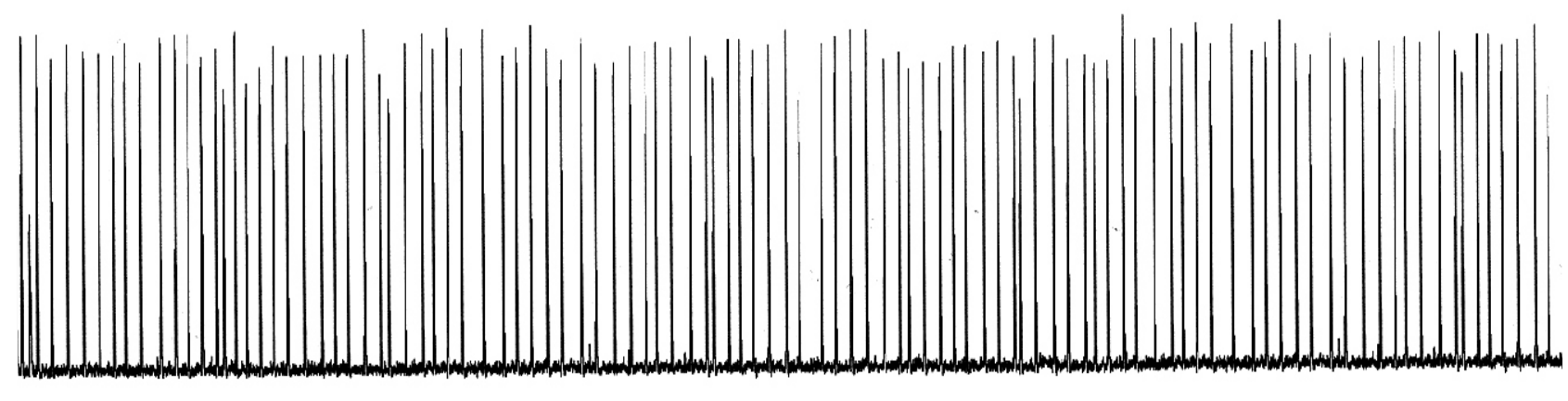

B

Kontrolle

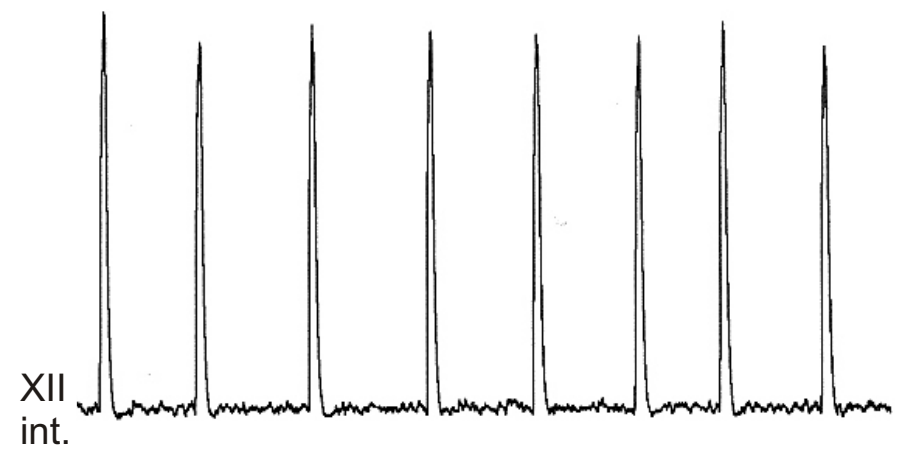

C

$50 \mu \mathrm{M}$ Ketanserin nach $60 \mathrm{~min}$
XII

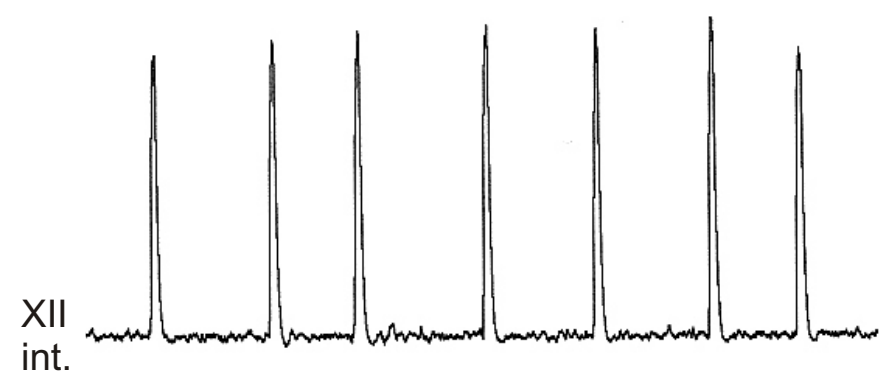

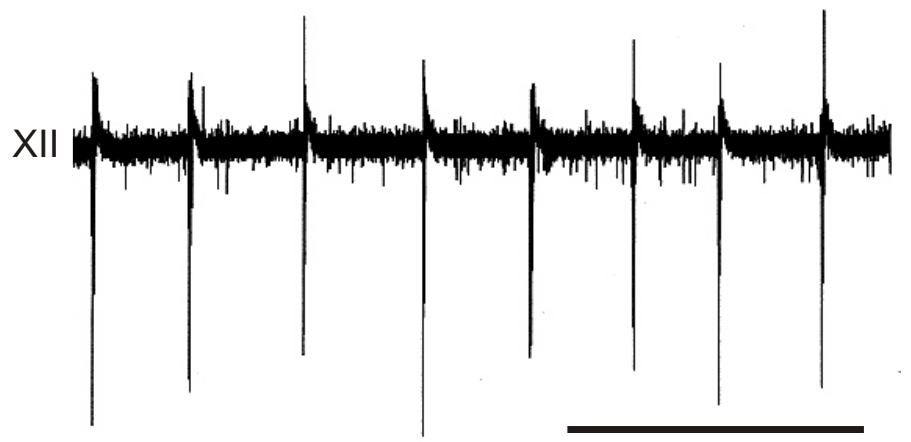

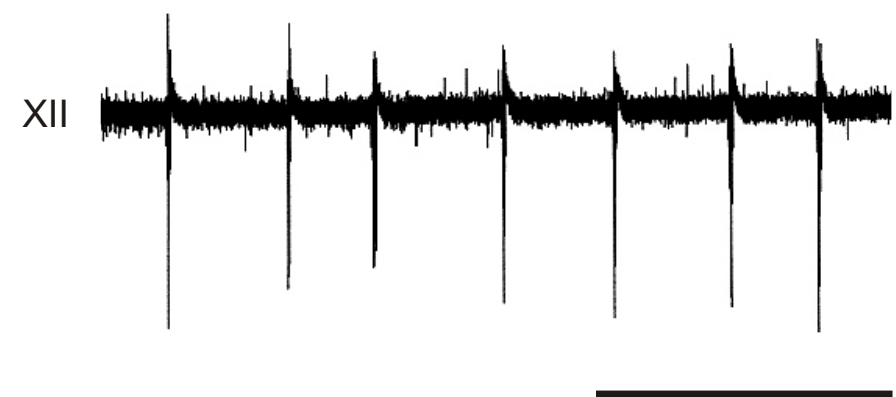

$20 \mathrm{~s}$

Abb. 3.11: Badapplikation des 5HT 2A Rezeptor Antagonisten Ketanserin

A: Abgebildet ist hier das Integral der Ableitung einer XII Wurzel eines spontan rhythmisch aktiven Schnittpräparats. Der schwarze Balken zeigt den Verlauf der systemischen Badapplikation des 5HT 2A Rezeptor Antagonisten Ketanserin $(50 \mu \mathrm{M})$. Der schwarze Balken signalisiert den Verlauf der Applikation. In den ersten 10min der Applikation ist keine Auswirkung auf den Atemrhythmus zu erkennen.

B: Ausschnittsvergrößerung der Originalableitung (XII) und des Integrals (XII int.) der Ableitung der XII Wurzel vor der Badapplikation von Ketanserin. C: Ausschnittsvergrößerung der Originalableitung (XII) und des

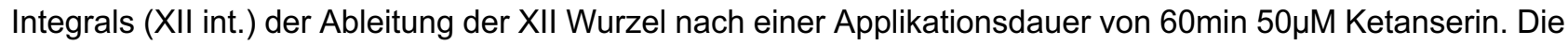
langanhaltende Applikation von Ketanserin zeigte keine Auswirkungen auf den respiratorischen Rhythmus. 


\section{Diskussion}

\subsection{Das rhythmisch aktive Schnittpräparat des Hirnstamms}

Für das Verständnis der genauen Zusammenhänge innerhalb des respiratorischen Netzwerks ist es von Vorteil, wenn zusätzliche interne und externe Einflüsse auf dieses Netzwerk minimiert werden. Argumente, dass die minimierte Präparation des rhythmisch aktiven Schnittpräparats der neonatalen Ratte, die das erhaltene respiratorische Netzwerk auf den PBC reduziert, nicht die entscheidenden Anteile des lokalen Atemzentrums enthält, können entkräftet werden. In Studien an der adulten Katze in vivo wurde gezeigt, dass sowohl über die Blockade der synaptischen Transmission, als auch durch eine Läsion des PBC ein Atemstop ausgelöst werden kann (Pierrefiche et al., 1998; Ramirez et al., 1998). Es gilt mittlerweile als gesichert, dass der PBC tatsächlich das Atemzentrum beinhaltet (Reckling and Feldmann, 1998; Smith et al., 1991, 2000; Johnson et al., 2001).

Untersuchungen ergaben, dass der aus dem rhythmisch aktiven Schnittpräparat abgeleitete Rhythmus nur geringfügige Unterschiede zu dem in vivo abgeleiteten Atemrhythmus neoataler Ratten aufweist (Smith et al., 1990, 1991). Diese auftretenden Unterschiede können zum einen damit erklärt werden, dass in dem Präparat der Einfluss der peripheren Afferenzen des N. vagus fehlt; zum anderen könnten die bei den Experimenten herrschenden Bedingungen dafür verantwortlich sein. Beispielsweise wird die Temperatur der Perfusionslösung auf $27^{\circ} \mathrm{C}$ gehalten. Diese Temperatur liegt deutlich unter dem physiologischen Wert 
von $37^{\circ} \mathrm{C}$. Allerdings wird das Präparat auf dieser Temperatur gehalten, um einen regelmäßigen spontanen Rhythmus und eine stabile Ableitsituation über mehrere Stunden zu gewährleisten (Smith et al., 1990). Außerdem wird der Gehalt an K'Ionen in der Perfusionslösung auf $8 \mathrm{mM} \mathrm{K}^{+}$angehoben, im Gegensatz zu der physiologischen Konzentration von $3 \mathrm{mM} \mathrm{K}^{+}$(Smith et al., 1991; Funk et al., 1995; Al - Zubaidy et al., 1996). Diese erhöhte Konzentration von $\mathrm{K}^{+}$-lonen wird eingesetzt, um die spontane rhythmische Aktivität des Hirnstammschnittes zu erhalten (Smith et al., 1991; Greer et al., 1992).

Bei einer $\mathrm{K}^{+}$Konzentration von $3 \mathrm{mM}$ zeigen einige Präparate keinen spontanen Rhythmus; allerdings bleiben die Präparate bei einer $\mathrm{K}^{+}$Konzentration von $8 \mathrm{mM}$ für mehrere Stunden funktionsfähig.

Demnach sind bis heute dünne transversale medulläre Schnittpräparationen, die den PBC enthalten, das optimale experimentelle Modell, um sowohl die innewohnenden zellulären, als auch die Netzwerkeigenschaften des Atemzentrums zu untersuchen (Johnson et al., 2001). 


\subsection{Intrazelluläre Ableitungen}

Intrazelluläre Ableitungen von respiratorischen Interneuronen des PBC haben entscheidende Vorteile. Zum einen ist die genaue Identifikation der Zellen als respiratorische Interneurone aufgrund ihres Burstverhaltens im Vergleich mit der Wurzelableitung des N. hypoglossus möglich. Das bedeutet, dass man das genaue Verhalten einer Zelle der untersuchten Population (respiratorische Neurone des PBC) beobachten kann. Wird die synaptische Transmission blockiert, können auch Wechselwirkungen und Einflüsse von anderen Zellen ausgeschlossen werden. Allerdings wird in einem Experiment immer nur eine einzige Zelle untersucht, nicht die gesamte Zellpopulation, die evtl. von Interesse ist.

Ein weiterer Nachteil der Einzelzellableitung mit Hilfe der Patch clamp Technik ist, dass das Zellmilieu nicht mehr in seinem ursprünglichen Zustand ist. Das Zytosol wird über Diffusionsprozesse mit der Pipettenlösung ausgetauscht; wichtige Metabolite und intrazelluläre Botenstoffe können darüber verloren gehen. Dementsprechend kann in Frage gestellt werden, ob die beobachtete Reaktion der Zelle auf beispielsweise iontophoretisch applizierte Rezeptor Agonisten der Situation einer voll intakten Zelle entspricht.

Daher wurden in der vorliegenden Arbeit die Wirkungen von 5HT Rezeptor Agonisten an Einzelzellen mit der Reaktion der Zellpopulation des PBC bzw. des Nucleus XII bei Mikroinjektion und bei Badapplikation der selben 5HT Rezeptor Agonisten verglichen. 


\subsection{Iontophorese}

Der Hauptvorteil bei der iontophoretischen Applikation liegt darin, dass die zu applizierende Droge direkt in die Nähe der abgeleiteten Zelle gebracht wird. Dadurch kann die unmittelbare Reaktion der abgeleiteten Zelle auf den applizierten Stoff beobachtet werden.

Eine Verunreinigung des Gewebes durch zu viel applizierte Stoffe, und damit längeranhaltende und eventuell. unspezifische Effekte werden somit minimiert. Die tatsächlich applizierte Menge ist gering und an der Grenze der physiologisch relevanten Konzentration. Andererseits kann die tatsächlich applizierte Menge nicht genau bestimmt werden.

Ein Nachteil dieser Methode ist die mögliche Störung der intrazellulären Ableitung durch das Heranbringen der zusätzlichen Pipette. Im schlimmsten Fall wird die Ableitung so gestört, dass die Zelle verloren geht. Da bei der lontophorese die Applikation des Stoffes über positive Ströme erfolgt, kann die Qualität der Ableitung leiden; Artefakte durch Verschieben des Membranpotentials können beobachtet werden. Diese Artefakte können ausgeglichen werden, indem man während der iontophoretischen Applikation einen leichten negativen Kompensationsstrom gibt, um die Zelle auf dem ursprünglichen Membranpotential zu halten. 


\subsection{Vergleich von Badapplikation und Mikroinjektion}

Bei der Mikroinjektion von 5HT oder 5HT Rezeptor Agonisten können Artefakte beobachtet werden, die durch die mechanischen Belastung des Gewebes zustande kommen. Gerade beim Einführen der Pipette in das Gewebe und unmittelbar bei der Injektion können durch die mechanische Belastung des Gewebes Störungen zustande kommen.

Allerdings wurden bei den im Rahmen dieser Arbeit gezeigten und ausgewerteten Versuchen jeweils die möglichen Artefakte kontrolliert; vor jeder Mikroinjektion des zu untersuchenden Agonisten wurden Kontrollinjektionen mit ACSF durchgeführt. Gelegentlich konnte eine Störung der Amplitude der Bursts direkt nach der Mikroinjektion beobachtet werden. Dies kann damit erklärt werden, dass durch die Mikroinjektion die betreffende Region teilweise irreversibel geschädigt wurde.

Ein Vorteil der lokalen Mikroinjektion ist, dass über die lokale Injektion nur die gewünschte Zielpopulation an Neuronen erreicht wird. Druckinjektionen des 5HT 2B Rezeptor Agonisten BW 723C86 oder des 5HT 2 Rezeptor Agonisten $\alpha$-Methyl $5 \mathrm{HT}$ in den PBC und in den Nucleus hypoglossus zeigten entweder eine Frequenzmodulation (bei Injektionen in den PBC) oder eine tonische Exzitation (bei Injektionen in den Nucleus hypoglossus), niemals beide Effekte gleichzeitig. 
Bei der Badapplikation der 5HT 2A und 5HT 2B Rezeptor Agonisten hingegen trat sowohl eine tonische Exzitation der XII Motoneurone, als auch eine Frequenzmodulation der rhythmischen Burstentladungen auf. Somit konnte ausgeschlossen werden, dass die bei der Mikroinjektion beobachteten Effekte aufgrund von Diffusionsprozessen innerhalb des Präparats zustande kamen.

Die Tatsache, dass man die applizierte Menge des Stoffes über Konzentration und Dauer der Applikation sehr genau dosieren kann, ist ein Vorteil der systemischen Badapplikation bestimmter Stoffe wie 5HT, 5HT 2 Rezeptor Antagonisten und Agonisten. Außerdem können Artefakte, wie sie durch die mechanische Belastung des Gewebes bei Mikroinjektionen hervorgerufen werden können, ausgeschlossen werden.

Allerdings ist die systemische Badapplikation auch kritisch in der Anwendung. Die manchmal nicht einheitlichen Effekte, die beispielsweise bei der Badapplikation von 5HT beobachtet werden konnten (Schwarzacher et al., 2002), können damit erklärt werden, dass alle reaktiven Zellen des Präparats angesprochen werden; somit können Wechselwirkungen innerhalb des rhythmisch aktiven Schnittpräparats entstehen, die schwer zu kalkulieren sind. Hier führt die Methode der direkten Mikroinjektion in das Gewebe eher zu reproduzierbaren Reaktionen, da mit Hilfe der Mikroinjektion genau die Population an Zellen angesprochen werden kann, die gerade untersucht werden soll. 


\subsection{Verwendete 5HT Rezeptor Agonisten und Antagonisten}

Der Erfolg der Untersuchungen ist erheblich von den erhältlichen Rezeptor Agonisten und Antagonisten und deren Spezifität für die jeweiligen Rezeptoren abhängig. So haben alle im Rahmen dieser Arbeit verwendeten Serotonin Rezeptor Agonisten und Antagonisten zwar ihre maximalen Bindungsaffinitäten zu dem jeweiligen Rezeptor Subtyp; durch die hohe Ähnlichkeit der Rezeptoren untereinander jedoch - die Proteinsequenzen zeigen Homologien von 70-95\% (Negibil et al., 2001a) weisen die Rezeptor Agonisten und Antagonisten auch Bindungsaffinitäten zu den jeweils anderen Rezeptor Subtypen auf.

Deshalb wurden in dieser Arbeit die jeweiligen Agonisten sowohl gegen den spezifischen Antagonisten als auch gegen die Antagonisten anderer 5HT Rezeptoren bzw. 5HT Rezeptor Subtypen getestet, um die Selektivität der Agonisten und Antagonisten unter den speziellen Bedingungen des neonatalen rhythmisch aktiven Schnittpräparats abzusichern. 


\subsection{Modulatorische Wirkungen von 5HT Rezeptoren an respiratorischen Interneuronen}

Bei der iontophoretischen Applikation von $\alpha$-Methyl $5 \mathrm{HT}$ auf respiratorische Interneurone des PBC konnte stets eine Depolarisation des Membranpotentials, verbunden mit einer Reduktion des Membranwiderstands, gemessen werden. Diese Ergebnisse stimmen mit den Beobachtungen von Lalley et al. (1995) überein, dass in der erwachsenen Katze die iontophoretische Applikation von $\alpha$-Methyl $5 \mathrm{HT}$ bei Stage 2 expiratorischen und Post-inspiratorischen Neuronen eine Depolarisation der Zellen zur Folge hat.

Diese Effekte wurden auch bei der Blockade der synaptischen Aktivität durch TTX und einer Mischung aus Inhibitoren der synaptischen Aktivität nachgewiesen. Deshalb kann als gesichert gelten, dass die über $\alpha$-Methyl $5 \mathrm{HT}$ vermittelten Effekte über aktivierbare postsynaptisch lokalisierte 5HT 2 Rezeptoren ausgelöst werden. Da die Depolarisation der PBC Neurone stets mit einer Reduktion des Membranwiderstands gekoppelt war, könnte dieser Depolarisation eine Zunahme in der $\mathrm{Ca}^{2+}$ - und/oder $\mathrm{Na}^{+}$Leitfähigkeiten, die möglicherweise mit einer Reduktion in der $\mathrm{K}^{+}$Leitfähigkeit gekoppelt sind, zugrunde liegen (Lindsay and Feldman, 1993; Morin et al., 1992; Onimaru et al., 1996, 1998).

Im Vergleich dazu wurde die Wirkungsweise des 5HT 1A Rezeptor Agonisten $8 \mathrm{OH}$ DPAT auf respiratorische Neurone innerhalb des PBC untersucht. Interessanterweise ergab sich ein gewisser Synergismus der Wirkungsweisen der 5HT 2 Rezeptoren und der des 5HT 1A Rezeptors. Die lontophorese des 5HT 1A Rezeptor Agonisten hatte ebenfalls eine Depolarisation des Membranpotentials 
zur Folge. Im Unterschied zu der Reaktion auf die Aktivierung der 5HT 2 Rezeptoren durch $\alpha$-Methyl 5HT wurde bei der Aktivierung der 5HT $1 \mathrm{~A}$ Rezeptoren eine Erhöhung des Membranwiderstands registriert. Außerdem konnten die $8 \mathrm{OH}$ DPAT Effekte unter Blockade der synaptischen Aktivität beobachtet werden. Dementsprechend kann auch hier die Schlussfolgerung gezogen werden, dass diese Wirkungen aufgrund von postsynaptisch lokalisierten 5HT 1A Rezeptoren zustande kommen.

Dass 5HT 1A Rezeptoren eine Rolle bei der Modulation des respiratorischen Netzwerks spielen, wurde in in vivo Versuchen an adulten Katzen gezeigt. Auf Stage 2 expiratorischen Zellen innerhalb der VRG wurden funktionell aktive $5 \mathrm{HT}$ 1A Rezeptoren nachgewiesen. Allerdings resultierte die systemische und iontophoretische Applikation des 5HT 1A Rezeptor Agonisten 8 OH DPAT in der adulten in vivo Situation in einer Hyperpolarisation des Membranpotentials, sowie einer Reduktion des Membranwiderstands. In der Zellgruppe der Stage 2 expiratorischen Neurone der Katze wurden diese Effekte vermutlich über Aktivierung sogenannter GIRK (G-Protein-dependent inwardly rectifying $\mathrm{K}^{+}$ conductances) vermittelt (Lalley et al., 1994 a,b,c).

Auf respiratorische Zellen des PBC der neugeborenen Ratte jedenfalls hatte die lontophorese des 5HT 1A Rezeptor Agonisten 8 OH DPAT die entgegengesetzten Auswirkungen. Entsprechend könnte sie durch eine G-Protein vermittelte Reduktion von $\mathrm{K}^{+}$Leitfähigkeiten erklärt werden.

Da es sich um die gleichen Rezeptoren und Rezeptor Agonisten handelte, könnte man vermuten, dass diese Unterschiede in der Wirkung auf altersabhängige Veränderungen in der intrazellulären Signaltransduktion der 5HT 1A Rezeptoren beruhen. 
Die Rezeptoren der 5HT 1 Rezeptor Familie sind über G-Proteine an die Adenylat Cyclase, die Rezeptoren der 5HT 2 Rezeptor Familie jedoch über G-Proteine an die Protein Kinase C gekoppelt. So beruhen die teilweise identischen Effekte der Rezeptoren auf unterschiedlichen intrazellulären Signaltransduktionswegen.

Die depolarisierende Wirkung des 5HT 2 Rezeptor Agonisten $\alpha$-Methyl 5HT auf respiratorische Neurone des PBC war wesentlich ausgeprägter als die des 5HT 1A Rezeptor Agonisten.

Aus diesem Grund wurde im weiteren Verlauf der Arbeit der Schwerpunkt der Untersuchungen auf die Rezeptoren der 5HT 2 Rezeptor Familie gelegt. Außerdem hatte durch neuere Untersuchungen der 5HT 2B Rezeptor als potentieller morphogenetischer Faktor an Bedeutung gewonnen (Launay et al., 1996; Choi et al., 1997; Negibil et al., 2000a, 2001a, 2001b).

Mit den seit kurzem kommerziell erhältlichen Agonisten und Antagonisten für diesen Rezeptorsubtyp standen gute pharmakologische Mittel zur Verfügung, selektiv die Wirkungen des 5HT 2B Rezeptors auf das, im rhythmisch aktiven Schnittpräparat erhaltene, respiratorische Netzwerk zu untersuchen. 


\subsection{Lokale Wirkungsweise der verschiedenen 5HT 2 Rezeptor Subtypen}

Anhand intrazellulärer Messungen wurde festgestellt, dass in der neonatalen Phase die stimulatorische Wirkung des 5HT vorwiegend über 5HT 2 Rezeptoren vermittelt wird. Deshalb sollte aufgeschlüsselt werden, welche Funktionen innerhalb der Familie der 5HT 2 Rezeptoren die 5HT 2A und 5HT 2B Rezeptorsubtypen erfüllen. In bisherigen Arbeiten waren entweder die gesamte 5HT 2 Rezeptorfamilie oder allein der 5HT 2A Rezeptor Subtyp untersucht worden. So wurde beispielsweise gezeigt, dass 5HT 2A Rezeptoren an XII Motoneuronen depolarisierend und tonisch aktivierend wirken (Berger et al., 1992).

So wurde zunächst über vergleichende Mikroinjektionen untersucht, ob, sowohl auf XII Motoneuronen, als auch auf PBC Neuronen, Rezeptoren des Typs 5HT 2A und $5 \mathrm{HT} 2 \mathrm{~B}$ funktionell vorhanden sind.

Injektionen des 5HT 2A Rezeptor Agonisten $\alpha$-Methyl 5HT in den Nucleus hypoglossus bewirkten eine starke tonische Aktivierung; desgleichen führte die Aktivierung der 5HT 2B Rezeptoren über BW 723C86 zu einer tonischen Exzitation der XII Motoneurone. Das bedeutet, dass die Effekte, die über diese Rezeptorsubtypen vermittelt werden, letztendlich die gleiche Wirkung zeigen. 
Durch die Badapplikation des spezifischen 5HT 2B Rezeptor Antagonisten LY 272015 konnte gezeigt werden, dass die Blockade des 5HT 2B Rezeptors eine komplette reversible Blockade des BW 723C86 Effekts, jedoch keine Auswirkung auf die von $\alpha$-Methyl-5HT vermittelte Reaktion hat. Somit war gesichert, dass LY 272015 eine hohe Spezifität für den 5HT 2B Rezeptor aufweist.

Andererseits resultierte die Blockade der 5HT 2A Rezeptoren über den spezifischen 5HT 2A Rezeptor Antagonisten Ketanserin nicht nur in einer kompletten Inhibition des von $\alpha$-Methyl-5HT vermittelten Effekts, sondern außerdem in einer deutlichen Reduktion des von BW 723C86 vermittelten Effekts.

Der Agonist $\alpha$-Methyl 5HT zeigt Bindungsaffinitäten für alle Rezeptoren der 5HT 2 Rezeptor Familie. Die Tatsache, dass durch den selektiven 5HT 2A Rezeptor Antagonisten Ketanserin, der nur eine geringe Bindungsaffinität für den $5 \mathrm{HT} 2 \mathrm{~B}$ Rezeptorsubtyp aufweist (Kennet, 1997), der Effekt des $\alpha$-Methyl 5HT komplett blockiert wird, kann so gedeutet werden, dass die durch $\alpha$-Methyl $5 \mathrm{HT}$ vermittelten Effekte zum Großteil auf 5HT 2A Rezeptoren zurückzuführen sind. Durch den selektiven 5HT 2B Rezeptor Antagonisten LY 272015 wird der Effekt des $\alpha$-Methyl 5HT jedoch nicht beeinflusst; die 5HT 2B Rezeptoren scheinen in diesem System somit eine untergeordnete Rolle zu spielen.

Dafür spricht auch, dass der Effekt des 5HT 2B Rezeptor Agonisten BW 723C86 durch die Badapplikation von Ketanserin deutlich reduziert werden konnte. Das legt die Vermutung nahe, dass BW 723C86 in rhythmisch aktiven Schnittpräparat nicht ausschliesslich 5HT 2B Rezeptoren sondern auch 5HT 2A Rezeptoren aktiviert. Durch die Badapplikation des 5HT 2B Rezeptor Antagonisten LY 272015 konnte der Effekt des BW 723C86 komplett blockiert werden. Deshalb kann als 
gesichert gelten, dass der 5HT 2B Rezeptor Antagonist LY 272015 unter den herrschenden experimentellen Bedingungen vorwiegend an 5HT 2B Rezeptoren bindet.

Eine mögliche Erklärung der zum Teil überlappenden Wirkungen der 5HT 2A und 5HT 2B Rezeptor Agonisten und Antagonisten könnte sein, dass zumindest an XII Motoneuronen die Anzahl der aktivierbaren postsynaptischen 5HT 2A Rezeptoren die der 5HT 2B Rezeptoren deutlich übersteigt.

Für diese Erklärung sprechen die Ergebnisse der Badapplikation der 2HT 2A und 5HT 2B Rezeptor Agonisten $\alpha$-Methyl 5HT und BW 723C86. Diese ergaben, dass durch $\alpha$-Methyl $5 \mathrm{HT}$ eine stärkere tonische Exzitation der XII Motoneurone hervorgerufen wird, als mit BW 723C86. $\alpha$-Methyl 5HT hat bei einer geringeren Konzentration $(10 \mu \mathrm{M})$ im Vergleich mit BW $723 \mathrm{C} 86(50 \mu \mathrm{M})$ eine vergleichbare tonische Exzitation der XII Motone urone zur Folge. 


\subsection{HT 2A und 5HT 2B Rezeptor vermittelte 5HT Effekte auf das Atemzentrum im Prä-Bötzinger Komplex}

Mikroinjektionen in den PBC führten zu einer Erhöhung der respiratorischen Frequenz, sowohl bei Injektionen mit $\alpha$-Methyl 5HT, als auch mit BW 723C86. Somit konnte nachgewiesen werden, dass funktionelle 5HT 2B Rezeptoren auch auf respiratorischen Neuronen des PBC vorhanden sind.

Ein Vergleich der Wirkungen der 5HT 2A und 5HT 2B Rezeptor Agonisten auf respiratorische Neurone des PBC, beziehungsweise auf die Frequenz der respiratorischen Bursts, ergibt keine Hinweise auf eine Vorrangstellung des 5HT 2A Rezeptors, wie sie nach den vorliegenden Befunden für XII Motoneurone nahe liegt.

Hingegen zeigt sowohl die Badapplikation, als auch die lokale Mikroinjektion der beiden Agonisten vergleichbare stimulierende Wirkungen auf die respiratorische Frequenz.

Die Bedeutung des 5HT 2B Rezeptors gerade im PBC wird offensichtlich bei alleiniger Gabe des selektiven 5HT 2B Rezeptor Antagonisten LY 272015 über längere Zeiträume. So resultierte die Badapplikation des Antagonisten bereits nach wenigen Minuten in einer Reduktion der Amplitude der respiratorischen Bursts, gefolgt von einer Abnahme der Frequenz bis hin zu einer totalen Blockade des Atemrhythmus. Diese Effekte waren nach dem Auswaschen des 5HT 2B Rezeptor Antagonisten voll reversibel. 
Im Vergleich dazu konnte durch die Applikation des spezifischen 5HT 2A Rezeptor Antagonisten Ketanserin selbst nach 60 Minuten keine Reduktion des Atemrhythmus ausgelöst werden.

Selbst bei der Annahme von Überlappungen der Spezifität der 5HT 2A bzw. 5HT 2B Rezeptor Antagonisten, zeigt der direkte Vergleich der Antagonisten in ihrer Wirkung auf das rhythmisch aktive Schnittpräparat, dass im wesentlichen die Blockade des 5HT 2B Rezeptors für den Atemstop verantwortlich ist.

Diese Beobachtung macht eine, wie für die XII Motoneurone postulierte, Dominanz der 5HT 2A Rezeptoren innerhalb des PBC unwahrscheinlich.

Die Tatsache, dass die reine Gabe des 5HT 2B Rezeptor Antagonisten LY 272015 ohne Applikation eines Liganden (5HT oder 5HT Rezeptor Agonisten) eine deutliche Wirkung zeigte, lässt den Schluss zu, dass innerhalb des rhythmisch aktiven Schnittpräparats $5 \mathrm{HT}$ endogen ausgeschüttet wird.

Als Quelle für dieses endogen ausgeschüttete $5 \mathrm{HT}$ kommen die innerhalb des Präparats enthaltenen serotonergen Neurone der Raphe Kerne in Frage (Al-Zubaidy, et al., 1996). Immunzytochemische Studien erwiesen, dass 5HT immunoreaktive Neurone der lokalen Raphe Kerne mit ihren terminalen Verzweigungen den PBC erreichen(Schwarzacher, unveröffentlichte Daten). Die Aktivierung von Raphe Neuronen mit Mikroinjektionen des Glutamat Rezeptor Agonisten AMPA führte im neonatalen rhythmisch aktiven Schnittpräparat der Ratte $\mathrm{zu}$ einer serotonergen Modulation der PBC Neurone (Al-Zubaidy, et al., 1996). 
Wie in anderen monoaminergen Systemen auch, sind die Terminalen serotonerger Neurone dadurch charakterisiert, dass sie durch lokale synaptische und nicht synaptische Freisetzung von 5HT einen konstanten extrazellulären 5HT Spiegel aufrecht erhalten (Jacobs et al., 1984; Whitaker-Azmitia et al., 1987).

Sowohl in vivo, als auch in vitro wurde gezeigt, dass serotonerge Raphe Neurone eine rhythmische Aktivität, die zum Teil an den respiratorischen Rhythmus gekoppelt ist, aufweisen (Lindsey et al., 1994; Al-Zubaidy, et al., 1996). Dies macht eine konstante endogene Ausschüttung von 5HT auch im rhythmisch aktiven Schnittpräparat wahrscheinlich.

Der Befund, dass der 5HT 2B Rezeptor Antagonist LY 272015 im rhythmisch aktiven Schnittpräparat einen Stop des Atemrhythmus bewirkt, demonstriert, dass unter den in diesem Präparat herrschenden Bedingungen endogenes $5 \mathrm{HT}$ für die Aufrechterhaltung der respiratorischen Aktivität essentiell ist.

Neuere Arbeiten an in vitro Präparationen und primären Gewebekulturen zeigten chemosensitive Neurone innerhalb der medullären Raphekerne auf, die zum Teil serotonergen Neuronen zugeordnet werden konnten (Richerson et al., 2001). Die beschriebene Chemosensitivität innerhalb der Raphekerne nahm während der Neonatalperiode deutlich zu, entsprechend der Entwicklung der zentralen respiratorischen Chemorezeption. Damit könnte sowohl 5HT 2A als auch 5HT 2B Rezeptoren im PBC eine essentielle Bedeutung bei der Aktivierung des Atemzentrums als Reaktion auf eine zentrale Hypoxie zukommen. 


\subsection{HT 2B Rezeptor vermittelte trophische Wirkungen}

In der vorliegenden Arbeit wurde zum ersten Mal der Nachweis einer funktionellen Wirkung von 5HT über 5HT 2B Rezeptoren an Neuronen innerhalb des ZNS des Säugers erbracht. Neben der funktionellen Bedeutung des 5HT 2B Rezeptors im Rahmen der Modulation des Membranpotentials von respiratorischen Interneuronen und Motoneuronen, könnte die Lokalisation des 5HT 2B Rezeptors im Hirnstamm der neonatalen Ratte auch eine trophische Rolle im Rahmen der Entwicklung des respiratorischen Netzwerks spielen.

Der 5HT 2B Rezeptor besitzt ein hohes morphogenetisches Potential. So zeigt die 5HT 2B Rezeptor -/- Maus als einzige der bisher untersuchten 5HT Rezeptor knock out Mäuse einen klaren morphogenetischen Phänotyp. Dieser Phänotyp ist unter anderem durch kraniofaziale Missbildungen und eine Herzdystrophie charakterisiert (Nebigil et al., 2000a, 2001b).

Eine weitere Besonderheit stellen die für den 5HT 2B Rezeptor beschrieben intrazellulären Signaltransduktionswege dar. Neben dem, auch über die 5HT 2A und 5HT 2C Rezeptoren vermittelten, PLC- $\mathrm{P}_{3}$ Signaltranduktionsweg wurde eine G-Protein vermittelte Stimulation einer ras-Mitogen aktivierten Protein Kinase (ERK/MARK) Kaskade beschrieben. Diese hat eine Regulation des Zellzyklus zur Folge (Nebigil et al., 2001a). Während der frühembryonalen Entwicklung finden sich hohe Expressionsraten der 5HT 2B Rezeptor mRNA, während der 5HT 2A Rezeptor nur gering und der 5HT 2C Rezeptor nicht exprimiert werden (Choi et al., 1997). 
In embryonalen Hirnstammpräparaten findet sich die erste spontane rhythmische Aktivität am Ende des 16. Embryonaltags (Greer et al., 1992; Di Pasquale et al., 1994; Pestean, 1999). Zum selben Zeitpunkt finden im Bereich der ventrolateralen Medulla die letzten Mitosen statt (Altmann and Bayer, 1980a,b). 5HT immunoreaktive Neurone treten aber in den lokalen kaudalen Raphekernen schon zum 14. Embryonaltag auf und erste $5 \mathrm{HT}$ immunoreaktive Terminale lassen sich ab dem 15. Embryonaltag im PBC nachweisen (Aitken and Törk, 1988).

Damit könnte lokal freigesetztes 5HT möglicherweise über 5HT 2B Rezeptoren dazu beitragen, die Proliferationsphase von potentiellen respiratorischen Neuronen zu stoppen und die Differenzierung einzuleiten. Gerade die Kombination von trophischen Wirkungen mit der, hier nachgewiesenen, 5HT 2B Rezeptor vermittelten exzitatorischen Wirkung auf respiratorische Interneurone, könnte im Sinne einer positiven Bahnung zur Verstärkung der erregenden synaptischen Verschaltung führen. Damit könnte im sich entwickelnden respiratorischen Netzwerk die Voraussetzung zur Generierung eines spontanen Atemrhythmus geschaffen werden. 


\section{Zusammenfassung}

An spontan rhythmisch aktiven medullären Schnittpräparaten der neugeborenen Ratte wurden serotonerge Effekte auf respiratorische Interneurone des medullären Atemzentrums (Prä-Bötzinger Komplex, PBC) sowie auf respiratorische Motoneurone des Nucleus hypoglossus (XII Motoneurone) untersucht. Der Schwerpunkt lag dabei auf den von der Familie der 5HT 2 Rezeptoren vermittelten Effekten.

Respiratorische Interneurone wurden mit Patch clamp Elektroden im PBC aufgesucht und im Whole cell Current clamp intrazellulär abgeleitet. Über eine parallel geführte Iontophorese Elektrode wurden unterschiedliche 5HT Rezeptor Agonisten in direkter Nachbarschaft lokal injiziert.

Die iontophoretische Applikation des 5HT 1A Rezeptor Agonisten 8 OH DPAT resultierte in einer Erhöhung des Eingangswiderstands um 22,8 $\pm 3,6 \%(n=6)$. Das Membranpotential der Zellen stieg um 5,0 $\pm 2,5 \mathrm{mV}(\mathrm{n}=6)$. Bei iontophoretischer Applikation des 5HT 2A Rezeptor Agonisten $\alpha$-Methyl 5HT auf respiratorische Interneurone des PBC konnte eine Depolarisation des Membranpotentials um $4,8 \pm 3,0 \mathrm{mV}$, verbunden mit einer Reduktion des Membranwiderstands um $29,3 \pm 12,0 \%$ beobachtet werden ( $n=18)$. Badapplikation einer Mischung aus verschiedenen Hemmern der synaptischen Übertragung mit TTX $(0,4 \mu \mathrm{M})$, AP5 $(20 \mu \mathrm{M})$, Strychnin $(5 \mu \mathrm{M})$ und Bicucullin $(10 \mu \mathrm{M})$ konnten weder die Effekte der iontophoretischen Applikation von 8 OH DPAT $(n=3)$ noch von $\alpha$-Methyl 5 HT ( $n=5)$ 
beeinflussen. Badapplikation des 5HT 2A Rezeptor Antagonist Ketanserin $(50 \mu \mathrm{M}$, 20min) blockierte den Effekt des $\alpha$-Me 5HT komplett ( $n=3)$.

Die intrazellulären Untersuchungen zeigten funktionelle postsynaptisch lokalisierte 5HT Rezeptoren des Typs 5HT 1A und 5HT 2 an respiratorischen Interneuronen auf. 5HT 1A und 5HT 2 Rezeptoren vermittelten synergistisch eine Depolarisation.

Lokale Mikroinjektion des 5HT 2 Rezeptor Agonisten $\alpha$-Methyl 5HT in den PBC resultierte in einer reversiblen Erhöhung der Frequenz der respiratorischen Aktivität um 364,2 $\pm 124,3 \%(n=3)$. Dieser Effekt konnte durch die systemische Badapplikation des spezifischen 5HT 2A Rezeptor Antagonisten Ketanserin $(50 \mu \mathrm{M}, 20 \mathrm{~min})(\mathrm{n}=3)$ blockiert werden.

Die Mikroinjektion des 5HT 2B Rezeptor Agonisten BW 723C86 in den PBC induzierte ebenfalls eine reversible Frequenzerhöhung der respiratorischen Aktivität um 395,1\% $\pm 131,9(n=4)$. Dieser Effekt konnte durch die Badapplikation

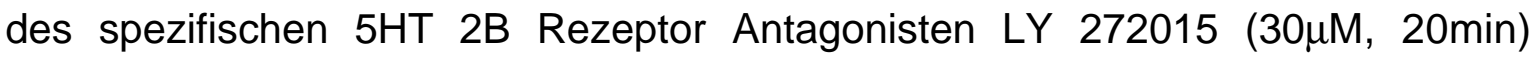
komplett blockiert werden $(n=4)$. Damit zeigt sich, dass neben 5HT 2A auch 5HT 2B Rezeptoren auf respiratorischen Neuronen des PBC vorhanden sind.

Lokale Druckinjektion über Mikroelektroden von $\alpha$-Methyl $5 \mathrm{HT}$ in den Nucleus hypoglossus erzeugte eine tonische Aktivität der XII Motoneurone $(n=12)$. Dieser Effekt konnte durch die systemische Badapplikation des Antagonisten Ketanserin $(50 \mu \mathrm{M}, 30 \mathrm{~min})$ komplett blockiert werden $(\mathrm{n}=6)$. Die systemische Badapplikation

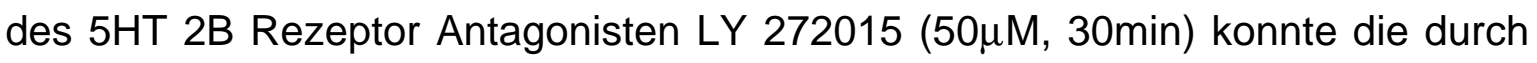
$\alpha$-Methyl 5HT induzierte tonische Aktivierung der XII Motoneurone nicht beeinflussen. 
Bei Mikroinjektionen des 5HT 2B Rezeptor Agonisten BW 723C86 in den Nucleus hypoglossus konnte ebenfalls eine tonische Aktivität der XII Motoneurone beobachtet werden $(n=17)$, die durch die systemische Applikation des 5HT 2B Rezeptor Antagonisten LY $272015(50 \mu \mathrm{M}, 30 \mathrm{~min}, \mathrm{n}=4)$ komplett blockiert, und durch den 5HT 2A Rezeptor Antagonisten Ketanserin $(50 \mu \mathrm{M}, 30 \mathrm{~min}, \mathrm{n}=6)$ reduziert wurde. Das beweist, dass auf respiratorischen Neuronen des Nucleus hypoglossus neben 5HT 2A auch 5HT 2B Rezeptoren vorhanden sind. Damit wurden zum ersten Mal funktionelle 5HT 2 Rezeptoren des 5HT 2B Subtyps an Neuronen innerhalb des ZNS nachgewiesen.

Die Badapplikation des 5HT 2B Rezeptor Agonisten BW $723 \mathrm{C} 86$ in einer Konzentration von 50 $\mu \mathrm{M}$ über 2,5-3,0 Minuten führte zu einer tonischen Exzitation in Kombination mit einer Depolarisation der XII Motoneurone sowie einem Anstieg der Frequenz der inspiratorischen Burstentladungen um 175,3 $\pm 35,4 \%(n=5)$.

Im Vergleich zur Badapplikation des 5HT 2B Rezeptor Agonisten BW 723C86 zeigte die Applikation von $\alpha$-Methyl $5 \mathrm{HT}$ eine wesentlich ausgeprägtere tonische Exzitation der XII Motoneurone in Kombination mit einem Anstieg der Frequenz der rhythmischen Burstentladungen um 284,2 $\pm 37,8 \%(n=3)$.

Damit ist erwiesen, dass die bei der lontophorese und Mikroinjektion untersuchten lokalen Effekte auch mit der systemischen Badapplikation der 5HT 2A und 5HT 2B Rezeptor Agonisten in kontrollierten Konzentrationen (30-50 $\mu \mathrm{M})$ ausgelöst werden können.

Bei der Badapplikation des 5HT 2B Rezeptor Antagonisten LY 272015 in einer Konzentration von $50 \mu \mathrm{M}$ über einen Zeitraum von 30 Minuten konnte eine Reduktion der respiratorischen Aktivität beobachtet werden $(n=7)$, die nach mehr 
als 30 Minuten zu einer kompletten und reversiblen Blockade des Atemrhythmus führte $(n=12)$. Damit wurde gezeigt, dass die Aktivität des 5HT 2B Rezeptors essentiell für die Aufrechterhaltung des respiratorischen Rhythmus ist. Die Tatsache, dass die alleinige Gabe des 5HT 2B Rezeptor Antagonisten zur Blockade der respiratorischen Aktivität führte, lässt den Schluss zu, dass endogen ausgeschüttetes $5 \mathrm{HT}$ im rhythmisch aktiven Schnittpräparat über 5HT 2B Rezeptoren die Neurone des PBC stimuliert. Endogenes 5HT könnte von serotonergen Neuronen stammen, die in den im rhythmisch aktiven Schnittpräparat enthaltenen lokalen Raphekernen lokalisiert sind.

Die systemische Badapplikation des 5HT 2A Rezeptor Antagonisten Ketanserin $(50 \mu \mathrm{M}, 60 \mathrm{~min})$ hatte hingegen keine Wirkung auf den respiratorischen Rhythmus $(n=8)$.

Die Ergebnisse dieser Arbeit weisen der Gruppe der 5HT 2 Rezeptoren sowohl an respiratorischen Interneuronen des medullären Atemzentrums als auch an respiratorischen Motoneuronen des Nucleus hypoglossus eine entscheidende Rolle bei der Vermittlung der exzitatorischen Wirkung von $5 \mathrm{HT}$ zu.

Im neonatalen Schnittpräparat werden sie dabei synergistisch durch 5HT 1A Rezeptor vermittelte exzitatorische Wirkungen an respiratorischen Interneuronen unterstützt. Innerhalb der Gruppe der 5HT 2 Rezeptoren wurden sowohl 5HT 2A, als auch 5HT 2B Rezeptor vermittelte Effekte festgestellt. Dabei sind beide Rezeptorsubtypen sowohl an Motoneuronen wie an Interneuronen kolokalisiert.

Die tonisch exzitatorische Wirkung von 5HT auf Motoneurone wird zum größeren Teil über 5HT 2A Rezeptoren vermittelt. 
Hingegen erscheint in erster Linie die 5HT 2B Rezeptor vermittelte Wirkung auf den respiratorischen Rhythmus von essentieller Bedeutung für die Erhaltung eines neonatalen Atemrhythmus zu sein.

Im Zusammenhang mit der bekannten Chemosensitivität medullärer serotonerger Raphe Neurone könnte den hier erstmals im Atemzentrum nachgewiesenen 5HT 2B Rezeptoren bei der Stimulation der Atmung infolge zentraler Hypoxie eine entscheidende Bedeutung zukommen.

Während der embryonalen und neonatalen Entwicklung des Säugers wurde der 5HT 2B Rezeptor als wichtiger morphogenetischer Faktor beschrieben. Der Nachweis funktioneller 5HT 2B Rezeptoren an medullären respiratorischen Neuronen eröffnet die Möglichkeit, dass die embryonale und neonatale serotonerge Kontrolle des Atemzentrums über 5HT 2B Rezeptoren neben funktionellen auch trophische Einflüsse beinhaltet. 


\section{Literaturverzeichnis}

Aitken, A.R., Törk, I., 1988

Early developement of serotonin-containing neurons and pathways as seen in wholemount preparation of the fetal rat brain.

J Comp Neurol, 274: 32-47

Altman,J., Bayer, S.A., 1980a

Developement of the brain stem in the rat. I. Thymidine-radiographic study of the time of origin of neurons of the lower medulla.

J Comp Neurol, 154: 1-35

Altman,J., Bayer, S.A., 1980b

Developement of the brain stem in the rat. II. Thymidine-radiographic study of the time of origin of neurons of the upper medulla, excluding the vestibular and auditory nuclei.

J Comp Neurol, 154: 37-56

Al-Zubaidy, Z.A., Erickson, R.L., Greer, J.J., 1996

Serotonergic and noradrenergic effects on respiratory neural discharge in the medullary slice preparation of neonatal rats.

European J Physiol, 431: 942-949

Azmitia, E.C., 2001

Modern views on an ancient chemical: serotonin effects on cell proliferation, maturation, and apoptosis.

Brain Res Bull, 56: 413-424

Azmitia, E.C., Whitaker-Azmitia, P.M., 1991

Awakening the sleeping giant: anatomy and plasticity of the brain serotonergic system.

J Clin Psychiatry, 52: 4-16 
Ballanyi, K., Onimaru, H., Homma, I., 1999

Respiratory network function in the isolated brainstem-spinal cord of newborn rats.

Progr Neurobiol, 59, 583-643

Berger, A.J., Bayliss, D.A. and Viana, F., 1992

Modulation of neonatal rat hypoglossal motoneuron excitability by serotonin.

Neurosci Letters, 143: 164-168

Bianchi, A.L., Denavit-Saubie, M., Champagnat, J., 1995

Central control of breathing in mammals: neural circuitry membrane properties, and neurotransmitters.

Physiol Rev, 75: 1-45

Bou-Flores, C., Lajard, A.-M., Monteau, R., De Maeyer, E., Seif, I., Lanoir, J., Hilaire, G., 2000

Abnormal Phrenic Motoneuron Activity and Morphology in Neonatal Monoamine Oxidase A-Deficient Transgenic Mice: Possible Role of a Serotonin Excess.

J Neurosci, 20: 4646-4656

Choi, D.-S., Ward, S.J., Messaddeq, N., Launay, J.-M., Maroteaux, L. 1997

5-HT2B receptor-mediated serotonin morphogenetic functions in mouse cranial neural crest and myocardic cells.

Development 124: 1745-1755

Dahlström, A., Fuxe, K., 1964

Evidence for the existence of monoamine-containing neurons in the ventral nervous system. 1. Demonstration of monoamines in the cell bodies of brain stem neurons.

Acta Physiol Scand, 62: 1-55 
Di Pasquale, E., Monteau, R., Hilaire, G., 1994

Endogenous serotoin modulates fetal respiratory rhythm: an in vitro study in the rat.

Brain Res Dev Brain Res, 80: 222-232

Duxon, M.S., Flanigan, T.P., Reavley, A.C., Baxter, G.S., Blackburn, T.P. and Fone, K.C., 1997a

Evidence for expression of the 5-hydroxytryyptamine-2B receptor protein in the rat central nervous system.

Neuroscience, 76: 323-329

Duxon, M.S., Kennett, G.A., Lightowler, S., Blackburn, T.P. and Fone, K.C., 1997b Activation of $5-\mathrm{HT}_{2 B}$ receptors in the medial amygdala causes anxiolysis in the social interaction test in the rat.

Neuropharmacology, 36: 601-608

Eckert, R., Randall, D., Augustine, G.

Tierphysiologie.

Georg Thieme Verlag; Stuttgart, New York 1993

Feldman, J.L., Ellenberger, H.H., 1988

Central coordination of respiratory and cardiovascular conrtol in mammals.

Annu. Rev. Pysiol, 50: 593-606

Feldman, J.L., Smith, J.C., Liu, G., 1991

Respiratory pattern generation in mammals: in vitro bloc analyses.

Curr Opin Neurobiol, 1: 590-594

Feldman, J.L., Smith, J.C., 1998

Cellular mechanisms underlying modulation of breathing pattern in mammals.

Ann NY Acad Sci, 563: 114-130 
Fiorica-Howells, E., Maroteaux, L. and Gershon, M.D., 2000

Serotonin and the $5-\mathrm{HT}_{2 \mathrm{~B}}$ receptor in the development of enteric neurons

J Neurosci, 20: 294-305

Funk, G.D. and Feldman, J.L., 1995

Generation of respiratory rhythm an pattern in mammals: insights from developmental studies.

Curr Opin Neurobiol, 5: 778-785

Gerhardt, C.C., van Heerikhuizen, H., 1997

Functional characteristics of heterologously expressed $5-\mathrm{HT}$ receptors.

Eur J Pharmacol, 334: 1-23

Gingrich, J.A., Hen, R., 2001

Dissecting the role of the serotonin system in neuropsychiatric disorders using knockout mice.

Psychopharmacology, 155: 1-10

Greer, J.J., Smith, J.C. and Feldman, J.L., 1992

Respiratory and locomotor patterns generated in the fetal rat brain stem-spinal cord in vitro.

J Neurophysiol, 67: 996-999

Günther, S.K., Pestean, A., Schwarzacher, S.W., 2000a

Perinatal regulation of the medullary breathing center by serotonin in rats.

Int Soc Dev Neurosci, Heidelberg

Günther, S.K., Schwarzacher, S.W:, 2000b

Postnatal changes of postsynaptic 5-HT receptor mediated modulation of respiratory neurons in the medullary breathing center in rats.

Verh d Anat Ges, Würzburg 
Günther, S.K., Schwarzacher, S.W., 2001a

5-HT2B receptor mediated modulation of medullary respiratory interneurons and motoneurons of the developing brainstem respiratory netwo rk in rodents.

Soc Neurosci, Abstr. 594.7

Günther, S.K., Schwarzacher, S.W., 2001b

5-HT2B-receptor mediated modulation of medullary respiratory interneurons and motoneurons in neonatal rats.

Göttingen Neuroreport 2001, 931

Günther, S.K., Schwarzacher, S.W., 2002

Modulation of medullary respiratory interneurons and motoneurons by differend subtypes of $5-\mathrm{HT} 2$ receptors in neonatal rats and mice.

Int Soc Neurochem, Soelden

Guyenet, P.G. and Wang, H., 2001

Pre-Bötzinger neurons with preinspiratory discharges "in vivo" express NK1 receptors in the rat.

J Neurophysiol, 86: 438-446

Halliday, G., Harding, A., Paxinos, G., 1995

Serotonin and tachykinin systems. in: The rat nervous sysem.

Academic press, San Diego

Herder - Lexikon der Biologie, Band eins;

Spektrum Akademischer Verlag GmbH; Heidelberg, Berlin, Oxford, 1994.

Hilaire, G. Bou, C., Monteau, R. 1997

Serotonergic modulation of central respiratora activity in the neonatal mouse: an in vitro study.

Eur J Pharmacol, 329: 115-120 
Hilaire, G., Duron, B., 1999

Maturation of the mammalian respiratory system.

Physiol Rev, 79: 325-360

Hoyer, D., Martin, G., 1997

5-HT receptor classification and nomenclature: owards a hamonization with the human genome.

Neuropharmacology, 36: 419-428

Jacobs, B.L., Gannon, P.J., Azmitia, E.C., 1984

Atlas of serotonergic cell bodies in the cat brainstem: an immunocytochemical analysis.

Brain Res Bull, 13: 1-31

Jacobs, B.L. and Azmitia, E.C., 1992

Structure and function of the brain serotonin system.

Physiol Rev, 72: 165-229

Jacobs, B.L., Fornal, C.A., 1993

5-HT and motor control: a hypothesis.

Trends Neurosci, 16: 346-352

Johnson S.M., Koshiya, N. and J. C. Smith, 2001

Isolation of the kernel for respiratory rhythm generation in a novel preparation: the Pre-Bötzinger Complex "island".

J Neurophysiol, 85: 1772-1776

Julius, D., 1998

Serotonin receptor knockouts: A moody subject.

Proc Natl. Acad Sci USA, 95: 15153-15153

Kennett, G.A., 1997

Serotonin receptors and their function.

Tocris, Bristol, UK 
Koshiya N. and Smith, J. C., 1999

Neuronal pacemaker for breathing visualized in vitro.

Nature 400: 360-363

Lalley, P.M., 1994

The excitability and rhythm of medullary respiratory neurons in the cat are altered by the serotonin receptor agonist 5-methoxy-N,N,dimethyltryptamine.

Brain Res, 648: 87-98

Lalley, P.M., Benacka, R., Bischoff, A., Richter, D.W., 1994a

Nucleus raphe obscurus evokes 5-HT1A receptor-mediated modulation of respiratory neurons.

Brain Res, 747: 156-159

Lalley, P.M., Bischoff, A., Richter, D.W., 1994b

Serotonin $1 \mathrm{~A}$ receptor activation supresses respiratory apneusis in the cat.

Neurosci Lett, 172: 59-62

Lalley, P.M., Bischoff, A., Richter, D.W., 1994c

$5-\mathrm{HT}-1 \mathrm{~A}$ receptor-mediated modulation of medullary expiratory neurones in the cat.

J Physiol, 476: 117-130

Lalley, P.M., Bischoff, A., Schwarzacher, S., Richter, D.W., 1995

$5-\mathrm{HT}_{2}$ receptor-controled modulation of medullary respiratory neurones in the cat. J Physiol, 487: 653-661

Lauder, J.M., 1990

Ontogeny of the serotonergic system in the rat: serotonin as a developmental signal. Ann NY Acad Sci, 600: 297-313 
Launay, J.-M., Birraux, G., Bondoux, D., Callebert, J., Choi, D.-S., Loric, S., Maroteuaux, L. 1996

Ras involvment in signal transduction by the serotonin 5-HT2B receptor. J Biol Chem, 271: 3141-3147

Leonard, B.E., 1994:

Serotonin receptors-where are they going?

Int Clin Psychopharmacol, 9, Suppl. 1: 7-17

Levitt, P., Harvey, J.A., Freidman, E., Simansky, K., Murphy, E.H., 1997

New evidence for neurotransmitter influences on brain development.

Trends Ne urosci, 20: 269-274

Lieske, S.P., Thoby-Brisson, M., Telgkamp, P., and Ramirez, J.M., 2000

Reconfiguration of the neural network controlling multiple breathing patterns: eupnea, sighs and gasps.

Nature Neuroscience, 3: 600-607

Lindsay, A.D. and Feldman, J.L., 1993

Modulaton of respiratory activity of neonatal rat phrenic motoneurons by serotonin. J Physiol, 461: 213-223

Lindsey, B.G., Segers, L.S., Morris, K.F., Hernandez, Y.M., Saporta, S., Shannon, R., 1994

Distributed actions and dynamic associations in respiratory-related neuronal assemblies of the ventrolateral medulla and brain stem midline: evidence from spike train analysis.

J Neurophysiol, 72: 1830-1853

Lindsey, B.G., Arata, A., Morris, K.F., Hernandez, Y.M., Shannon, R., 1998 Medullary raphe neurons and baroreceptor modulation of the respiratory motor pattern in the cat.

J Physiol, 512: 863-882 
Liu, Y-Y, Ju, G., Wong-Riley, M.T., 2001

Distribution and colocalization of neurotransmitters and receptors in the preBötzinger complex of rats.

J Appl Physiol, 91: 1387-1395

Mitchell, G.S., Baker, T.L., Nanda, S.A., Fuller, D.D., Zabka, A.G., Hodgeman, B.A., Bavis, R.W., Mack, K.J. and Olson Jr., E.B., 2001

Physiological and genomic consequences of intermittent hypoxia. Invited Review: Intermittet hypoxia and respiratory plasticity.

J Appl Physiol, 90: 2466-2475

Monteau, R., Morin, D., Hennequin, S., Hilaire, G. 1990

Differential effects of serotonin on respiratory activity of hypoglossal and cervical motoneurons: an in vitro study on the newborn rat.

Neurosci Lett, 111: 127-132

Morin, D., Hennequin, S., Monteau, R., Hilaire, G., 1990

Serotonergic influences on central respiratory activity: an in vitro study in the newborn rat.

Brain Res, 535: 281-287

Morin, D., Monteau, R., Hilaire, G., 1991

Serotonin and cervical respiratory motoneurons: intracellular studyin the newborn rat brainstem spinal cord preparation.

Exp Brain Res 84: 229-232

Morin, D., Monteau, R., Hilaire, G., 1992

Compared Effects of serotonin on cervical and hypoglossal inspiratory activities: an in vitro study in the newborn rat.

J Physiol Lond 451: 605-629 
Murphy, D.L., Andrews, A.M., Witchems, C.H., Li, Q., Tohda, M., Greenberg, B., 1998

Brain serotonin neurotransmission: an overview and update with an emphasis on serotonin subsystem heterogeneity, multiple receptors, interactions with other neurotransmitter systems, and consequent implications for understanding the actions of serotonergic drugs.

J Clin Psychiatry, 59: 15 4-12

Nebigil, C.G, Choi, D.-S., Dierich, A., Hickel, P., Le Meur, M., Messaddeq, N., Launay, J.-M., Maroteaux, L., 2000a

Serotonin $2 \mathrm{~B}$ receptor is required for heart development.

Proc Natl Acad Sci USA, 97: 9508-9513

Nebigil, C.G., Launay, J.-M., Hickel, P., Tournois, C., Maroteaux, L., 2000b

5-Hyroxytryptamine $\not B$ receptor regulates cell-cycle progression: crosstalk with tyrosine kinase pathways.

Proc Natl Acad Sci USA, 97: 2591-2596

Nebigil, C.G., Etienne, N., Schaerlinger, B., Hickel, P., Launay, J.-M., Maroteaux, L., $2001 \mathrm{a}$

Developmentally regulated serotonin $5-\mathrm{HT}_{2 \mathrm{~B}}$ receptors.

Int J Dev Neurosci, 19: 365-372

Nebigil, C.G., Hickel, P., Messaddeq, N., Vonesch, J.L., Douchet, M.P., Monassier, L., Gyorgy, K., Matz, R., Andriantsitohaina, R., Manivet, P., Launay, J.M., Maroteaux, L., 2001b

Ablation of serotonin $5-\mathrm{HT}(2 \mathrm{~B})$ receptors in mice leads to abnormal cardiac structure and function.

Circulation, 103: 2973-2979

Numberger, M., Draguhn, A.

Patch-Clamp-Technik.

Spektrum Akademischer Verlag GmbH; Heidelberg, Berlin, Oxford, 1996 
Oh, S.J., Ha, H.J., Chi, D.Y., Lee, H.K., 2001

Serotonin receptor and transporter ligands - current status.

Curr Med Chem, 8: 999-1034

Onimaru, H., Ballanyi, K., Richter, D.W., 1996

Calcium-dependend responses in neurons of the isolated respiratory network of newborn rats.

J Physiol, 491: 677-695

Onimaru, H., Shamoto, A., Homma, I., 1998

Modulation of respiratory rhythm by $5-\mathrm{HT}$ in the brainstem-Spinal cord preparation from newborn rat.

European J Physiol, 435: 485-494

Penzlin $\mathrm{H}$.

Lehrbuch der Tierphysiologie.

Gustav Fischer Verlag; Jena, 1991

Pestean, A.

Serotonin as a powerful modulator of the respiratory network during development. An in vitro study in transversal rhythmically active medullary slices of the fetal and neonatal rat.

Dissertation der Mathematisch-Naturwissenschaftlichen Fachbereiche der GeorgAugust Universität Göttingen; Göttingen, 1999

Pierrefiche, O., Schwarzacher, S.W., Bischoff, A.M., Richter, D.W., 1998

Blockade of synaptic inhibition within the pre-Bötzinger complex in the cat suppresses respiratory rhythm generation in vivo.

J Physiol, 509: 245-254

Ramirez, J.M., Richter, D.W., 1996

The neuronal mechanisms of respiratory rhythm generation.

Curr Opin Neuobiol, 6: 817-825 
Ramirez, J.M., Telgkamp, P., Elsen, F.P., Quellmalz, U.J., Richter, D.W., 1997 Respiratory rhythm generation in mammals: synaptic and membrane properties. Respir Physiol, 110: 71-85

Ramirez, J.M., Schwarzacher, S.W., Pierrefiche, O., Olivera, B.M., Richter, D.W., 1998

Selective leasioning of the cat pre-Bötzinger complex in vivo eliminates breathing but not gasping.

J Physiol, 507: 895-907

Reckling J.C. and Feldman, J.L., 1998

Pre Bötzinger complex and pacemaker neuros: hypothesized site and kernel for respiratory rhythm generation.

Annu Rev Physiol, 60: 385-405

Richerson, G.B., Wang, W., Tiwari, J., Bradley, S.R., 2001

Chemosensitivity of serotonergic neurons in the rostral ventral medulla.

Respir Physiol, 129: 175-189

Richter, D.W.

"Rhythmogenese der Atmung und Atmungsregulation." in: Physiologie des Menschen; Springer - Verlag; Berlin, Heidelberg, New York, 1997

Richter, D.W., Spyer, K.M., 1990

Cardio-respiratory control. in: Loewy, A.D. Spyer, K.M. (eds.) Central regulation of autonomic functions.

Oxford University Press, Oxford, 189-207

Richter, D.W., Ballanyi, K., Schwarzacher, S., 1992

Mechanisms of respiratory rhythm generation.

Curr Opin Neurobiol. 2: 788-793 
Richter, D.W. and Spyer, K.M., 2001

Studying rhythmogenesis of breathing: comparison of in vivo and in vitro models.

Trends Neurosci, 24: 464-472

Schwarzcher, S.W., Günther, S.K., 2002a

Serotonergic control of the developing brainstem respiratory network in rodents.

Int J Devl Neurosci, 19: 687-699

Schwarzacher, S.W., Günter, S.K., 2002b

Perinatale serotonerge Kontrolle medullärer respiratorischer Neurone über 5HT2A- und 5-HT2B-Rezeptoren.

Verh d Anat Ges, Halle

Schwarzacher, S.W., Pestean, A., Günther, S., Ballanyi, K., 2002c

Serotonergic modulation of respiratory motoneurons and interneurons in brainstem slices of neonatal rats.

Neuroscience (in revision)

Smith, J.C., Greer, J.J., Liu, G.S., Feldman, J.L., 1990

Neural mechanisms generating respiratory pattern in mammalian brain stemspinal cord in ivtro. I. Spatiotemporal patterns of motor and medullary neuron aktivity.

J Neurophysiol. 64: 1149-1169

Smith, J.C., Ellenberger, H.H., Ballanyi, K., Richter, D.W:, and Feldman, J.L., 1991 Pre-Bötzinger Complex: a brainstem region that may generate respiratory rhythm in mammals.

Science, 254: 726-729

Smith, J.C., Butera, R.J., Koshiya, N., Del Negro, C., Wilson C.G. and Johnson, S.M., 2000

Respiratory rhythm generation in neonatal and adult mammals: the hybrid pacemaker model.

Respir Physiol, 122: 131-148 
Thews, G.

"Lungenatmung." in: Physiologie des Menschen.

Springer - Verlag; Berlin, Heidelberg, New York, 1997

Wehner, R., Gehring, W.

Zoologie.

Georg Thieme Verlag; Stuttgart, New York, 1990

Whitaker-Azmitia, P.M., 2001

Serotonin and brain development: role in human developmental diseases.

Brain Res Bull, 56: 479-485

Whitaker-Azmitia, P.M., Lauder, J.M., Shemmer, A., Azmitia, E.C., 1987

Postnatal changes in serotonin receptors following prenatal alterations in serotonin levels: further evidence for functional fetal serotonin receptors.

Brain Res, 430: 285-289

Wu, C., Dias, P., Kumar, S., Lauder, J.M., Singh, S., 1999

Differential expression of serotonin 5-HT2 receptors during rat embryogenesis.

Dev Neurosci, 21: 22-28 


\section{Danksagung}

Dr. Stephan Schwarzacher danke ich für die stete Unterstützung und die Diskussionsbereitschaft in jedem Stadium der Arbeit.

Aurelian Pestean danke ich für die Unterstützung und Einarbeitung im elektrophysiologischen Labor.

Prof. Dr. Joachim Wolff danke ich für das Interesse an meiner Arbeit und die vielen anregenden Diskussionen.

PD. Dr. Michael Rickmann danke ich ebenfalls für das Interesse an meiner Arbeit und die Unterstützung in technischen Fragen.

Prof. Dr. F.W: Schürmann, Leiter der Abteilung Zellbiologie, 1. Zoologisches Institut der Universität Göttingen, danke ich für sein Interesse und seine Bereitschaft, mich vor der Biologischen Fakultät zu promovieren.

Prof. Dr. N. Elsner, Leiter des Lehrstuhls für Zoologie1, 1. Zoologisches Institut der Universität Göttingen danke ich für seine Bereitschaft, als Korreferent bei dieser Arbeit zu fungieren.

Des Weiteren möchte ich mich bei meinen Kollegen im Institut für die gute Zusammenarbeit bedanken.

Den Tierpflegern Kerstin Beyer, Susann Peter und Axel Zigan gilt mein besonderer Dank für das gute Einvernehmen und die tatkräftige Unterstützung. 


\section{Lebenslauf}

\section{Angaben zur Person}

geboren am 24. Februar 1974

in Schweinfurt

ledig

deutsche Staatsbürgerin

\section{Schule und Hochschule}

Sept. 1980 - Juli 1984

Sept. 1984 - Juli 1993

Nov. 1993 - Nov.1998

Dez. 1997

Jan. 1998 - Nov. 1998

Seit März 1999
Grundschule in Schweinfurt

Olympia-Morata-Gymnasium in Schweinfurt Abitur 1993

Studium der Biologie an der Julius-Maximilians-

Universität Würzburg; Vordiplomsprüfung März 1996,

Diplomprüfungen in den Fächern Biotechnologie

(Hauptfach), Botanik mit Schwerpunkt

Pflanzenphysiologie und Physiologische Chemie

Diplomarbeit am Lehrstuhl für Biotechnologie an der Universität Würzburg mit dem Thema: „Herstellung menschlicher monoklonaler Antikörper: Kultivierung einer Hybridomzellinie in serumreduzierten Medien zur Optimierung der Antikörperproduktion“

Tätigkeit als wissenschaftliche Mitarbeiterin am Lehrstuhl für Anatomie mit Schwerpunkt Neuroanatomie der Georg-August-Universität Göttingen 